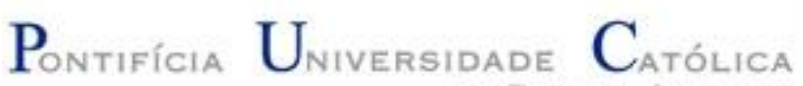

Bruno Chame Rodrigues Lins

\section{Estrutura de modelo de referência para Sales and Ope- rations Planning e Integrated Business Planning}

Dissertação de Mestrado

Dissertação apresentada como requisito parcial para obtenção do grau de Mestre pelo Programa de Pós-Graduação em Engenharia de Produção do Departamento de Engenharia Industrial da PUC-Rio.

Orientador: Prof. Luiz Felipe Roris Rodriguez Scavarda do Carmo

Coorientador: Prof. Bernd Hellingrath 


\section{Pontifícia Universidade Chtólica $_{\text {a }}$

Bruno Chame Rodrigues Lins

\section{Estrutura de modelo de referência para Sales and Opera- tions Planning e Integrated Business Planning}

Dissertação apresentada como requisito parcial para obtenção do grau de Mestre pelo Programa de Pós-Graduação em Engenharia de Produção do Departamento de Engenharia Industrial da PUC-Rio. Aprovada pela Comissão Examinadora abaixo.

Prof. Luiz Felipe Roris Rodriguez Scavarda do Carmo Orientador Departamento de Engenharia Industrial - PUC-Rio

Prof. Bernd Hellingrath Coorientador Chair for Information Systems and Supply Chain Management - Westfälische Wilhelms-Universität Münster

Prof. Antônio Márcio Tavares Thomé Departamento de Engenharia Industrial - PUC-Rio

Prof. Rodrigo Goyannes Gusmão Caiado Departamento de Engenharia de Produção - PUC-Rio

Rio de Janeiro, 20 de setembro de 2019. 
Todos os direitos reservados. É proibida a reprodução total ou parcial do trabalho sem autorização do autor, do orientador e da universidade.

\section{Bruno Chame Rodrigues Lins}

Graduou-se em Engenharia de Produção pelo Ibmec em 2016. Aluno de mestrado com dedicação exclusiva no Departamento de Engenharia Industrial da PUC-Rio desde 2017.

Ficha Catalográfica

Estrutura de modelo de referência para sales and operations planning e integrated business planning / Bruno Chame Rodrigues Lins ; orientador: Luiz Felipe Roris Rodriguez Scavarda do Carmo ; co-orientador: Bernd Hellingrath. - 2019.

106 f. : il. color. ; $30 \mathrm{~cm}$

Dissertação (mestrado)-Pontifícia Universidade Católica do Rio de Janeiro, Departamento de Engenharia Industrial, 2019.

Inclui bibliografia

1. Engenharia Industrial - Teses. 2. Estrutura de modelo de referência. 3. Planejamento de vendas e operações. 4. Planejamento integrado de negócios. 5. Estudo empírico. I. Carmo, Luiz Felipe Roris Rodriguez Scavarda do. II. Hellingrath, Bernd. III. Pontifícia Universidade Católica do Rio de Janeiro. Departamento de Engenharia Industrial. IV. Título. 


\section{Agradecimentos}

Agradeço à minha família e amigos por todo o suporte e compreensão, por conta de algumas faltas nas reuniões.

Um agradecimento especial à minha companheira Vivianne Julianelli, por estar sempre ao meu lado, não importa a situação.

Ao meu orientador Luiz Felipe Scavarda pelos conhecimentos compartilhados e pelo apoio nos momentos mais difíceis.

Aos professores da PUC-Rio pelos conhecimentos, que contribuíram para o meu desenvolvimento pessoal e profissional.

Aos funcionários da PUC-Rio pela solicitude e cortesia de sempre.

E às agências de fomento à pesquisa $\mathrm{CNPq}$ e FAPERJ, pelo suporte vital para a realização e conclusão do curso.

O presente trabalho foi realizado com apoio da Coordenação de Aperfeiçoamento de Pessoal de Nível Superior - Brasil (CAPES) - Código de Financiamento 001. 


\section{Resumo}

Lins, Bruno Chame Rodrigues; do Carmo, Luiz Felipe Roris Rodriguez Scavarda (Orientador); Hellingrath, Bernd (Co-orientador); Estrutura de referência para Sales and Operations Planning e Integrated Business Planning. Rio de Janeiro, 2019. 106p. Dissertação de Mestrado - Departamento de Engenharia Industrial, Pontifícia Universidade Católica do Rio de Janeiro.

Sales and Operations Planning (S\&OP), também chamado de Integrated Business Planning (IBP), é um processo de negócios que integra os planejamentos dos setores de uma empresa de forma a balancear a oferta e a demanda por produtos em um horizonte de planejamento de médio prazo, apoiando assim a integração horizontal da empresa. O S\&OP/IBP serve também de ponte entre os planejamentos estratégico e operacional, apoiando assim a integração vertical da empresa. Apesar de esse processo ter adquirido um papel de destaque na área de gestão da cadeia de suprimentos, os benefícios esperados ainda não foram totalmente obtidos, na prática, pela indústria. Além disso, a literatura indica a necessidade de uma caracterização completa do processo e que um modelo de referência beneficiaria os usuários do processo. Visando endereçar tais carências, esta dissertação elabora uma estrutura de modelo de referência preliminar para o processo de S\&OP/IBP, com base em trabalhos acadêmicos, white papers escritos por praticantes, um estudo de caso em uma indústria química do Brasil e a aplicação de grupos focais e painel de especialistas em S\&OP/IBP. Este trabalho contribui com um estudo empírico no tema, além de oferecer uma estrutura de modelo de referência preliminar, avaliada por praticantes de $\mathrm{S} \& \mathrm{OP} / \mathrm{IBP}$, que pode ser usada como inspiração para empresas que desejam desenhar ou melhorar seu processo e por acadêmicos em pesquisas futuras com o intuito de aprimorá-lo. Ademais, são apresentados 13 pontos de atenção a serem avaliados pelos praticantes, a fim de amenizar os impactos das diferenças entre contextos.

\section{Palavras-chave}

Estrutura de modelo de referência; Planejamento de Vendas e Operações; Planejamento Integrado de Negócios; Estudo empírico 


\section{Abstract}

Lins, Bruno Chame Rodrigues; do Carmo, Luiz Felipe Roris Rodriguez Scavarda (Advisor); Hellingrath, Bernd (Co-advisor); Reference Model Structure for Sales and Operations Planning and Integrated Business Planning. Rio de Janeiro, 2019. 106p. Dissertação de Mestrado - Departamento de Engenharia Industrial, Pontifícia Universidade Católica do Rio de Janeiro.

Sales and Operations Planning (S\&OP), also called Integrated Business Planning (IBP), is a business process that integrates business plans from different functional areas of a firm to balance supply and demand of products in a mid-term planning horizon, thus supporting the horizontal integration of the firm. S\&OP/IBP also serves as a bridge between strategic and operational plans, thus supporting the vertical integration of the firm. Although this process has gained prominence in the area of supply chain management, the expected benefits at the time of implementation have not yet been fully realized in practice by the industry. Moreover, the literature indicates the need for a complete characterization of the process and that a reference model would benefit process users. To address these research-practice gaps, this dissertation elaborates a preliminary reference model structure for the S\&OP/IBP process, based on academic papers, white papers written by practitioners, a case study in a Brazilian chemical industry and the application of focus group with S\&OP/IBP experts. This work contributes with an empirical study on the theme, as well as it offers a preliminary reference model structure, evaluated by practitioners of S\&OP/IBP, which can be used as a guidance for firms willing to design or improve their own process and for academics in future researches with the aim of refining it. In addition, 13 points of attention to be assessed by practitioners are presented in order to mitigate the impacts of differences between contexts.

\section{Keywords}

Reference Model Structure; Sales and Operations Planning; Integrated Business Planning; Empirical study 


\section{Sumário}

1 Introdução 14

2 Fundamentação teórica 17

2.1. Sales and Operations Planning (S\&OP) 17

2.1.1. Contexto 18

2.1.2. Plano de negócios e plano estratégico da empresa 19

2.1.3. Entradas 20

2.1.4. Estrutura do processo 20

2.1.4.1. Colaboração 21

2.1.4.2. Estrutura organizacional do S\&OP/IBP 21

2.1.4.3. Tecnologia da informação 22

2.1.4.4. Métricas 22

2.1.5. Saídas e resultados 23

2.2. Modelos de Referência 24

3 Metodologia 27

3.1. Definição do problema 28

3.1.1. Identificação de lacunas 29

3.1.2. Definição dos interessados e beneficiários 30

3.1.3. Definição dos requisitos 30

3.1.4. Escolha da técnica e linguagem de modelagem 31

3.2. Construção da estrutura de referência 32

3.2.1. Identificação das fontes de conhecimento 33

3.2.2. Desenho da estrutura de referência 34

3.2.2.1. Estudo de caso 34

3.2.2.1.1. Definição da unidade-caso e unidade de análise 35

3.2.2.1.2. Coleta de dados 35

3.2.2.1.3. Análise e interpretação de dados 36 
3.2.2.1.4. Elaboração da primeira versão da estrutura de referência

3.2.2.2. Grupo focal 1

3.2.3. Definição dos processos Principal, de Suporte e de Coordenação 38

3.3. Construção da estrutura do modelo de referência 39

3.3.1. Determinação dos níveis de detalhamento do processo Principal 40

3.3.2. Identificação de analogias entre estruturas 41

3.3.3. Construção do modelo do processo de referência 41

3.3.3.1. Painel de especialistas 41

3.3.3.2. Grupo focal 2 43

4 Estrutura de modelo de referência 45

4.1. Visão geral 45

4.2. Processo Principal 49

4.2.1. Demand Review (DR) 49

4.2.2. Supply Review (SR) 52

4.2.3. Financial Reconciliation (FR) 54

4.2.4. Executive Review (ER) 56

4.2.5. Pre-works 58

4.2.5.1. Pre-work Demand Review 58

4.2.5.2. Pre-work Supply Review 60

4.2.5.3. Pre-work Financial Reconciliation 64

4.2.5.4. Pre-work Executive Review 65

4.3. Processos de Suporte - Perspectiva Pessoas 66

4.3.1. Processos de Suporte - Perspectiva Pessoas - Demand Review 67

4.3.2. Processo de Suporte - Perspectiva Pessoas - Supply Review 70

4.3.3. Processo de Suporte - Perspectiva Pessoas - Financial Reconciliation

4.3.4. Processo de Suporte - Perspectiva Pessoas - Executive Review 73 
4.4. Suporte Tecnológico $\quad 75$

4.5. Processos de Coordenação 76

5 Discussões $\quad 80$

5.1. Finanças em S\&OP/IBP $\quad 80$

5.2. Período congelado (Frozen period) 82

5.3. Horizonte de planejamento 82

5.4. Pre-works 83

5.5. Ganhos operacionais com o S\&OP/IBP 84

5.6. Realização de diversas reuniões em paralelo referentes à mesma etapa 86

5.7. Participação de clientes e fornecedores 86

5.8. System Setup 88

5.9. Etapa de Global Roll-Up 89

5.10. Quem deve ser o responsável pelas previsões? 89

5.11. Gestão de atendimento 89

5.12. Existência de um time para gerenciar o S\&OP/IBP 90

5.13. Desafios para melhorar os resultados 91

6 Conclusões e considerações finais 93

7 Referências bibliográficas $\quad 96$

Apêndice I: Questionário de S\&OP/IBP para a empresa XYZ 102

Apêndice II: Condução do grupo focal 1 (não estruturado e exploratório) 104

Apêndice III: Questionário aos praticantes 105

Apêndice IV: Condução do grupo focal 2 (estruturado e explicativo) 106 


\section{Lista de figuras}

Figura 1 - Procedimento adotado com base no método de Schütte (1998)

Figura 2 - Primeira etapa de Schütte (1998): Definição do problema......29

Figura 3 - Notação Fluxograma .........................................................32

Figura 4 - Segunda etapa de Schütte (1998): Elaboração da estrutura de referência

Figura 5 - Terceira etapa de Schütte (1998): Elaboração da estrutura do modelo de referência................................................................... 40

Figura 6 - Processo Principal (nível 1) ..........................................4

Figura 7 - Processo Principal (nível 2) ................................................48

Figura 8 - Processo Principal (nível 2) - Alternativa 1 ...........................48

Figura 9 - Processo Principal (nível 2) - Alternativa 2 ............................49

Figura 10 - Processo Principal - Demand Review (nível 2) ....................50

Figura 11 - Processo Principal - Demand Review (nível 3) ....................51

Figura 12 - Processo Principal - Supply Review (nível 2) .......................53

Figura 13 - Processo Principal - Supply Review (nível 3) .......................54

Figura 14 - Processo Principal - Financial Reconciliation (nível 2) .........55

Figura 15 - Processo Principal - Financial Reconciliation (nível 3) .........56

Figura 16 - Processo Principal - Executive Review (nível 2)...................57

Figura 17 - Processo Principal - Executive Review (nível 3)...................58

Figura 18 - Pre-work Demand Review 1 (nível 3) ..................................59

Figura 19 - Pre-work Demand Review 2 (nível 3) .................................60

Figura 20 - Pre-work Demand Review 3 (nível 3) .................................60

Figura 21 - Pre-work Supply Review 1 (nível 3) .....................................61

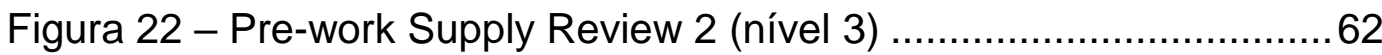

Figura 23 - Pre-work Supply Review 3 (nível 3) ………………...........63

Figura 24 - Pre-work Supply Review 4 (nível 3) ....................................64

Figura 25 - Pre-work Financial Reconciliation (nível 3) ..........................65

Figura 26 - Pre-work Executive Review (nível 3) ...................................66

Figura 27 - Processos de Suporte - Demand Review - Perspectiva

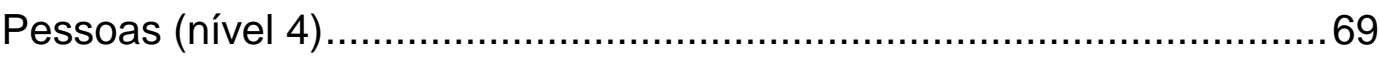

Figura 28 - Processos de Suporte - Supply Review - Perspectiva

Pessoas (nível 4) ............................................................................. 72

Figura 29 - Processos de Suporte - Financial Reconciliation -

Perspectiva Pessoas (nível 4) .............................................................73

Figura 30 - Processos de Suporte - Executive Review - Perspectiva

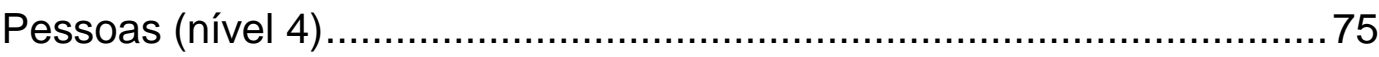

Figura 31 - Processos de Coordenação - Indicadores de desempenho sugeridos para Pre-work Demand Review ...........................................77 Figura 32 - Processos de Coordenação - Indicadores de desempenho sugeridos para Pre-work Supply Review. 
Figura 33 - Processos de Coordenação - Indicadores de desempenho sugeridos para Pre-work Financial Reconciliation.

Figura 34 - Processos de Coordenação - Indicadores de desempenho sugeridos para Pre-work Executive Review

Figura 35 - Processos de Coordenação - Indicadores de desempenho sugeridos para a Corporação 


\section{Lista de quadros}

Quadro 1 - Especialistas consultados .............................................. 38

Quadro 2 - Praticantes entrevistados ................................................4 42 


\section{Lista de Abreviaturas e Sigla}
APS - Advanced Planning and Scheduling
ERP - Enterprise Resource Planning
IBP - Integrated Business Planning
MPS - Master Production Schedule
MRP - Material Requirement Planning
MRP II - Manufacturing Resources Planning
SCOR - Supply Chain Operations Reference
S\&OP - Sales and Operations Planning
SKU - Stock Keeping Unit
WMS - Warehouse Management System
YTD - Year-To-Date 


\section{1 \\ Introdução}

A corrida por diferenciais competitivos é o grande motivador para as empresas buscarem sempre novas e melhores maneiras de trabalhar. A concorrência, cada vez mais acirrada, e o nível de exigência cada vez maior por parte dos clientes forçaram as organizações a abandonar a visão individualista, com foco apenas dentro de suas operações, para uma visão global, em forma de cadeia de suprimentos (Olhager, 2013).

O processo de Sales and Operations Planning (S\&OP) surgiu com base nessa visão em cadeia, o que demandou um processo de integração entre os departamentos, as áreas funcionais das empresas e parceiros de negócios da cadeia (clientes e fornecedores). S\&OP é um processo de negócios cujo objetivo é alinhar a empresa horizontal e verticalmente (Wagner et al., 2014), onde alinhamento horizontal refere-se à integração dos planos das diferentes áreas em um único plano, de forma a equilibrar oferta e demanda, ou seja, produzir para atender ao cliente de acordo com o necessário e com os recursos disponíveis. Verticalmente refere-se à possibilidade de visualizar o desdobramento do plano de negócios em objetivos operacionais (Kathuria et al., 2007; Thomé et al., 2012a; Wagner et al., 2014).

Além do termo S\&OP outro termo também vem sendo utilizado para descrever o processo de alinhamento entre os planos das diferentes áreas da empresa, o Integrated Business Planning (IBP) - (Viswanathan, 2009). Ambos os termos chegaram a ser tratados como sinônimos por Skipworth et al. (2015). Porém, Kristensen e Jonsson (2018) afirmam que a diferença é que, no processo de IBP, existe uma participação maior da área financeira. Para Palmatier e Crum (2013), o IBP está associado a um elevado estágio de maturidade de S\&OP.

Apesar de esse processo ter adquirido um papel de destaque na área de gestão da cadeia de suprimentos (Stadtler, 2005), os benefícios prometidos no momento da implementação ainda não foram totalmente obtidos, na prática, pela indústria (Lapide, 2005; Tuomikangas e Kaipia, 2014; Wagner et al., 2014; Swaim et al., 2016). Explicar o porquê de cada caso sem êxito é praticamente impossível, 
uma vez que o processo é muito dependente do contexto (interno e externo) de cada empresa (Kristensen e Jonsson, 2018; Goh e Eldridge, 2019). Tuomikangas e Kaipia (2014) indicam que a padronização do processo de S\&OP/IBP é um dos mecanismos necessários para a coordenação do mesmo. Visando essa padronização, uma caracterização completa do processo é necessária (Pedroso et al., 2016), para que guias para implementação e uso do processo sejam propostos (Pedroso et al., 2016; Danese et al., 2017). Entretanto, muitos praticantes não entendem plenamente a essência do processo (Pedroso et al., 2016; Scavarda et al., 2017). Portanto, uma vez que o processo não apresenta previsibilidade na entrega de resultados, nem todos possuem a familiaridade necessária para executar o processo e que é apontada a necessidade por uma caracterização completa do processo, a criação de um Modelo de Referência para o processo de S\&OP/IBP ajuda a endereçar tais desafios (Kreuter et al., 2019).

Um Modelo de Referência pode ser desenvolvido em cinco etapas: definição do problema, construção da estrutura de referência, construção da estrutura do modelo de referência, construção do modelo de referência e aplicação do modelo de referência (Schütte, 1998). Meise (2001) sugere que uma estrutura de referência seja defina por três categorias de processos: Principal, Suporte e Coordenação. Processo Principal está atrelado à estratégia da empresa, ou seja, ele precisa ser executado para que os planos de negócios sejam alcançados. Suporte atende aos requerimentos para o funcionamento do Principal. Coordenação atua de forma a medir e controlar a execução do Principal. O foco desta dissertação é a terceira etapa de Schütte (1998): construção da estrutura do modelo de referência, que engloba o detalhamento do Processo Principal de Meise (2001) em níveis macro e micro.

Neste contexto, o objetivo geral dessa dissertação é elaborar uma estrutura de modelo de referência preliminar para o processo de S\&OP/IBP, a partir do método de Schütte (1998), e com base em trabalhos acadêmicos, white papers escritos por praticantes, um estudo de caso em uma indústria química do Brasil, que trabalha com o processo de $\mathrm{S} \& \mathrm{OP} / \mathrm{IBP}$ em um nível elevado de maturidade, na aplicação de dois grupos focais e em um painel com especialistas em S\&OP/IBP. A empresa escolhida para o estudo de caso (aqui denominada XYZ) é uma multinacional com sede na Alemanha. A XYZ implementou seu processo de S\&OP há mais de uma década. Em 2016, implementou uma nova versão desse processo, que chamaram de IBP. Este objetivo geral é desdobrado em dois objetivos específicos. O primeiro 
está associado ao desenvolvimento da estrutura de referência com as diversas etapas de campo do estudo empírico. O segundo objetivo específico está associado a análise das lições obtidas com a condução do estudo empírico.

Este trabalho contribui com um estudo empírico no tema, caracterização completa de um processo de S\&OP/IBP, possibilidades de caracterização da interação entre as pessoas, além de oferecer uma estrutura de modelo de referência preliminar, avaliada e validada por especialistas e praticantes de S\&OP/IBP, que pode ser usada como inspiração e/ou guia para empresas que desejam desenhar ou melhorar seu próprio processo. A estrutura também pode ser usada por acadêmicos em pesquisas futuras, com o intuito de aprimorá-lo, sendo esta a próxima etapa proposta por Schütte (1998) para o desenvolvimento de um primeiro modelo de referência para S\&OP/IBP. Além disso, são apresentados 13 pontos de atenção a serem avaliados pelos praticantes, a fim de amenizar os impactos das diferenças entre contextos.

O uso de tecnologias que suportem o processo (subprocesso de Tecnologia da Informação do Processo de Suporte) não faz parte do escopo desta dissertação. Outra limitação está relacionada à continuidade do ciclo de reuniões para o nível global (Global Roll-Up). No processo de S\&OP/IBP, algumas empresas agregam os números de cada país de forma a obter um número regional e, por consequência, um consolidado global. O fluxo operacional do processo que faz essa consolidação dos países não foi detalhado no modelo.

Esta dissertação está dividida em 6 capítulos, sendo esse primeiro o introdutório. No segundo capítulo, a fundamentação teórica é descrita. A metodologia adotada é detalhada no terceiro capítulo. O resultado do procedimento descrito no terceiro capítulo é apresentado no quarto capítulo. No quinto capítulo, os aprendizados e resultados consolidados são discutidos. O sexto, e último capítulo, contém as conclusões, considerações finais e recomendações para trabalhos futuros. 


\section{2 \\ Fundamentação teórica}

Este capítulo apresenta os fundamentos do S\&OP/IBP e de Modelos de Referência, necessários para a elaboração da estrutura do modelo de referência.

\section{1. \\ Sales and Operations Planning (S\&OP)}

Sales and Operations Planning (S\&OP) é um processo de negócios que integra os planos de negócios das diversas áreas funcionais de uma empresa (e.g. marketing, vendas, produção e finanças) em um único plano, de forma a balancear a oferta e a demanda por produtos em um horizonte de planejamento (Cox e Blackstone, 2002). Isto é, o S\&OP traz alinhamento horizontal e vertical na empresa, onde alinhamento horizontal refere-se a tal integração das áreas funcionais de uma empresa na elaboração de um único plano que equilibra oferta e demanda com os recursos disponíveis (Thomé et al., 2012a; Wagner et al., 2014). Alinhamento vertical refere-se à possibilidade de visualizar o desdobramento do plano de negócios em objetivos operacionais (Kathuria et al., 2007; Thomé et al., 2012a; Wagner et al., 2014).

A indústria e as consultorias, com o objetivo de destacar o papel de finanças no processo, também estão adotando o termo Integrated Business Planning (IBP) (Viswanathan, 2009). Apesar de trabalhos acadêmicos levarem em consideração o papel de finanças, materiais elaborados por praticantes afirmam que há diferença entre os termos.

Pelo lado dos trabalhos acadêmicos, Kristensen e Jonsson (2018) definem IBP como sendo S\&OP que envolve finanças. Já Wagner et al. (2014) defendem que Finanças deve fazer parte das reuniões de S\&OP e que o objetivo do S\&OP é maximizar o lucro. Thomé et al. (2012a) apresentam uma estrutura conceitual onde as informações financeiras influenciam diretamente no processo de S\&OP.

No caso de praticantes da indústria, Palmatier e Crum (2013) afirmam que IBP é um S\&OP mais avançado, e definem IBP como um processo gerenciado pela 
alta liderança, que avalia e revisa as premissas acerca de mudanças no padrão de demanda, abastecimento, gestão de portfólio, projetos estratégicos e os planos financeiros resultantes. Baumann (2010) destaca que o IBP não faz apenas o balanceamento entre oferta e demanda, mas que alinha os planos operacionais com o planejamento estratégico e o plano financeiro. Aberdeen (2011) e Thor e Dhir (2011) mostram que o processo de IBP envolve todas as áreas da organização, ou seja, além de Marketing, Vendas, Produção e Finanças, são envolvidas as áreas de Pesquisa e Desenvolvimento, Projetos, Qualidade, entre outras.

Baseado nas definições encontradas nas literaturas acadêmica e grey, notase que os termos S\&OP e IBP diferem pontualmente na definição dos praticantes. Por isso, os termos S\&OP e IBP são tratados em conjunto nesta dissertação (S\&OP/IBP), assim como em Aberdeen (2016).

Apesar de uma aparente simplicidade, o processo de S\&OP/IBP é complexo (Rexhausen et al., 2012; Pedroso et al., 2016). A literatura ainda carece de uma caracterização completa do processo (Pedroso et al., 2016). O modelo de Thomé et al. (2012) oferece os principais elementos associados ao S\&OP/IBP e é considerado, na literatura, como um modelo geral válido para parametrizar o processo. Ele tem sido usado em inúmeros estudos, como Tuomikangas e Kaipia (2014), Ivert et al. (2015b), Hulthén et al. (2016), Noroozi e Wikner (2017), Scavarda et al. (2017), Kristensen e Jonsson (2018) e Seeling et al. (2019a, 2019b). Portanto, é o escolhido para fundamentar o processo de S\&OP/IBP, conforme apresentado a seguir.

\subsection{1. Contexto}

O processo geral de S\&OP/IBP, introduzido por Wallace e Stahl (2008), pode ser aplicado em qualquer contexto, porém cada empresa tem uma particularidade, o que não garante que as mesmas soluções sejam adequadas para todas as empresas. Segundo Kristensen e Jonsson (2018), nenhum estudo foi realizado de forma a determinar os impactos que os diferentes contextos geram no resultado do S\&OP/IBP. Porém, mostram alguns fatores de contexto debatidos na literatura, como os agentes humanos e o tipo e complexidade do mercado. Goh e Eldridge (2019) condensam outros influenciadores do processo de S\&OP/IBP trabalhados na literatura: as características dos produtos (perecíveis, com demanda incerta e frequência de lançamentos), a economia do país, diferenças culturais e tamanho da 
empresa. Elementos cada vez mais presentes nos contextos são a quantidade crescente de Stock Keeping Units (SKUs) e ciclos de vida de produtos cada vez mais curtos (Swaim et al., 2016; Danese et al., 2017). Portanto, o desenho do processo precisa se enquadrar para lidar cada vez mais com essas condições.

Os aspetos humanos foram trabalhos em Ambrose e Rutherford (2016), onde identificaram fatores relacionados à equipe, que impactam na eficácia do S\&OP/IBP. Rexhausen et al. (2012) tratam da imaturidade encontrada nas empresas para que o processo possa gerar engajamento e resultados satisfatórios. As características de um produto foram tratadas em Ivert et al. (2015a). Seus resultados apontam para uma maior relevância aos aspectos relacionados às variações em relação à demanda e abastecimento, bem como mostrado em Kaipia et al. (2017). As características relacionadas aos produtos não se mostraram tão relevantes no setor de alimentos. Em outros setores, pode ser que o S\&OP/IBP impacte positivamente na performance (Thomé et al., 2014a). Não foi identificada uma relação forte entre o tamanho da empresa e a economia de um país, no que diz respeito ao desenho do S\&OP/IBP (Grimson e Pyke, 2007; Thomé et al., 2014a; Thomé et al., 2014b).

Thomé et al. (2012a) destacam os seguintes elementos de contexto: região/país, tipo de indústria, estratégia de manufatura, posicionamento da empresa na matriz produto-processo, o horizonte de planejamento, as famílias de produtos e a hierarquia no processo de planejamento. Ivert el al. (2015a) acrescentam os parâmetros de planejamento, porém como parte da estrutura e processos.

\subsection{2.}

\section{Plano de negócios e plano estratégico da empresa}

Conforme mencionado, o S\&OP/IBP auxilia no desdobramento do plano de negócios em objetivos operacionais (Kathuria et al., 2007; Thomé et al., 2012a; Wagner et al., 2014). Contudo, Kristensen e Jonsson (2018) afirmam que existe uma carência de estudos que mostrem a forma com que o S\&OP/IBP faz essa integração vertical na prática, de forma a interagir com outros sistemas de planejamento, como o Material Requirement Planning (MRP) e Master Production Schedule (MPS). E complementam dizendo que o S\&OP/IBP, para ter um bom desempenho, precisa estar alinhado aos processos operacionais. 


\subsection{3.}

\section{Entradas}

Conforme ilustrado em Thomé et al. (2012a), o processo de S\&OP/IBP é alimentado por diversas fontes de informações que influenciam na tomada de decisão. Os planos das áreas funcionais são entradas muito importantes. Além dos aspectos relacionados ao contexto, mencionados na subseção 2.1.1, o S\&OP/IBP leva em consideração o resultado operacional, como o nível de serviço, níveis de estoques, capacidade utilizada e acuracidade das previsões. Além desses indicadores, a empresa leva em consideração o desempenho financeiro, isto é, se a empresa obteve lucro, se o orçamento está sob controle, entre outros. Todos esses resultados são comparados às metas estabelecidas no planejamento estratégico. O nível de descolamento entre o planejado e o realizado indica os pontos de melhoria que a empresa precisa se concentrar, além de impactar diretamente nos direcionamentos da empresa ao longo do período em análise.

\subsection{4.}

\section{Estrutura do processo}

O processo de S\&OP/IBP tradicional, sugerido por Wallace e Stahl (2008), descreve um processo mensal iniciando com uma coleta de dados atrelados à demanda e ao abastecimento. Esses dados são tratados de forma a atualizar o plano de demanda em um segundo momento. Na terceira etapa, é atualizado o plano de abastecimento. Uma vez que, normalmente, existem diferenças entre o plano de demanda e o plano de abastecimento, é preciso alinhar esses dois planos. Porém, esse alinhamento implica em investimentos, e nem sempre é trivial. Por isso, é realizada uma quarta etapa, com uma reunião pré-executiva, onde são tomadas decisões em relação à forma como os planos são entregues para satisfazer o orçamento. Tudo que estiver na alçada dos gerentes, é definido até essa reunião. A última etapa, uma reunião executiva, envolve o corpo de diretores para que as decisões em aberto sejam tomadas em consenso, de forma a garantir a visão estratégica da empresa no plano tático de maneira imparcial.

Conforme apresentado em Thomé et al. (2012a), para que esse fluxo seja efetivo, a literatura trata de elementos que devem ser discutidos e analisados para o bom funcionamento do S\&OP/IBP. Esses tópicos foram introduzidos no modelo de 
maturidade de Grimson e Pyke (2007). São eles: a colaboração, a estrutura organizacional do processo, as tecnologias utilizadas e as métricas adotadas na medição de desempenho.

\subsubsection{1.}

\section{Colaboração}

Segundo Grimson e Pyke (2007), esse tópico visa estimular um melhor uso das informações para que todos os participantes possam criar planos realistas e que satisfaçam os objetivos estratégicos da companhia. A ideia é que não seja praticada uma visão por silos, onde cada área busca os seus indicadores em detrimento dos outros, mas que as áreas relacionadas à operação, ao mercado e finanças busquem cada vez mais o compartilhamento de informações para que o resultado seja o melhor para toda a empresa.

O modelo de maturidade de Grimson e Pyke (2007) prega que o estágio mais avançado do processo de S\&OP/IBP é quando o processo é feito "event driven", isto é, assim que algum imprevisto ocorre, os times não esperam a próxima reunião para conversar, eles se reúnem imediatamente para desenhar a forma de contornar o problema. Apesar de ser difícil atingir tal estágio de maturidade, esse nível de colaboração se torna cada vez mais importante em uma economia cada vez mais dinâmica, conforme apresentado em Lim et al. (2014). Swaim et al. (2016) mostraram que um fator chave para o sucesso do S\&OP/IBP é a colaboração. Oliva e Watson (2011) trabalharam e recomendam estudos mais profundos no aspecto comportamental do S\&OP/IBP.

Thomé et al. (2012a) ressaltam, também, a necessidade de confiança e comprometimento dos participantes com o processo de S\&OP/IBP como fundamentais para o sucesso na sua implementação e uso.

\subsubsection{2.}

\section{Estrutura organizacional do S\&OP/IBP}

Dependendo da intimidade que a empresa tenha com o processo, o processo por ser estruturado de diversas maneiras (Grimson e Pyke, 2007). Nas menos maduras, as pessoas não se preocupam em separar informações relevantes para outras áreas tomarem ciência e auxiliarem na resolução de problemas. À medida que as pessoas entendem e se engajam com o processo de S\&OP/IBP, as pessoas passam 
a entender a importância que cada área tem no processo e conseguem alinhar melhor os planos de maneira mais lucrativa para a empresa. O S\&OP/IBP é organizado em times (Pedroso et al., 2016) e em passos, geralmente os destacados em Wallace e Stahl (2008). Thomé et al. (2012a) destacam, ainda, a importância da agenda e do empoderamento dos participantes do processo.

\subsubsection{3. Tecnologia da informação}

Nesse tópico, o aspecto mais relevante é o fluxo de informações (Grimson e Pyke, 2007). Em empresas menos familiarizadas com a importância desse fluxo, as informações são mantidas em planilhas eletrônicas, que são pouco difundidas pelos departamentos. Em um ambiente mais competitivo, onde organizações buscam cada vez mais visibilidade ao longo de suas cadeias de suprimentos (Olhager, 2013), a demanda por sistemas de informação mais sofisticados tende a aumentar.

Além dos sistemas, também podem ser incorporados ao processo de S\&OP/IBP softwares que gerem informações praticamente em tempo real, o que agiliza a tomada de decisão. Sem essas ferramentas, é difícil o S\&OP/IBP obter bons resultados (Ivert e Jonsson, 2010). Ivert e Jonsson (2014) abordam a importância de um sistema Advanced Planning and Scheduling (APS), que permite simular cenários futuros e otimizar o abastecimento, com base nas restrições levantadas e concluem que tais sistemas são facilitadores para decisões rápidas e precisas. Kaipia et al. (2017) apontam estudos que mostram como o uso das tecnologias pode melhorar a acuracidade das previsões de vendas e serviços aos clientes e parceiro da cadeia de suprimentos. SAP (2018) trata da importância do uso de sistemas Enterprise Resource Planning (ERP) combinados com ferramentas estatísticas e de otimização durante o processo para facilitar o fluxo de informações e tomar decisões de maneira rápida e precisa.

\subsubsection{4. Métricas}

É preciso avaliar se os processos estão entregando resultados esperados e, caso necessário, identificar os pontos de atenção para que ajustes sejam feitos (Hulthén et al., 2016). A avaliação dos processos é feita através do estabelecimento de indicadores de desempenho. A escolha desses indicadores deve ser feita de forma a 
incentivar que as áreas sejam recompensadas se entregarem resultados que deixem a empresa mais próxima de alcançar seus objetivos estratégicos (Hulthén et al., 2017). Hulthén et al. (2016) afirmam não existir um consenso acerca da melhor maneira de medir o processo, portanto propuseram um framework com diversas métricas possíveis de serem aplicadas.

Contudo, algumas métricas ainda estão premiando áreas de maneira isolada (Thomé et al., 2012a). Grimson e Pyke (2007) mostraram que o conjunto de indicadores adotado está diretamente relacionado ao nível de maturidade da empresa em relação ao processo de S\&OP/IBP. Visando amenizar essa falta de coordenação, Cecere et al. (2009) e Tohamy et al. (2013) propuseram um conjunto de métricas para cada nível de maturidade do modelo de Grimson e Pyke (2007). Entretanto, isso não garante que seja genérico, nem flexível, pois nem todas as empresas usam o modelo de Grimson e Pyke (2007) como referência.

\subsection{5. \\ Saídas e resultados}

Uma vez que que o processo de $S \& O P / I B P$ é muito dependente do contexto (Goh e Eldridge, 2019), os resultados gerados precisam ser analisados com base no cenário específico da empresa (Kristensen e Jonsson, 2018). Por isso, os principais resultados a serem levados em consideração no processo de S\&OP/IBP são o plano unificado, com as visões de mercado, de operações e finanças (Grimson e Pyke, 2007; Thomé et al., 2012a; Swaim et al., 2016) e a integração horizontal e vertical (Wagner et al, 2014; Noroozi e Wikner, 2017)

Thomé et al. (2012b) mostraram que o S\&OP/IBP exerce uma influência positiva no desempenho das empresas. Thomé et al. (2014a) identificaram que essa influência é potencializada quando existe integração entre a empresa e seus fornecedores. Em contrapartida, Rexhausen et al. (2012) não observaram benefícios na relação entre o $\mathrm{S} \& \mathrm{OP} / \mathrm{IBP}$ e a gestão de demanda, porém afirmaram que o motivo para tal conclusão estava no nível de maturidade das empresas que praticavam o $\mathrm{S} \& \mathrm{OP} / \mathrm{IBP}$ até aquele momento, que ainda era insuficiente. O nível de maturidade baixo reflete no comportamento das pessoas, logo na integração entre as áreas. Esse efeito do aspecto comportamental foi explorado por Oliva e Watson (2011) e Ambrose e Rutherford (2016). 
Devido à divergência de resultados obtidos com o processo de S\&OP/IBP, Swaim et al. (2016) trabalharam na identificação dos precedentes de um S\&OP/IBP efetivo. Além do engajamento da empresa com o processo, a Integração Organizacional foi apontada como o principal precedente. Goh e Eldridge (2015) avaliaram os impactos que a implementação do S\&OP/IBP gerou em empresas asiáticas. Elas conseguiram reduzir o tempo de lançamento de produtos, o nível de inventário e melhorar a qualidade das previsões de maneira significativa. Esses resultados foram possíveis, pois amenizaram a visão em silos, uma das barreiras para o funcionamento adequado do S\&OP/IBP (Pedroso et al., 2016), e começaram a aplicar a Integração Organizacional.

Ambrose e Rutherford (2016) mostraram que a colaboração dentro do processo de S\&OP/IBP e autonomia na tomada de decisão são fatores-chave para o resultado obtido com o processo. Para que esses dois fatores funcionem, identificaram a necessidade de se garantir qualidade da informação, dos procedimentos e dos sistemas de recompensas. Esses três requisitos são abordados de acordo com o contexto da organização.

\section{2. \\ Modelos de Referência}

Na área de Sistemas de Informação, o conceito de Modelos de Referência é utilizado há muitos anos (Fettke et al., 2005). Alguns modelos são muito dependentes de um contexto, como o ambiente onde são aplicados e os pré-requisitos que os usuários devem atender para usá-los adequadamente (Becker et al., 2007).

Modelos de Referência oferecem, por definição, as melhores práticas de um processo (Becker et al., 2007). Para que o modelo possa ser considerado de referência, é preciso que ele atenda algumas condições: auxiliar na avaliação do impacto da tomada de decisões (Chalmeta et al., 1997), ser reutilizável de maneira genérica em diferentes contextos (Biemans e Vissers, 1989; Rehse et al., 2017), ser adaptável às necessidades dos usuários (Fettke et al., 2005; Becker et al., 2007; Rehse et al., 2017) e ilustrar exemplos de como o processo pode ocorrer (Rehse et al., 2017).

Os principais benefícios dos Modelos de Referência estão relacionados à redução de custos e esforços de implementação, bem como a possibilidade de rea- 
proveitar um conhecimento já gerado e estruturado com base em diversas experiências (Becker et al., 2007; Rehse et al., 2017). Segundo Rehse et al. (2017), o uso de Modelos de Referência tende a melhorar a comunicação interna e reduzir o desgaste entre as áreas de uma empresa.

Uma vez que as empresas precisam se adaptar com cada vez mais frequência e rapidez, os Modelos de Referência precisam guiar as mudanças de maneira rápida e simples, mesmo com um processo já implementado (Oztemel e Tekez, 2009). As diretrizes de um modelo de referência devem ser estabelecidas através da descrição das atividades a serem realizadas, a sequência na qual as atividades devem ocorrer, os participantes do processo, as funções dos participantes e a forma como os participantes interagem entre si para que os resultados desejados sejam entregues (Biemans e Vissers, 1989; Fettke et al., 2005).

Em seu estudo empírico, Kreuter et al. (2019) mostraram que executivos viram potencial benéfico na criação de um modelo de referência para o processo de S\&OP/IBP. O modelo precisa contemplar não apenas a caracterização completa do processo, mas também a forma como as pessoas e as tecnologias são envolvidas durante o mesmo. Tal ferramenta pode amenizar o grande impacto que as diferenças contextuais exercem no funcionamento do processo de S\&OP/IBP. Além disso, tal modelo ajudaria a reduzir os esforços de implementar um processo sob demanda, já que a modelagem de um processo isolado consome muitos recursos e apresenta falhas (Fettke et al., 2005). Biemans e Vissers (1989) ressaltam que só é possível colocar o modelo de referência em prática após o alinhamento entre as recomendações do modelo de referência e o modelo de negócios da empresa. Tal alinhamento só é possível ao se analisar caso a caso, pois a dinâmica de funcionamento do S\&OP/IBP é muito dependente do contexto no qual a empresa está inserida (Kristense e Jonsson, 2018).

Schütte (1998) define que a elaboração de um modelo de referência é feita em cinco etapas: definição do problema, construção da estrutura de referência, construção da estrutura do modelo de referência, construção do modelo de referência e aplicação do modelo de referência. Como o foco desta pesquisa é construir a estrutura de um modelo de referência, esta dissertação atende até a terceira etapa de Schütte (1998). Meise (2001) recomenda que uma estrutura de referência defina três categorias de processos: Principal, Suporte e Coordenação. Processo Principal está atrelado à estratégia da empresa, ou seja, ele precisa ser executado para que os 
objetivos do negócio sejam alcançados. Suporte atende aos requerimentos para o funcionamento do Principal, ou seja, auxilia o Principal fornecendo os recursos necessários para que o desempenho seja o melhor possível. Coordenação, através de indicadores de desempenho, atua de forma a medir e controlar a execução do Principal, evidenciando a necessidade de eventuais ajustes. 


\section{3 \\ Metodologia}

Este capítulo apresenta a metodologia adotada para o desenvolvimento da estrutura do modelo de referência desta dissertação. Foi utilizado o processo de elaboração de modelos de referência de Schütte (1998), juntamente às recomendações oferecidas em Meise (2001), Becker et al. (2002), Fettke (2014), Püster (2016) e Rehse et al. (2017), que complementam o procedimento, de forma a proporcionar um melhor aproveitamento do mesmo. O processo é constituído por cinco etapas: definição do problema, construção da estrutura de referência, construção da estrutura do modelo de referência, construção do modelo de referência e aplicação do modelo de referência. Uma vez que não existe nenhum modelo de referência proposto para o processo de $\mathrm{S} \& \mathrm{OP} / \mathrm{IBP}$, este trabalho avançou até a terceira etapa, onde é detalhado o processo de S\&OP/IBP em diversos níveis, e adotou termos universais, familiares a todos os envolvidos (Schütte, 1998). Os quarto e quinto passos só podem ser devidamente validados após maior cobertura de diferentes contextos, o que fica como sugestão para pesquisas futuras.

A Figura 1 resume o procedimento adotado. A primeira etapa tem como objetivo, além da definição do problema, estruturar a forma como o modelo de estrutura de referência é construído. Na segunda, as fontes de conhecimento são identificadas e os métodos utilizados para construir a estrutura de referência são executados e documentados. Na terceira, o processo de refinamento da estrutura é executado, de forma a validá-la e categorizá-la como uma estrutura de modelo de referência. Na Figura 1, cada etapa de Schütte (1998) e seus subprocessos são detalhados, bem como o que foi feito para que a estrutura do modelo de referência fosse construída. 


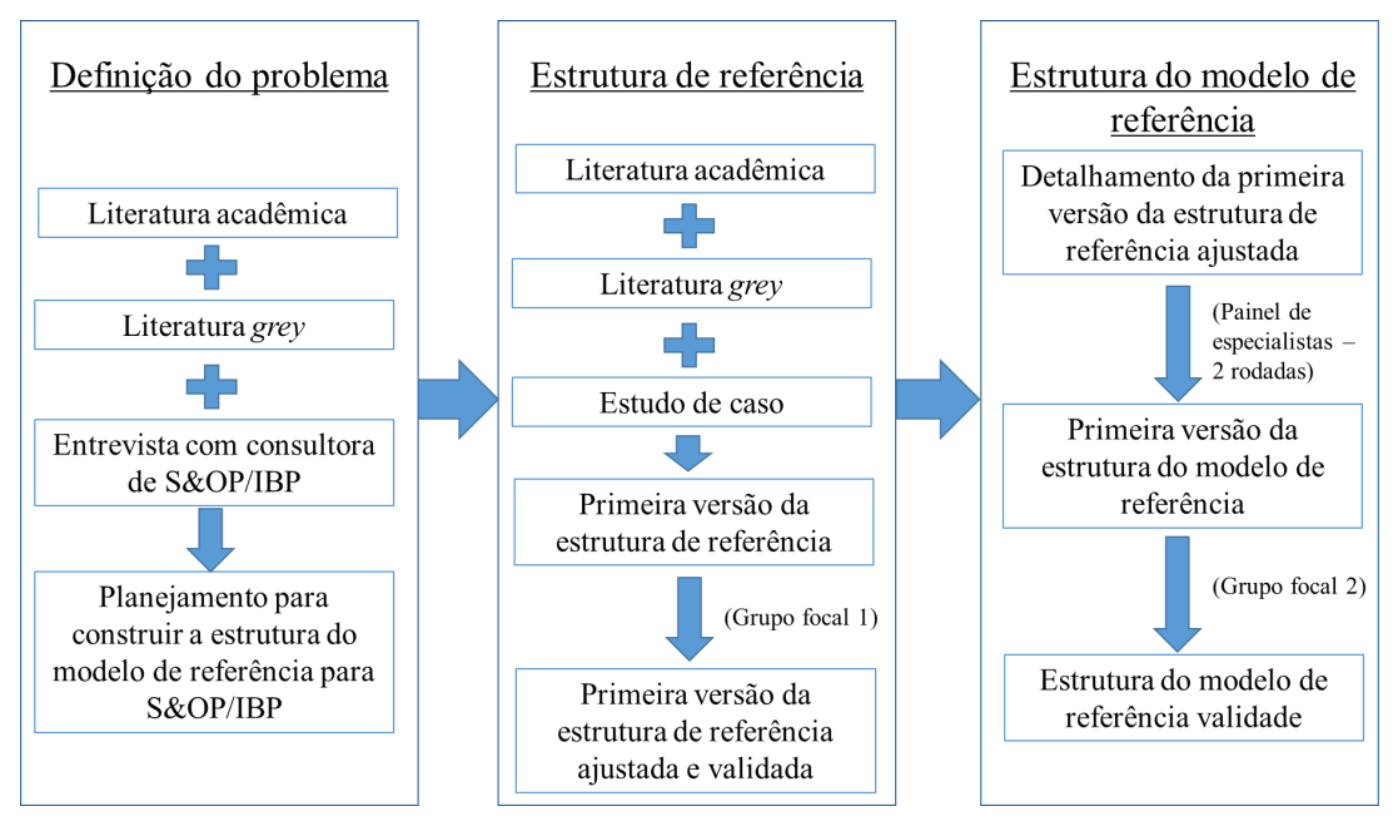

Figura 1 - Procedimento adotado com base no método de Schütte (1998). Fonte: Autor

\section{1. \\ Definição do problema}

Esta primeira etapa de Schütte (1998) tem como objetivo o estabelecimento de um problema relatado na literatura, propor e validar uma solução e planejar o procedimento de elaboração da estrutura do modelo de referência. O problema foi definido como sendo a dificuldade de se obter os resultados prometidos pelo processo de S\&OP/IBP. A solução proposta e validada foi o desenvolvimento de um modelo de referência para esse processo. O planejamento foi a execução do método de Schütte (1998) para elaborar modelos de referência. A primeira etapa de Schütte (1998) é realizada em 4 subprocessos: identificação de lacunas, definição dos interessados e beneficiários, definição de requisitos e escolha da técnica e linguagem de modelagem. A Figura 2 ilustra a primeira etapa de Schütte (1998), com os subprocessos para atingir o objetivo desta etapa, que são detalhados a seguir. 


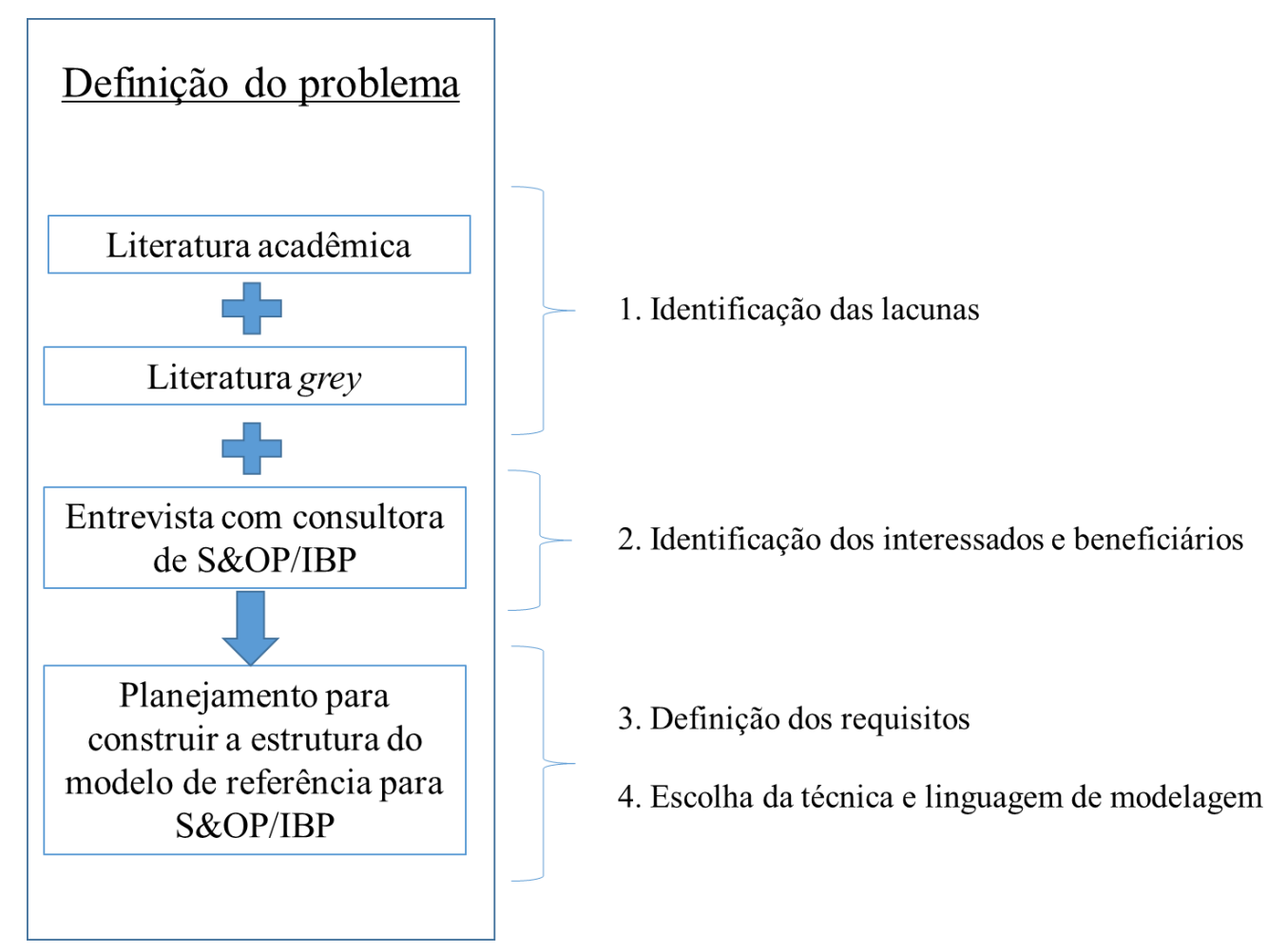

Figura 2 - Primeira etapa de Schütte (1998): Definição do problema. Fonte: Autor

\subsection{1. Identificação de lacunas}

Este subprocesso foi executado a partir de uma revisão narrativa das literaturas acadêmica e grey. Foi identificado que existem opiniões divergentes acerca da efetividade do processo de $\mathrm{S} \& \mathrm{OP} / \mathrm{IBP}$, pois nem todas as empresas foram capazes de colher o resultado esperado no momento da implementação (Lapide, 2005; Tuomikangas e Kaipia, 2014; Wagner et al., 2014; Swaim et al., 2016; Scavarda et $a l ., 2017)$. E que existe carência de uma caracterização completa do processo (Pedroso et al., 2016) e de guias de implementação e uso do processo de S\&OP/IBP (Pedroso et al., 2016; Danese et al., 2017), além de uma falta de entendimento total por parte dos usuários do processo (Pedroso et al., 2016; Scavarda et al., 2017).

Schütte (1998) afirma que esse subprocesso deve apresentar não apenas um problema a ser abordado, mas também que uma solução seja proposta e acordada com os potenciais beneficiários. Isso ameniza o fato de "problema" ser um conceito subjetivo, que depende de pontos de vista. A fim de se investigar a necessidade prática de um modelo de referência para o processo de S\&OP/IBP, uma consultora com ampla experiência em implementação desse processo em diversas empresas foi entrevistada. Ela confirmou que as dificuldades relatadas na literatura estão de 
acordo com a realidade dos usuários do processo de $\mathrm{S} \& \mathrm{OP} / \mathrm{IBP}$, e que o uso do conceito de modelo de referência tem potencial para suportar os praticantes, principalmente, por se tratar de uma ferramenta que ameniza os efeitos das variações de contexto. Isto corrobora com os resultados obtidos em Kreuter et al. (2019).

\subsection{2.}

\section{Definição dos interessados e beneficiários}

Este subprocesso envolve a identificação dos possíveis beneficiários e dos interessados no uso do modelo de referência (Becker et al., 2002). Os usuários do processo de $\mathrm{S} \& \mathrm{OP} / \mathrm{IBP}$ foram definidos como beneficiários e interessados através da revisão narrativa nas literaturas acadêmica e grey e da entrevista com a consultora de S\&OP/IBP. Outros interessados identificados são os pesquisadores que estão buscando melhorias para o processo de S\&OP/IBP, pois a estrutura de modelo de referência obtida deve ser continuamente testada com os praticantes, especialistas e potenciais usuários em diversos contextos de forma a aprimorá-la (Schütte, 1998).

\subsection{3. \\ Definição dos requisitos}

Os requisitos para desenvolver um modelo de referência são agrupados em requisitos metodológicos e requisitos de conteúdo (Püster, 2016). Os requisitos metodológicos definem a forma como o modelo é construído e refinado e o procedimento de documentação. Os requisitos de conteúdo definem o nível de detalhamento do processo e a caracterização completa do processo a ser abordado pelo modelo de referência.

A partir de uma revisão narrativa nas literaturas acadêmica e grey, foram identificadas lacunas de pesquisa e questionamentos acerca de como tratar tais lacunas. Com base nos questionamentos, foram elaborados os questionários utilizados na documentação do processo de S\&OP/IBP (ver Apêndice I).

Os questionários foram aplicados em um estudo de caso em uma empresa do setor químico, atuante no Brasil, denominada de XYZ. As informações coletadas foram comparadas às informações disponíveis nas literaturas acadêmica e grey, de forma a elaborar a primeira versão conceitual de uma estrutura de referência. Essa 
versão foi ajustada através da mediação de um grupo focal realizados com 6 especialistas em S\&OP/IBP de Brasil e Alemanha, buscando ajustes e incrementos na primeira versão (ver Apêndice II).

O refinamento da estrutura foi feito em duas rodadas de painel com especialistas. Na primeira rodada, um novo questionário foi elaborado e aplicado em entrevistas com 10 praticantes (ver Apêndice III). O objetivo foi documentar as opiniões de todos os entrevistados e implementar as melhorias sugeridas por eles. A segunda rodada foi a apresentação e validação da nova versão da estrutura refinada, ajustada de acordo com os feedbacks recebidos. Por último, foi mediado um grupo focal com 3 representantes da empresa química, 1 dos praticantes entrevistados e 2 especialistas do primeiro grupo focal para validação da versão final da estrutura proposta (ver Apêndice IV).

A partir da realização de um estudo de caso, juntamente ao conhecimento levantado na revisão narrativa das literaturas acadêmica e grey e na entrevista com a consultora, o processo de S\&OP/IBP de uma empresa química do Brasil foi mapeado do início ao fim. O nível de detalhamento foi desde as etapas macro do processo até a forma com que as pessoas participam do processo e interagem umas com as outras.

\subsection{4. Escolha da técnica e linguagem de modelagem}

Para os casos, nos quais existe um modelo de referência proposto, é recomendado que seja adotada a mesma técnica e linguagem (Schütte, 1998). Porém, é preciso avaliar se o modelo existente satisfaz plenamente aos usuários, ou se é preciso ajustá-lo para torna-lo mais abrangente. Como o processo de S\&OP/IBP ainda não possui um modelo proposto, foi adotada a técnica de mapeamento de processos de negócios, uma das mais utilizadas e que permite o detalhamento e níveis de abstração maiores (Rehse et al., 2017).

O mapeamento dos processos foi realizado no software Microsoft Visio ${ }^{\circledR}$ versão 2007. O processo foi representado por uma modelagem em diferentes níveis de detalhes. A modelagem do processo foi feita através da notação Fluxograma, que utiliza símbolos simples, facilitando a compreensão rápida do fluxo de um processo (ABPMP, 2013). Os símbolos são ilustrados na Figura 3. 


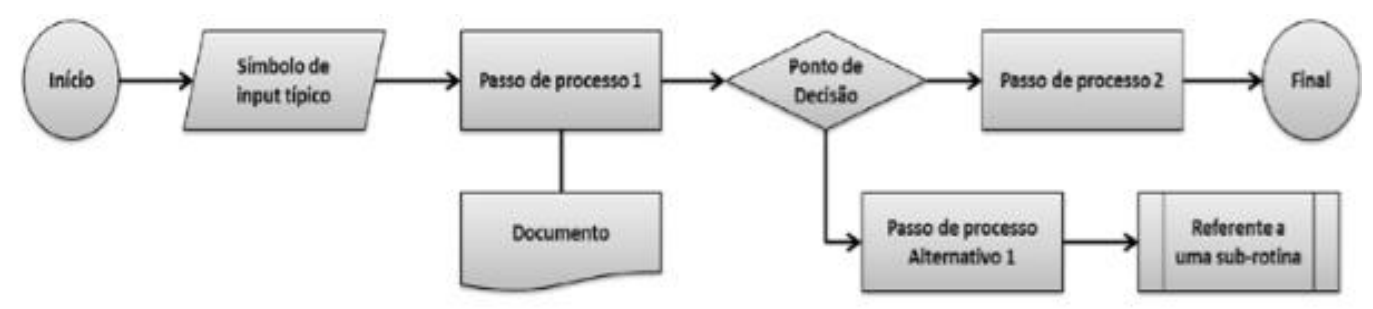

Figura 3 - Notação Fluxograma. Fonte: ABPMP (2013)

\section{2.}

\section{Construção da estrutura de referência}

Conforme o nome da etapa, o objetivo é entregar uma estrutura de referência. A primeira versão da estrutura oferecida nesta dissertação foi elaborada a partir do conhecimento adquirido na primeira etapa, em nova revisão narrativa de literatura e na aplicação de um estudo de caso. Essa primeira versão foi aprimorada após um grupo focal com 6 especialistas do Brasil e da Alemanha.

Schütte (1998) recomenda a construção a partir de matrizes. Para que o procedimento pudesse ser adaptado para processos fora da área de Sistemas de Informação, Püster (2016) recomenda que seja adotado o procedimento de Meise (2001) nesta etapa e sejam definidos os processos Principal, de Suporte e de Coordenação, visando a generalização da estrutura. Esta dissertação segue a recomendação de Püster (2016). Além disso, Püster (2016) adapta esta etapa para a criação de estruturas de referência subdividindo-a em 3 subprocessos: identificação das fontes de conhecimento, desenho da estrutura de referência e definição dos processos Principal, de Suporte e de Coordenação. A Figura 4 resume o procedimento para a elaboração do produto desta segunda etapa de Schütte (1998), junto aos subprocessos, que são detalhados a seguir. 


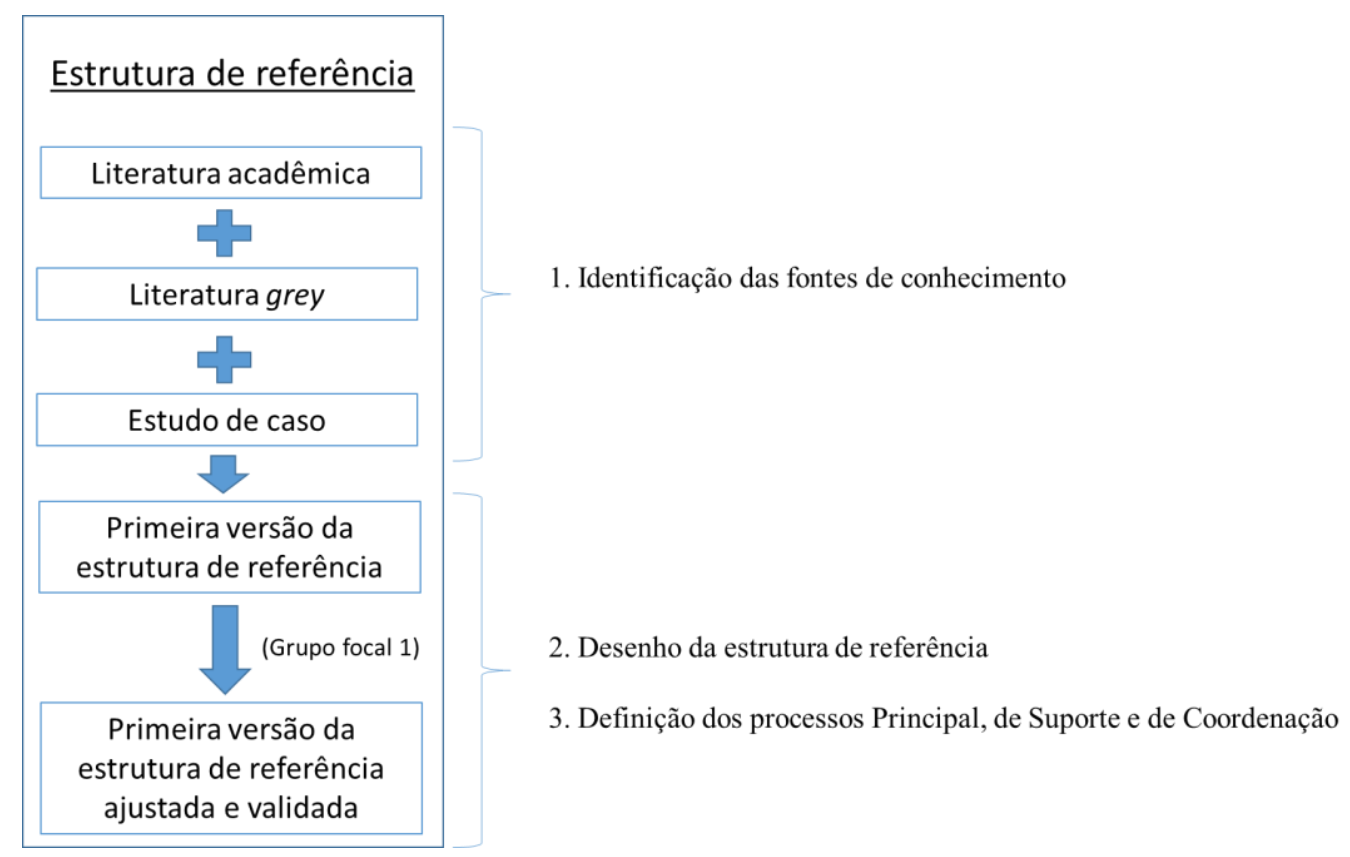

Figura 4 - Segunda etapa de Schütte (1998): Elaboração da estrutura de referência. Fonte: Autor

\subsection{1. Identificação das fontes de conhecimento}

Este subprocesso tem como finalidade promover um estudo prévio do assunto e dos termos utilizados, para que os termos adotados sejam comuns a todos os entendedores, garantindo universalidade da estrutura de referência. Püster (2016) divide as fontes de conhecimento em estruturadas e sociais. As fontes estruturadas são constituídas pelas literaturas acadêmica e grey e modelos existentes. As fontes sociais são formadas por especialistas, consultores e praticantes.

Ambas foram utilizadas na elaboração da estrutura de modelo de referência desta dissertação. As fontes estruturadas foram consultadas primeiro, pois antes de entrevistar os praticantes, é preciso entender os fundamentos do processo de $\mathrm{S} \& \mathrm{OP} / \mathrm{IBP}$ e montar uma estrutura de forma dedutiva, isto é, com base em princípios e premissas geralmente aceitos para se estabelecer o fluxo do processo de S\&OP/IBP (Rehse et al., 2017). Após a teoria do processo ser compreendida, foram consultadas as fontes sociais para iniciar um processo indutivo de refinamento, ou seja, um processo com base em dados do mundo real de um processo já existente e com especialistas e praticantes ajudando a tornar o modelo mais em conformidade com a prática (Rehse et al., 2017). 


\subsection{2.}

\section{Desenho da estrutura de referência}

A primeira versão da estrutura de referência foi elaborada com base no estudo prévio dos conceitos existentes nas literaturas acadêmica e grey, na entrevista com a consultora de S\&OP/IBP e no estudo de caso aplicado na empresa XYZ. Uma vez que não existe um modelo proposto para o processo de S\&OP/IBP, a estrutura foi desenhada com base na ideia de níveis de detalhamento presente no $\mathrm{Su}$ pply Chain Operations Reference (SCOR) e seguiu a base do quadro conceitual desenvolvido na Westfälische Wilhelms-Universität Münster, no laboratório comandado pelo professor Bernd Hellingrath.

A primeira versão foi ajustada após a moderação de uma seção de grupo focal com 6 especialistas de Brasil e Alemanha no tema S\&OP/IBP, a fim de direcionar as discussões acerca de ajustes e incrementos na primeira versão. $\mathrm{O}$ processo de refinamento dessa versão ajustada é descrito na seção 3.3. A seguir, são detalhados os dois processos executados para se obter o desenho da estrutura de referência após a consulta nas fontes estruturadas e a entrevista com a consultora: o estudo de caso e o primeiro grupo focal.

\subsubsection{1. \\ Estudo de caso}

O objetivo do estudo de caso é descrever como um processo ocorre para entender um fenômeno novo ou pouco conhecido (Yin, 2001). Os desafios desse método estão relacionados ao tempo necessário para conduzi-lo, à habilidade do entrevistador em obter as informações necessárias e a capacidade de elaborar conclusões gerais, apesar da limitação de um contexto específico (Voss et al., 2002). Tal procedimento foi adotado após a exploração das fontes estruturadas, para que fosse possível comparar o que diz a teoria e o que os praticantes executam. Conforme apresentado em Gil (2010), não existe uma estrutura rígida a ser seguida em um estudo de caso. Esta dissertação adotou o procedimento de Gil (2010) para estudos de caso na seguinte sequência: definição da unidade-caso e unidade de análise, coleta de dados, análise e interpretação de dados e elaboração da primeira versão da estrutura de referência. 


\subsubsection{1.}

\section{Definição da unidade-caso e unidade de análise}

A unidade-caso refere-se a uma subsidiária brasileira de uma multinacional europeia do setor químico, denominada XYZ, com mais de 50.000 funcionários em mais de 50 países, com vendas para grandes distribuidores de medicamentos por toda a América Latina, faturamento superior a 1 bilhão de reais ao ano e aproximadamente 250 SKUs.

A unidade de análise é o processo de $\mathrm{S} \& \mathrm{OP} / \mathrm{IBP}$ praticado na subsidiária brasileira. A empresa adota apenas o termo IBP, pois afirma que o IBP é um processo melhor do que o S\&OP. A unidade-caso e a unidade de análise foram escolhidas seguindo dois critérios. O primeiro está relacionado ao alto nível de maturidade no qual a empresa se encontra, podendo ser considerada um benchmark e um representante significativo para o tema (Yin, 2001). O segundo é o fato de a operação no Brasil ser complexa, envolvendo muitos clientes, fornecedores e dificuldades particulares a um país emergente, o que reforça o nível de efetividade do processo executado. A operação no Brasil é uma das mais importantes do continente americano.

\subsubsection{2.}

\section{Coleta de dados}

Para garantir a profundidade necessária ao estudo, os dados foram coletados através de observação espontânea, questionários e análise de documentos. Na observação espontânea, onde não houve interação entre o pesquisador e o processo, buscou-se as ações executadas, os participantes envolvidos, o tratamento dos dados levados e as métricas utilizadas. Os questionários foram aplicados em entrevistas individuais semiestruturadas gravadas (ver Apêndice I), onde o objetivo foi coletar informações pertinentes aos questionamentos levantados na etapa de análise das fontes estruturadas e permitir os entrevistados darem mais detalhes acerca do processo, já que não é um questionário com perguntas fechadas. Já a análise de documentos do processo de S\&OP/IBP, como as atas das reuniões e informações extraídas dos sistemas de informação da empresa, foi adotada visando a facilitação posterior de uma triangulação de dados. 
Por conta de muitos praticantes ainda não terem conseguido colher todos os resultados esperados, o foco inicial desde estudo de caso foi compreender os mecanismos envolvidos no processo de S\&OP/IBP da empresa XYZ, através da observação espontânea (McCutcheon e Meredith, 1993). A observação foi direcionada a elaboração de um fluxo para o processo de S\&OP/IBP praticado pela empresa XYZ. Isto foi complementado com análise de relatórios internos para garantir a posterior triangulação.

A seguir, foram reunidas as informações detalhadas do processo para construir a primeira versão da estrutura de referência. Elas foram coletadas por meio de entrevistas gravadas com participantes do processo. As entrevistas foram de caráter semiestruturado, para garantir a cobertura dos pontos desejados, e também para permitir que o entrevistador explore detalhes não planejados, que surgem no decorrer da entrevista. As entrevistas foram conduzidas, principalmente, face a face e sob acompanhamento de outro pesquisador experiente, visando suprir um dos desafios das entrevistas em estudo de caso apontado por Voss et al. (2002), que é a habilidade do pesquisador em coletar todas as informações de maneira precisa. As primeiras reuniões serviram para reconhecimento do contexto da empresa e do seu processo de IBP. Foram entrevistados o diretor de Supply Chain, a gerente do processo de IBP, os gerentes de Vendas, Marketing, Planejamento da Produção e Finanças e um analista do processo de IBP. Cada entrevista durou entre uma e duas horas.

\subsubsection{3.}

\section{Análise e interpretação de dados}

As entrevistas gravadas foram transcritas para garantir que nenhum detalhe fosse esquecido e para confirmar se o que foi observado em campo está de acordo com o que foi explicado. As respostas foram lidas de forma a compreender as ideias que cada um dos participantes tem em relação ao processo e buscar categorias que condensassem as ideias apresentadas. Uma vez que os termos usados pelos entrevistados seguem um padrão, foi possível resumir as ideias em tópicos para comparar e triangular os dados levantados pelas três fontes: observação, entrevistas e relatórios. Uma vez que pessoas relevantes para o funcionamento do processo foram ouvidas e houve alinhamento entre os dados coletados nas três fontes, o primeiro 
desenho da estrutura de referência pode ser feito com base em dados confiáveis e com credibilidade garantida.

\subsubsection{4.}

\section{Elaboração da primeira versão da estrutura de referência}

A primeira versão da estrutura de referência foi desenhada a partir dos conhecimentos levantados tanto nas fontes estruturadas, quanto no estudo de caso aplicado na empresa XYZ. O fluxo foi feito com base nas semelhanças encontradas nas informações obtidas com a pesquisa. A fim de melhorar essa primeira versão, foi aplicado um grupo focal, conforme descrito na subsubseção 3.2.2.2.

\subsubsection{2.}

\section{Grupo focal 1}

O grupo focal é um método qualitativo flexível que permite coletar dados mediante discussões sobre tópicos específicos do objeto de pesquisa, explorando o conhecimento e experiências dos participantes (Rodrigues et al., 2010). Rodrigues et al. (2010) recomendam o uso desse método após pesquisas na literatura ou pesquisas com questionários para o aprofundamento de determinado assunto. Recomendam, também, que a dinâmica seja feita com um número de 6 a 10 participantes, pois esse intervalo oferece os maiores níveis de riqueza de informações e controle.

As vantagens desse método são: é um bom método para tratar problemas de negócios (Bryman, 2004), permite tirar conclusões a partir de um pequeno grupo que representa um número significativo de pessoas (Krueger,1998) e permite que um especialista complemente o outro, aumentando a qualidade das informações (Patton, 2002).

As desvantagens identificadas foram: dificulta análises detalhadas (Krueger, 1998), em casos de opiniões divergentes, pode ocorrer ofuscamento de algum ponto de vista (Bryman e Bell, 2007) e a análise dos dados é demorada (Bryman e Bell, 2007). A primeira desvantagem foi contornada, pois o foco foi debater pontos macro, como contextos, e não o fluxo completo do processo. A segunda foi mitigada pelo perfil dos participantes e pelo fato de o foco estar em buscar pontos de atenção para refinamento. A terceira não foi possível ser amenizada, pois o foco foi a riqueza dos detalhes. Foi feito um trade off entre o tempo de análise e os detalhes. 
Portanto, com o objetivo de aprimorar a primeira versão da estrutura de referência, foi mediado um grupo focal com 6 especialistas no assunto S\&OP/IBP do Brasil e da Alemanha. Por conta do perfil proativo de todos, diversos pontos de atenção foram levantados para que fossem trabalhados com mais detalhes na etapa de refinamento. Foi adotado um caráter não estruturado para que a versão fosse explorada sem restrições. Ao final da reunião, os especialistas validaram a estrutura de referência desenhada e os pontos de atenção foram anotados para que um novo questionário fosse elaborado para a etapa de refinamento. O Quadro 1 sintetiza os especialistas, suas titulações, nacionalidades e tempo de estudo sobre S\&OP/IBP, incluindo o autor desse trabalho, que exerceu o papel de mediador do grupo focal. O Apêndice II apresenta o procedimento adotado para a execução desse primeiro grupo focal.

Quadro 1 - Especialistas consultados

\begin{tabular}{|c|l|c|l|}
\hline ID & \multicolumn{1}{|c|}{ Titulação } & País & $\begin{array}{l}\text { Tempo de } \\
\text { experiência com } \\
\text { S\&OP/IBP (anos) }\end{array}$ \\
\hline 0 & Engenheiro (mediador) & Brasil & Mais de 3 \\
\hline 1 & Doutor & Brasil & Mais de 10 \\
\hline 2 & Doutor & Brasil & Mais de 10 \\
\hline 3 & Doutorado em curso & Brasil & Mais de 20 \\
\hline 4 & Doutor & Alemanha & Mais de 5 \\
\hline 5 & Doutorado em curso & Alemanha & Mais de 5 \\
\hline 6 & Doutorado em curso & Alemanha & Mais de 3 \\
\hline
\end{tabular}

\subsection{3.}

\section{Definição dos processos Principal, de Suporte e de Coordenação}

Os processos Principal e de Suporte se baseiam nos pilares de um processo de S\&OP/IBP definidos por Lapide (2005): Processos, Pessoas e Tecnologia. O pilar Processos foi incluído na categoria Principal, que é representado pelas etapas do processo de $\mathrm{S} \& \mathrm{OP} / \mathrm{IBP}$ descritas no capítulo 4, tendo como base as etapas de Wallace e Stahl (2008). Pessoas e Tecnologia foram incluídos como processos de Suporte, uma vez que eles são vitais para o funcionamento do processo de S\&OP/IBP. O pilar Tecnologia não foi explorado em detalhes nesta dissertação, 
ficando como sugestão para trabalhos futuros. O processo de Coordenação foi baseado no trabalho de medição de desempenho do processo de S\&OP/IBP de Hulthén et al. (2016).

Importante ressaltar que a definição dos processos Principal, de Suporte e de Coordenação foi avaliada e validada nas etapas de refinamento, que são apresentadas na seção 3.3 .

\section{3. \\ Construção da estrutura do modelo de referência}

Segundo Schütte (1998) e Meise (2001), uma vez que não exista um modelo de referência proposto para determinada área, esta etapa deve buscar o detalhamento do processo Principal. Para que a construção da estrutura do modelo de referência seja feita, é preciso executar 3 subprocessos: determinação dos níveis de detalhamento do processo Principal, identificação de analogias entre estruturas e construção do modelo do processo de referência. Conforme Schütte (1998) orienta, utilizar modelos existentes torna essa etapa mais eficiente, pois os primeiros dois passos já estão prontos. Contudo, conforme mencionado, o processo de S\&OP/IBP não possui uma referência, o que resulta na necessidade de seguir o procedimento de Schütte (1998) por completo.

A estrutura do modelo de referência ilustra um modelo genérico, porém com detalhes, para o funcionamento de determinado processo (Püster, 2016). Uma vez que a estrutura desenhada na seção anterior foi elaborada com base em apenas um contexto prático, é preciso refiná-la, tornando-a mais abrangente. Visando o refinamento e abrangência da estrutura desenhada na seção anterior, foram adotadas estratégias indutivas, conforme sugerido por Fettke (2014) e Rehse et al. (2017). A indução se deu através de dois procedimentos: painel com especialistas e outro grupo focal. Ambos os procedimentos são detalhados na subseção 3.3.3. A Figura 5 ilustra o processo de refinamento da estrutura de referência para que ela possa ser chamada de estrutura do modelo de referência, junto aos subprocessos desta etapa, que são detalhados a seguir. 


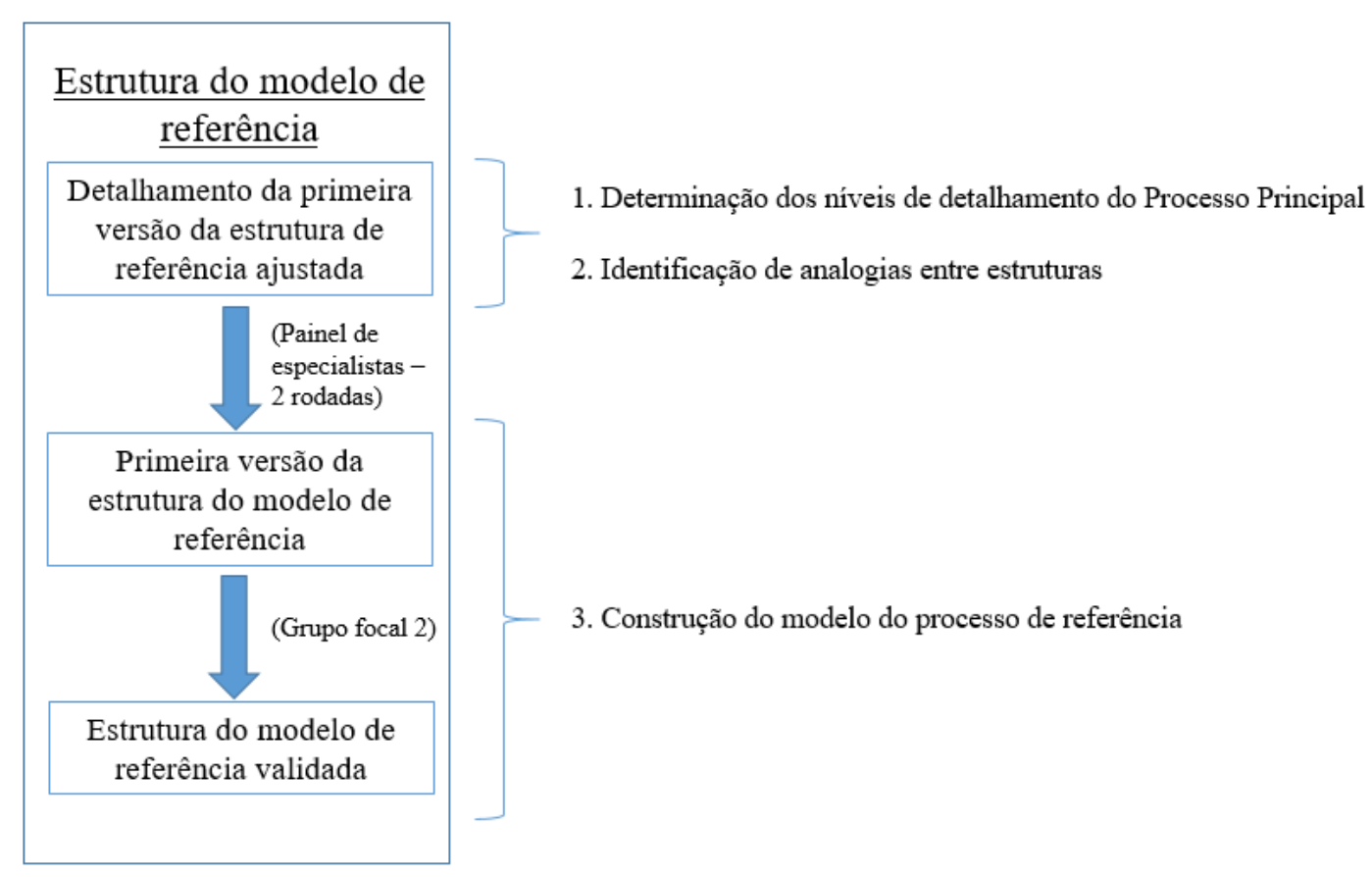

Figura 5 - Terceira etapa de Schütte (1998): Elaboração da estrutura do modelo de referência. Fonte: Autor

\subsection{1. \\ Determinação dos níveis de detalhamento do processo Principal}

O detalhamento da primeira versão ajustada, obtida após o primeiro grupo focal, seguiu a ideia do modelo SCOR, pois trata-se de um modelo de referência com grande compreensão e aceitação entre acadêmicos e praticantes. A estrutura foi dividida em quatro níveis. $\mathrm{O}$ primeiro se refere às etapas macro do processo de S\&OP/IBP. A ideia é que o primeiro nível seja genérico para todos os contextos, isto é, independentemente do tipo de empresa e suas particularidades, o fluxo do processo é o mesmo. O segundo nível detalha cada etapa do processo de maneira genérica. Esse segundo nível não é totalmente neutro em relação ao contexto, mas pode ser seguido por muitos usuários com poucas adaptações. O terceiro traz sugestões de participantes para cada etapa. O quarto, e último, sugere além dos participantes, a forma como os participantes podem interagir de forma a entregar os resultados esperados pelo processo de $\mathrm{S} \& \mathrm{OP} / \mathrm{IBP}$. Os dois últimos níveis são mais dependentes do contexto no qual a empresa está inserida. O capítulo 4 explicita os níveis de detalhamento do processo Principal. 


\subsection{2.}

\section{Identificação de analogias entre estruturas}

A busca por analogias entre estruturas visa identificar semelhanças entre um modelo e o processo na prática. Uma vez que não existe um modelo proposto, é preciso construir essa ponte entre modelo e processo real. Conforme mencionado na subseção 3.2.2, foi adotada a estrutura conceitual desenvolvida na Westfälische Wilhelms-Universität Münster, no laboratório comandado pelo professor Bernd Hellingrath. A estrutura foi mantida nesta etapa de detalhamento e refinamento do processo Principal e seus níveis. O SCOR também foi usado de maneira análoga, com a ideia de que a cada nível de detalhamento do processo Principal, mais detalhado e dependente do contexto o processo fica.

\subsection{3.}

\section{Construção do modelo do processo de referência}

A construção do modelo do processo de referência é a última fase da elaboração de uma estrutura de modelo de referência. Durante o primeiro grupo focal, a estrutura de referência foi validada pelos especialistas, porém ainda era preciso ouvir mais representantes dos beneficiários identificados: os praticantes. Seguindo a recomendação de Fettke (2014) e Rehse et al. (2017), a estrutura de referência foi submetida a estratégias indutivas de refinamento. Foram realizadas duas rodadas de painéis de especialistas com 10 praticantes de diferentes contextos. A primeira rodada teve como objetivo ouvir as opiniões acerca da estrutura desenhada na seção anterior. A segunda visou apresentar melhorias com base nos feedbacks recebidos. Por último, foi mediado um grupo focal com 2 representantes do primeiro grupo focal, 1 do painel de especialistas e 3 da empresa XYZ, de forma a validar a versão final do da estrutura do modelo de referência. A dinâmica do painel de especialistas e do segundo grupo focal são detalhados a seguir.

\subsubsection{1.}

\section{Painel de especialistas}

O primeiro painel de especialistas gerou diversos pontos a serem abordados com os praticantes e como eles tratavam tais pontos. Enquanto os praticantes eram contatados, um novo formulário visando o refinamento da estrutura foi elaborado (ver Apêndice III). Esse novo questionário buscou compreender as particularidades 
que cada praticante tinha que enfrentar no seu contexto de S\&OP/IBP. Dez praticantes com ampla experiência com o processo de S\&OP/IBP compartilharam informações detalhadas acerca dos processos executados em suas empresas e os principais fatores que influenciavam resultados positivos ou negativos. O Quadro 2 sintetiza os perfis dos praticantes, bem como características dos seus contextos e o tempo que cada entrevista durou. A caracterização do contexto seguiu as descrições usadas por Goh e Eldridge (2019), e as características dos produtos com os quais os praticantes trabalham foram divididas de acordo com Ivert et al. (2015a). Foram armazenadas 15 horas de gravações.

\begin{tabular}{|c|c|c|c|c|c|c|}
\hline ID & Cargo & $\begin{array}{c}\text { Tempo de } \\
\text { experiência com } \\
\text { S\&OP/IBP (anos) }\end{array}$ & Setor & Características dos produtos & \begin{tabular}{|c|} 
Tamanho \\
da \\
empresa
\end{tabular} & $\begin{array}{l}\text { Tempo de } \\
\text { entrevista } \\
\text { (horas) }\end{array}$ \\
\hline 1 & Diretor LATAM & 17 & Aço & $\begin{array}{l}\text { Baixa variedade, vida útil longa e poucos } \\
\text { lançamentos por ano }\end{array}$ & Grande & 03:00 \\
\hline 2 & Coordenador de Planejamento de Produção & 11 & Refrigeração & $\begin{array}{l}\text { Baixa variedade, vida útil longa e poucos } \\
\text { lançamentos por ano }\end{array}$ & Grande & 03:00 \\
\hline 3 & Coordenador de Supply Chain & 6 & Energia & $\begin{array}{l}\text { Baixa variedade, vida útil longa e poucos } \\
\text { lançamentos por ano }\end{array}$ & Média & 01:20 \\
\hline 4 & Gerente de Supply Chain & 10 & Farmacêutico & $\begin{array}{l}\text { Alta variedade, vida útil curta e muitos } \\
\text { lancamentos por ano }\end{array}$ & Grande & 01:20 \\
\hline \begin{tabular}{|l|l}
5 \\
\end{tabular} & Gerente de Soluções em Supply Chain & 10 & $\mathrm{TI}$ & Alta variedade e atualizações constantes & Grande & 01:10 \\
\hline 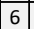 & Consultor Sênior de S\&OP & 15 & Consultoria & - & Grande & 01:10 \\
\hline \begin{tabular}{|l|}
7 \\
\end{tabular} & Instrutor de Supply Chain & 14 & Treinamento & - & Média & 02:00 \\
\hline 8 & Gerente de Logística & 5 & Bebidas & $\begin{array}{l}\text { Muita variedade, vida útil longa e poucos } \\
\text { lançamentos por ano }\end{array}$ & Grande & 02:00 \\
\hline 9 & Diretor de Supply Chain & 9 & Comida & $\begin{array}{l}\text { Baixa variedade, vida útil curta e poucos } \\
\text { lançamentos por ano }\end{array}$ & Grande & 01:30 \\
\hline 10 & Diretor de Logística & 10 & Bens de consumo & $\begin{array}{l}\text { Alta variedade, vida útil variável e muitos } \\
\text { lançamentos por ano }\end{array}$ & Grande & 01:30 \\
\hline
\end{tabular}

Todos os praticantes convidados aceitaram o convite porque julgaram que tinham condições de agregar no refinamento da estrutura de referência, e também porque vislumbraram uma boa oportunidade de observar uma estrutura baseada em trabalhos de relevância acadêmica e em uma empresa com nível de maturidade alto. As entrevistas foram gravadas e feitas de forma individual e com caráter semiestruturado. Essa configuração foi adotada segundo recomendações de Mason (2002), que mostra que tal organização permite a coleta dos dados planejados e de dados não planejados, que possam ser importantes para as conclusões. Além disso, essa forma de trabalho elimina a possibilidade de um contexto sobressair em relação a outro, isto é, todos são ouvidos em relação aos mesmos tópicos, o que evita que algum entrevistado mais falante ofusque outro mais introvertido. Em contrapartida, esse procedimento exige mais tempo de análise e interpretação dos dados coletados.

Inicialmente, a primeira rodada de entrevistas foi baseada na apresentação da estrutura desenhada após o primeiro grupo focal e coleta de opiniões dos profissionais acerca do fluxo mostrado. Em seguida, o questionário buscou informações 
acerca do contexto no qual cada praticante estava inserido. As sugestões de adaptação na estrutura apresentada foram pautadas nas particularidades das áreas de negócios e nos desenhos com os quais os entrevistados estão acostumados. Após reflexões e análises acerca dos pontos de vista apresentados, a estrutura foi ajustada e detalhada com base nos pontos de atenção que foram mais citados e que poderiam ser aplicadas em qualquer contexto. Os pontos que foram citados, porém eram muito específicos para determinados contextos, foram separados do modelo para que a discussão acerca deles seja feita de acordo com o contexto. Os pontos que possuem grande influência no processo, mas que precisam ser adaptados aos contextos de maneira específica são discutidos e detalhados no capítulo 5.

A segunda rodada do painel com especialistas teve o objetivo de apresentar a nova estrutura de referência, detalhada com as experiências de todos os praticantes e validar a abrangência da mesma, de modo que ela possa ser chamada de estrutura de modelo de referência. Todos concordaram que o fluxo proposto está satisfatoriamente abrangente. O principal fator que agradou os entrevistados foi o fato de que o fluxo foi elaborado de maneira abrangente e flexível, isto é, um processo de acordo com o $\mathrm{S} \& \mathrm{OP} / \mathrm{IBP}$ e com os pontos referentes às particularidades de contexto separados, para que cada usuário debata a melhor forma de tratar com cada aspecto.

\subsubsection{2. Grupo focal 2}

O último passo para validar a versão final da estrutura do modelo de referência foi através de um grupo focal. Essa prática é recomendada para aperfeiçoar modelos conceituais (Rodrigues et al., 2010). Seguindo uma recomendação de Rodrigues et al. (2010), foi estabelecido um bom relacionamento com os entrevistados ao longo do processo. Por isso, foi possível mediar um grupo focal com 3 representantes da empresa XYZ (diretor de Supply Chain, a gerente do processo de IBP e um analista do processo de IBP), 2 especialistas do primeiro grupo focal e 1 do painel de especialistas, de forma a validar a versão final da estrutura do modelo de referência.

Esse último grupo focal foi feito de forma estruturada, pois a ideia é validar a estrutura do modelo de referência elaborada ao longo do processo. Foi feita a apresentação do fluxo do processo, dos processos Principal, de Suporte e de Coordenação e os pontos de atenção a serem considerados no momento do desenho do 
processo. Após debates acerca de pontos específicos relacionados aos contextos, a estrutura do modelo de referência desenvolvida foi aprovada por todos os participantes da reunião, bem como os pontos de atenção a serem alinhados antes de desenhar de um novo processo de S\&OP/IBP ou adaptar um processo existente. $\mathrm{O}$ Apêndice IV apresenta o procedimento adotado nesse segundo grupo focal. 


\section{4 \\ Estrutura de modelo de referência}

Este capítulo apresenta o resultado final para a estrutura de um modelo de referência para S\&OP/IBP, obtido através do método de Schütte (1998), que envolveu um estudo de caso, grupos focais e painel com especialistas.

\section{1.}

\section{Visão geral}

A estrutura elaborada seguiu as recomendações de Meise (2001) e Püster (2016), dentro do método de Schütte (1998), onde é preciso definir os processos Principal, de Suporte e de Coordenação. Além disso, baseado no estudo de caso feito na empresa XYZ e na experiência compartilhada pelos especialistas, obtida nos grupos focais e painel com especialistas, são propostos exemplos de fluxos de processos. Esses fluxos foram divididos em 4 níveis, onde o nível 1 é o mais elevado e geral, chamado de industry neutral e o nível 4 é o mais detalhado, incluindo as áreas e como elas podem interagir durante as reuniões do ciclo mensal. Quanto mais elevado for o nível, menos dependente do contexto é a sequência de atividades do processo. O nível de detalhamento também depende das informações que a empresa dispõe (Rehse et al., 2017).

Em relação ao processo Principal, no nível 1, as etapas propostas por Wallace e Stahl (2008), bem como seus nomes, foram adaptadas na elaboração da estrutura. Segundo SAP (2018) e os praticantes da XYZ, os nomes clássicos não estavam transmitindo a ideia exata do objetivo do ciclo de reuniões. Demand Planning e Supply Planning foram alterados para Demand Review (DR) e Supply Review (SR). Isso se deve ao fato de a palavra "Planning" dar a entender que as reuniões serviriam para elaborar um plano, do zero, para atingir os objetivos estipulados no ano anterior. O termo "Review" é considerado mais "preciso", uma vez que as reuniões não constroem cenários totalmente novos, ao contrário, elas servem, como o nome diz, para revisar e ajustar as metas ao longo do ano, quando será possível ter 
uma visão mais clara acerca do comportamento do mercado. O Pre-Meeting, também chamado de Pre-S\&OP/IBP, recebeu o nome de Financial Reconciliation (FR), em função da importância de finanças nessa etapa. Nessa etapa, ocorre a primeira tentativa de balanceamento da oferta e demanda, principalmente, sob a perspectiva de quanto vai custar para fechar gaps entre os planos de demanda e abastecimento, de forma a satisfazer o plano financeiro. A última etapa recebeu o nome de Executive Review (ER) pelo mesmo motivo das primeiras duas etapas, ou seja, a reunião debaterá ajustes nos planos de forma a atender os objetivos de acordo com a realidade do mercado. A última adaptação feita no nível 1 é o destaque para os pre-works, que também precisam ser detalhados de acordo com a necessidade da empresa, a fim de fornecer os dados necessários para a tomada de decisão ao longo das reuniões.

Tanto a empresa XYZ, quanto os especialistas entrevistados concordaram que a primeira etapa do modelo de Wallace e Stahl (2008), Data Gathering, não precisa mais ser feita nos moldes originais, onde os funcionários passariam alguns dias acessando as bases de dados, extraindo informações acerca da operação do mês anterior e preparando apresentações para o próximo ciclo de reuniões que está por vir. Sistemas de informações mais avançados são capazes de acessar os dados, de maneira rápida e em tempo real, e montar relatórios já no formato necessário para servir de input para as reuniões do ciclo atual, ou seja, é possível ter os dados mais atuais a qualquer momento. Entretanto, isso não significa que o modelo não sirva como referência para empresas com menos recursos tecnológicos. Aqueles que utilizam apenas planilhas, ou um sistema menos automatizado, também podem tirar proveito seguindo recomendações nos pre-works, com atividades prévias a cada etapa. A Figura 6 ilustra a visão geral do fluxo do processo. 


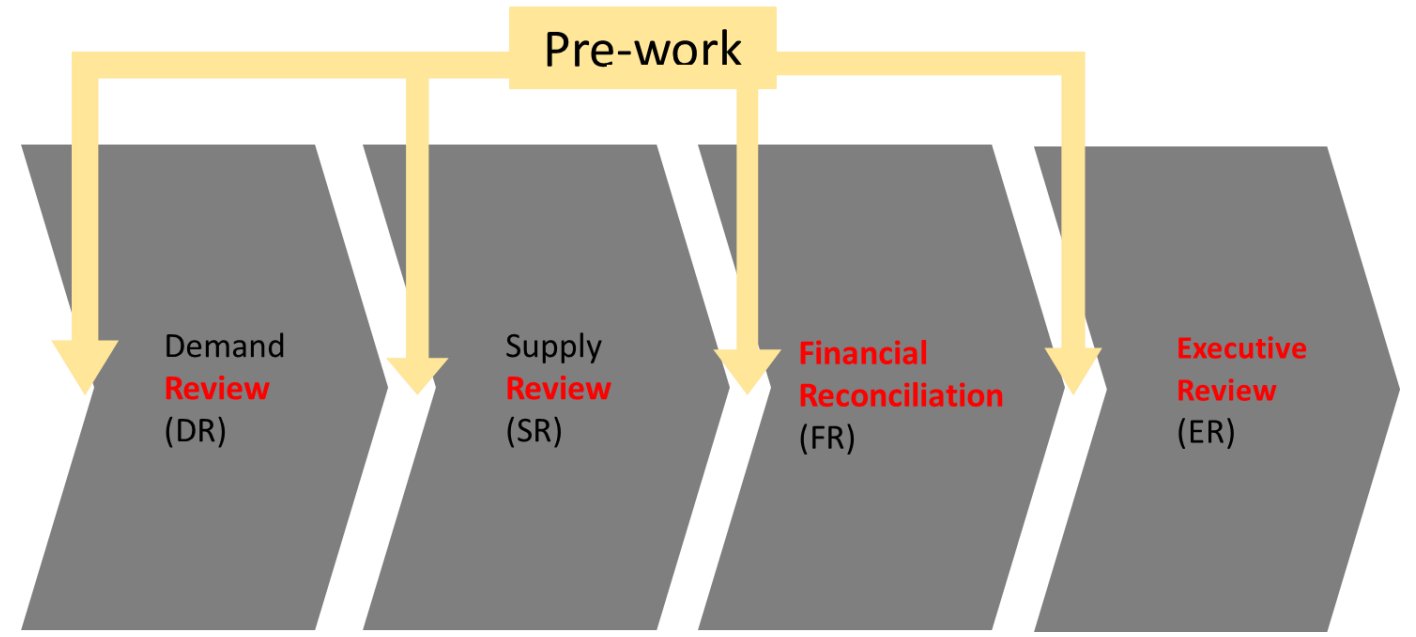

Figura 6 - Processo Principal (nível 1). Fonte: Autor

Todos os entrevistados consideraram a estrutura proposta bastante abrangente, principalmente no que diz respeito ao nível 2, a ser descrito a seguir. Uma das principais características que a torna abrangente é a flexibilidade que os usuários têm na hora de estruturar o fluxo de trabalho desejado. Uma vez que o processo é muito dependente do contexto (Ivert, Dukovska-Popovska, Fredriksson, Dreyer e Kaipia, 2015; Kaipia et al., 2017; Kristiesen e Jonsson, 2018; Goh e Eldridge, 2019), é fundamental que uma estrutura que almeje ser de referência para o processo de S\&OP/IBP seja flexível, de forma a atender as necessidades individuais de cada empresa (Fettke et al., 2005; Becker et al., 2007; Rehse et al., 2017), isto é, permita os praticantes definirem que atividades, interação entre os participantes, inputs, métricas que se enquadram melhor no contexto da organização antes de implementar e executar o processo (Biemans e Vissers, 1989). Além disso, a estrutura de modelo de referência deve permitir que os usuários, com base na mudança constante de realidade, consigam adaptar o processo de forma rápida e simples, através de debates olhando para o futuro de forma proativa, e não apenas apontando culpados ou falando sobre dificuldades locais que não impactam diretamente o resultado do sistema (Oztemel e Tekez, 2009). Para se tirar o máximo proveito do processo, recomenda-se adotar todos os subprocessos descritos na Figura 7, que ilustra o nível 2 (e.g., DR1, DR2, DR3). Isso não quer dizer que todos os usuários devam iniciar o processo usando todas as opções, mas que a evolução do processo passa por trabalhar com cada vez mais "caixas" até que se tenha todos os subprocessos atuando.

A estrutura proposta atende aos critérios estabelecidos por Rehse et al. (2017): ilustra como o processo pode ocorrer e não é limitado a nenhum contexto específico, pois pode ser usada em cenários de: restrição de capacidade, excesso de 
capacidade, demanda abaixo do necessário para atingir as metas financeiras, situações onde o consenso não é obtido de maneira simples, quando as pessoas não estiverem suficientemente treinadas para executar plenamente o processo, quando os recursos tecnológicos disponíveis não forem os mais avançados, para diversos tipos de produtos (e.g. perecíveis, duráveis, ciclo de vida curto) e para diferentes quantidades de SKUs. Por isso, o que pode trazer benefícios significativos para determinadas empresas, pode criar desarmonia em outras.

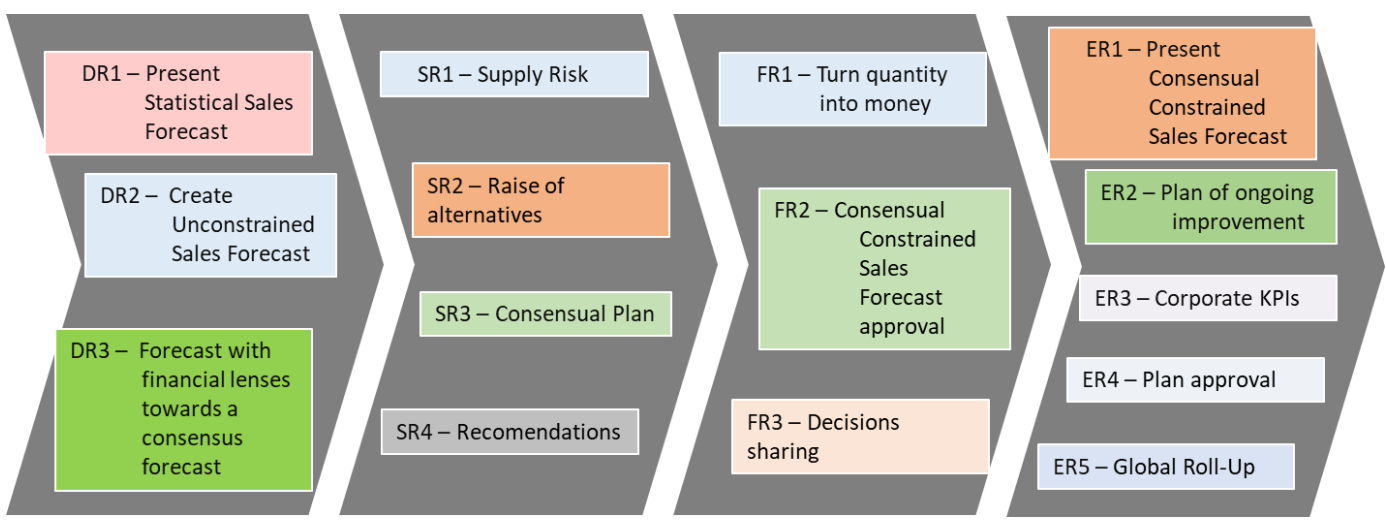

Figura 7 - Processo Principal (nível 2). Fonte: Autor

De forma a exemplificar a abrangência do modelo (Schütte, 1998; Becker, 2007), a alternativa 1, ilustrada na Figura 8, retrata uma realidade onde uma empresa nacional, que não adota do processo de Global Roll-Up (ER5), não analisa a previsão de vendas sob a perspectiva financeira logo na etapa de Demand Review (DR3) e não há restrição de capacidade para entregar o número pedido por Marketing ou Vendas. Uma vez que avaliados os riscos de abastecimento (SR1), não foi necessário avaliar alternativas para fechar gaps entre a demanda do mercado e a capacidade de entrega (SR2), ou seja, do processo SR1 vai para o SR3.

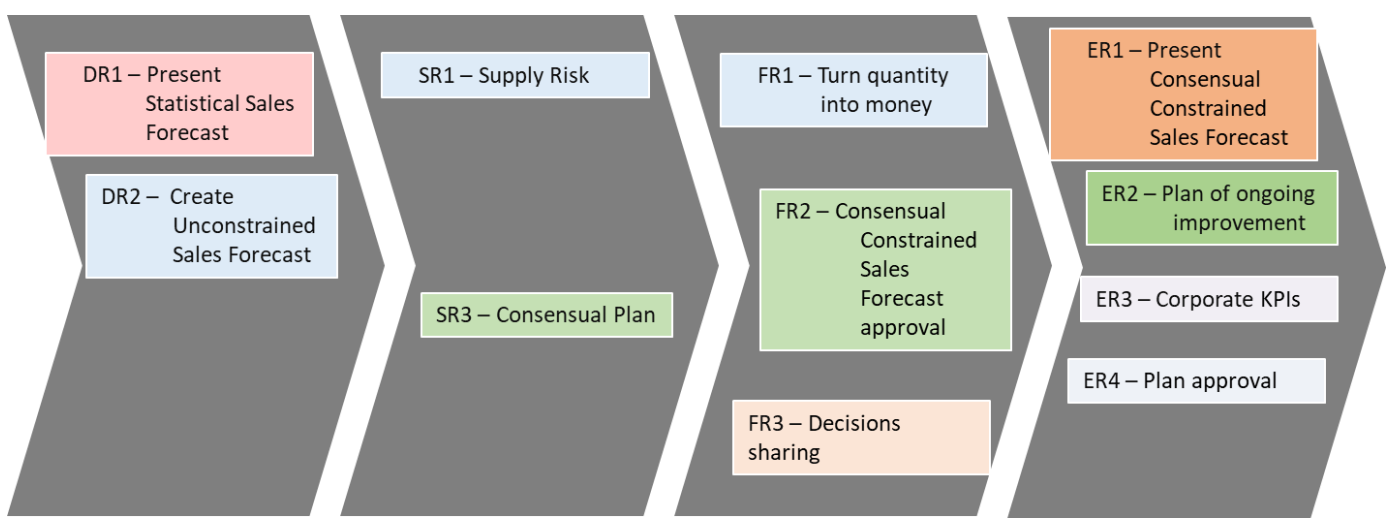

Figura 8 - Processo Principal (nível 2) - Alternativa 1. Fonte: Autor 
Já na alternativa 2, ilustrada na Figura 9, existe uma restrição de capacidade, que pode ser contornada com alternativas como fazer hora extra, adicionar um turno entre outras. Por isso, foi adicionado o processo SR2 entre o SR1 e o SR3.

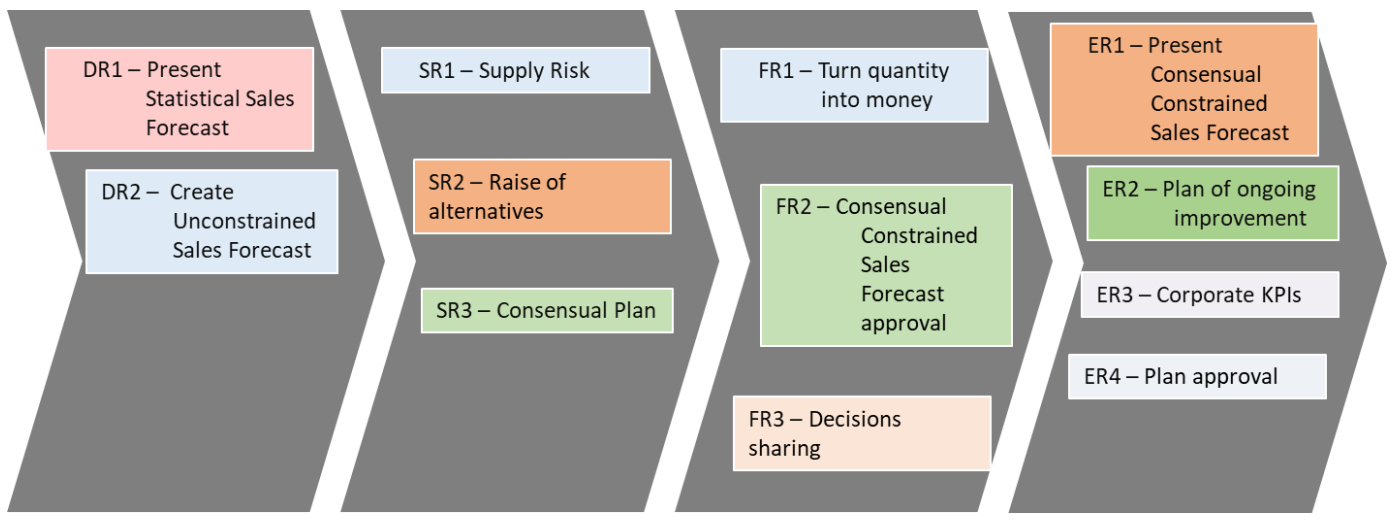

Figura 9 - Processo Principal (nível 2) - Alternativa 2. Fonte: Autor

Nas próximas seções, é apresentado um exemplo de funcionamento da estrutura baseado no contexto da empresa XYZ, isto é, setor químico no Brasil. Outras possibilidades, bem como os Processos de Suporte e Coordenação também são descritas com mais detalhes. Mensalmente, todas as reuniões da estrutura proposta iniciam com o gerente do processo (na estrutura proposta, chamado de IBP Manager, mas que pode ser alterado para $S \& O P$ Manager também) apresentando os resultados tanto do mês anterior, quanto do acumulado ao longo de um período determinado, como trimestre, semestre ou ano (year-to-date - YTD). A seguir, as reuniões iniciam com os comentários de cada participante em relação às pendências do último período e se os acordos do mês anterior foram cumpridos. Por último, as discussões para tomada de decisão iniciam.

\section{2. \\ Processo Principal}

Esta seção apresenta as etapas Demand Review, Supply Review, Financial Reconciliation e Executive Review desmembradas nos níveis 2 e 3 do Processo Principal e os pre-works.

\subsection{1.}

\section{Demand Review (DR)}

O Demand Review busca identificar o potencial do mercado, ou seja, com uma estimativa de quanto seria vendido de cada produto ou família de produtos, caso a empresa tivesse capacidade para produzir infinitamente. Porém, a lógica 
desse modelo é mais abrangente. Devido à possibilidade de avaliar o processo sob a ótica financeira (DR3), o risco de ser acordado um número de previsão irrestrita que não entregue resultados financeiros satisfatórios é reduzido.

Vale ressaltar que analisar a previsão irrestrita com a perspectiva financeira não torna obrigatória a participação de algum funcionário do setor financeiro nessa etapa. Algumas empresas possuem pessoas capacitadas, e com autonomia, para abordar os impactos financeiros, outras não. Para aquelas onde o funcionário tem liberdade para tratar as finanças, a participação de Finanças pode ser opcional. Onde não se tem a mesma realidade, recomenda-se a participação de um membro do financeiro capaz de associar as decisões com a influência no resultado financeiro da empresa, de forma melhorar a visibilidade dos planos.

O fluxo DR1-DR2 é utilizado pela empresa XYZ e por todas as empresas descritas pelos entrevistados. Nem todas as empresas adotam o DR3, porém todos disseram que esse incremento nas discussões tem potencial de tornar as decisões mais precisas, coerentes e rápidas. O que varia de forma considerável entre as empresas é o fluxo de atividades nos pre-works, que também podem incluir análises financeiras. Essas atividades são apresentadas com mais detalhes na seção 4.2.5. A Figura 10 apresenta a Demand Review no nível 2.

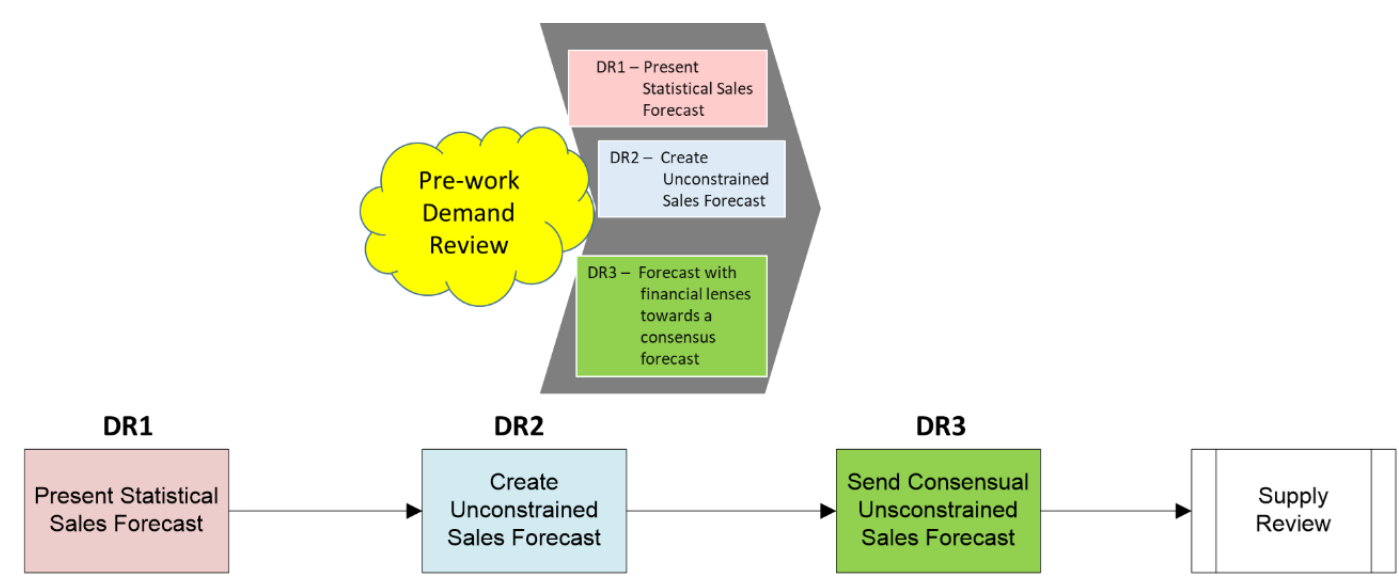

Figura 10 - Processo Principal - Demand Review (nível 2). Fonte: Autor

Em linhas gerais, o fluxo completo inicia com a apresentação da previsão de vendas gerada de forma meramente estatística, durante o Pre-work Demand Review, com base na análise fria dos dados históricos de venda (DR1). A seguir, cada um dos participantes apresenta suas análises e projeções, também feitas durante o Pre-work Demand Review. Esses dados serão usados de forma a tornar a previsão 
de vendas estatística mais próxima da realidade, pois levará em conta discussões acerca do mercado e riscos envolvendo a concretização daquela demanda projetada (DR2). Após a definição do potencial de vendas para o mercado, chamada de Previsão de Vendas Irrestrita, existe a possibilidade de a empresa avaliar se aquela quantidade em unidades também gera resultados financeiros satisfatórios (DR3). Esse exercício inicia com a conversão da Previsão de Vendas Irrestrita em valores monetários. Esses valores monetários são definidos pela empresa. Podem ser receita, margem, lucro entre outros. Se os valores monetários calculados estiverem de acordo com o orçamento acordado no ano anterior, a Previsão Irrestrita de Vendas passa a ser chamada de Previsão de Vendas Irrestrita Consensual e é enviada para os responsáveis por dizer se há capacidade produtiva para entregar aquelas unidades. A dinâmica para definir se é possível entregar a Previsão Irrestrita de Vendas é descrita na subseção 4.2.2. Caso a Previsão de Vendas Irrestrita não atenda a meta financeira, é preciso repensar a operação, os preços e as ações promocionais atuais, de forma a entregar o valor esperado pelos stakeholders. Contudo, se não houver tempo suficiente para propor um novo número de vendas para o ciclo atual, a solução precisa aparecer no ciclo seguinte e o resultado possível nas condições atuais também passam a se chamar Previsão Irrestrita de Vendas Consensual. A Figura 11 ilustra o processo com mais detalhes, já com o nível 3. A participação das pessoas é abordada na seção 4.3 .

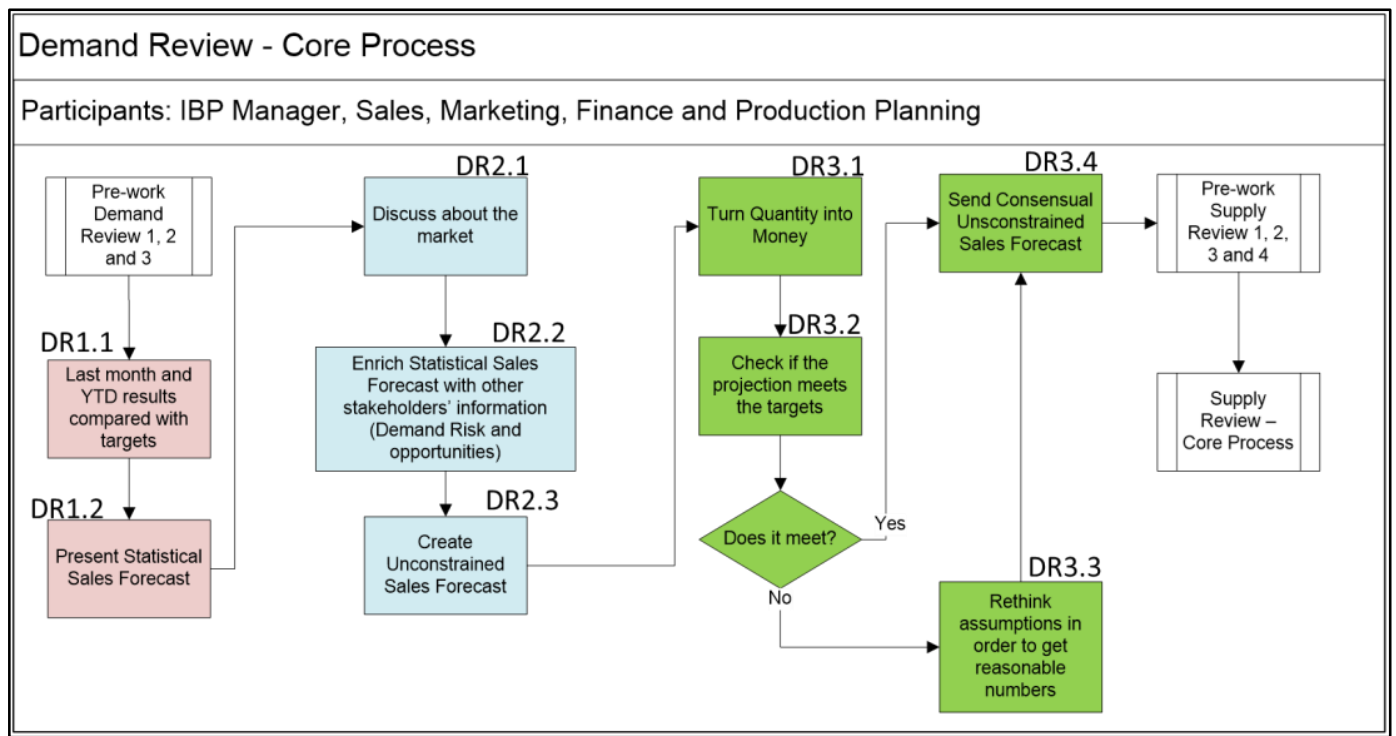

Figura 11 - Processo Principal - Demand Review (nível 3). Fonte: Autor 


\subsection{2.}

\section{Supply Review (SR)}

O objetivo da Supply Review é sair dessa reunião, caso não seja possível entregar a demanda (Previsão de Vendas Irrestrita Consensual) ou o resultado financeiro, com questionamentos como: o que fazer para fechar a diferença entre a demanda e a capacidade produtiva? Qual seria o custo de cada alternativa? A quantidade entregue a mais traz uma receita maior do que o gasto com a solução? Todos os produtos estratégicos estão sendo entregues? E também visa sair com planos de ação para riscos mapeados como: se houver queda de vendas (independentemente do motivo, como entrada de concorrente ou produto novo que vai tomar esse mercado), pode existir K\% de ociosidade no setor Z, ou no centro de distribuição por W meses. Como mitigar os impactos/riscos? Qual a melhor alternativa, caso esse risco aconteça?

Todos os participantes da Supply Review recebem a Previsão de Vendas Irrestrita Consensual logo após a reunião de Demand Review. Diversas tarefas são feitas no Pre-work Supply Review. O resultado dessas tarefas é responder se é possível entregar o número pedido na primeira reunião ou não, e quais os riscos envolvidos que podem impedir ou atrapalhar o abastecimento. Caso não seja possível atender, são montados cenários alternativos a serem avaliados antes de iniciar a reunião. Ainda antes de a reunião acontecer, cada área, em parceria com outras ou não, vai dizer se consegue entregar a demanda desejada e as alternativas. As áreas que não conseguirem corresponder vão sinalizar antes da reunião e preparar toda a explicação do porquê não ser possível entregar e o que precisa acontecer para aumentar a capacidade de processamento. A Figura 12 apresenta a Supply Review no nível 2 


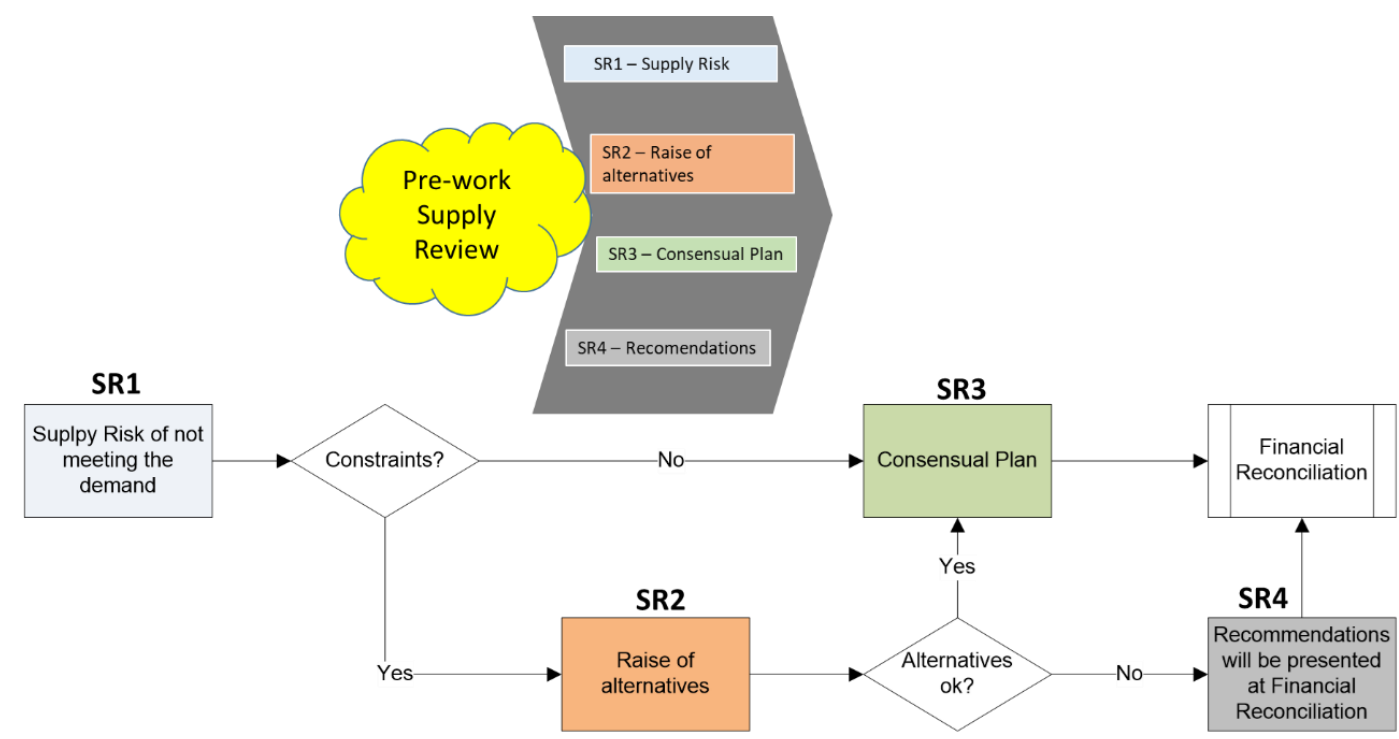

Figura 12 - Processo Principal - Supply Review (nível 2). Fonte: Autor

A Supply Review inicia com a apresentação da demanda pedida e o quanto foi dito ser possível ser entregue, contando as capacidades produtivas e os riscos associados à operação (SR1). Se a empresa tiver excesso de capacidade, não haverá restrição para a entrega da Previsão de Vendas Irrestrita Consensual, e está será chamada de Plano Consensual (SR3) antes de ser levado para a Financial Reconciliation. Se a empresa enfrentar um cenário de restrição de capacidade, ou seja, não é possível entregar tudo que foi pedido na primeira reunião, alternativas devem ser analisadas para verificar a viabilidade de aumentar a capacidade no curto prazo e atender à demanda (SR2). Dependendo de quão restritiva seja a capacidade, pode acontecer de mesmo trabalhando 24 horas por dia, inclusive aos fins de semana, não seja possível atender ao mercado plenamente. Uma vez que o gap entre demanda e capacidade não pode ser fechado, as alternativas precisam ser analisadas de forma a torna-lo o menor possível e entregar um resultado satisfatório para os stakeholders. Para isso, são feitas recomendações de ações para mitigar o desabastecimento dos produtos (SR4). Na Supply Review, o foco está em trabalhar o atendimento em unidades, por isso não são analisados os impactos que as alternativas possam gerar no orçamento e no plano financeiro. Essa atividade é feita no Prework Financial Reconciliation. Outra possibilidade é que em vez de a empresa buscar alternativas para entregar a Previsão de Vendas Irrestrita Consensual, procure atender outro mix que tenha sido proposto durante a reunião e apresenta um resultado economicamente satisfatório (em todas as reuniões, há o responsável por aprovar os planos), a chamada Proposta. Nesse caso, também existe uma tarefa no Pre- 
work Financial Reconciliation, que é o comunicado do mix definido. Esse mix ainda pode sofrer alterações nas próximas etapas. A Figura 13 ilustra o nível 3 da Supply Review, que contém mais detalhes sobre as possibilidades do processo.

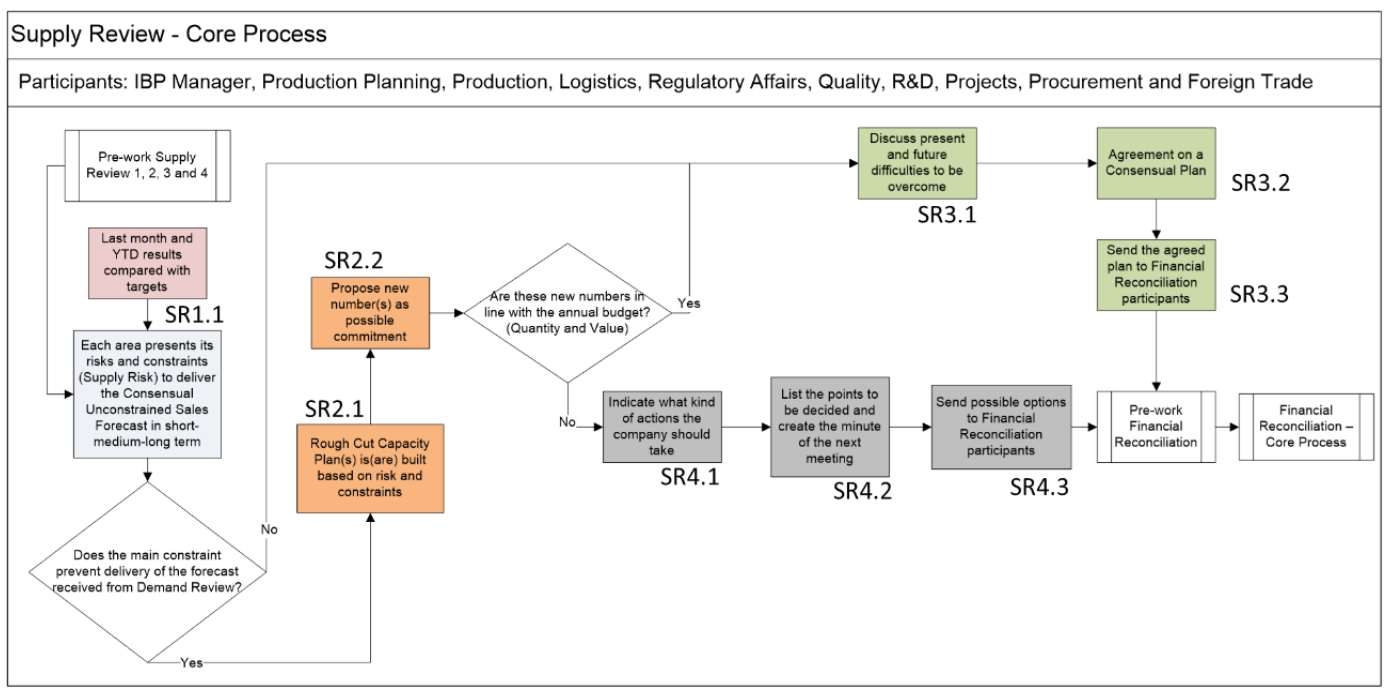

Figura 13 - Processo Principal - Supply Review (nível 3). Fonte: Autor

\subsection{3.}

\section{Financial Reconciliation (FR)}

Nessa etapa de Financial Reconciliation ocorre a conciliação dos cenários de demanda e abastecimento sob a ótica de operações e finanças. Possíveis conflitos, trade-offs e alternativas são discutidos e viram recomendações para a Executive Review.

O Pre-work Financial Reconciliation dessa etapa é dependente do ocorrido nas duas primeiras. Por exemplo, se a empresa possuir capacidade suficiente para entregar toda a demanda pedida pelo mercado, o Pre-work Financial Reconciliation seria opcional. A análise financeira pode ser feita tanto diretamente na Financial Reconciliation, quanto durante o Pre-work Financial Reconciliation, visando encurtar a reunião ou debater tópicos mais estratégicos. Outra ocasião na qual o Prework Financial Reconciliation pode não ocorrer é quando as alternativas levantadas na Supply Review são suficientes para entregar o número demandado pelo mercado. Porém, essa segunda opção pode não apresentar alternativas muito claras, o que pode exigir uma simulação mais detalhada antes de confirmar a decisão. O Prework Financial Reconciliation ocorreria para que fossem feitas as simulações de entrega, que serão o input para a Financial Reconciliation analisar financeiramente 
todos os cenários antes da recomendação para a Executive Review. O Pre-work Financial Reconciliation se faz mandatório nos contextos onde uma empresa lida com restrição de capacidade. Nesse último cenário, mesmo a empresa levantando diversas alternativas, não é possível atender à demanda trazida. É um caso típico de quando, por algum motivo, a demanda por algum produto aumenta de forma exponencial, contrariando todas as expectativas. Quando isso acontece, o foco do Prework Financial Reconciliation é elaborar propostas de planos de abastecimento. Essas propostas são avaliadas na Financial Reconciliation de forma atender ao máximo possível, de forma sustentável. A Figura 14 apresenta a Financial Reconciliation no nível 2.

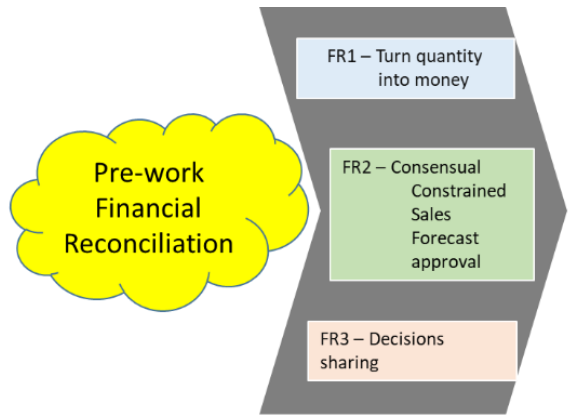

FR1
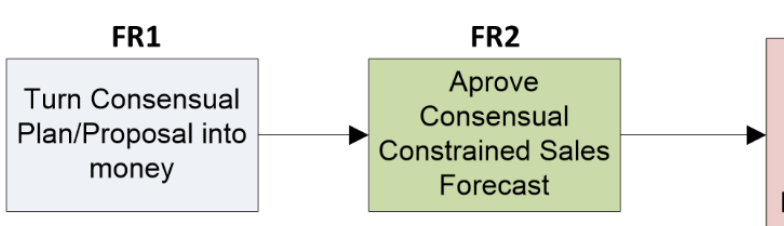

FR3

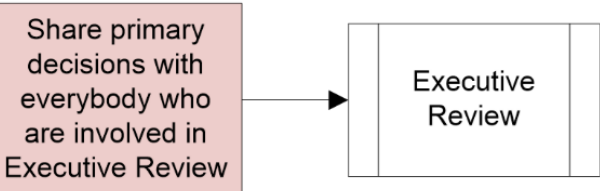

Figura 14 - Processo Principal - Financial Reconciliation (nível 2). Fonte: Autor

Independentemente do tipo de trabalho prévio, toda reunião de Financial Reconciliation inicia com a análise financeira dos números enviados (FR1). Baseado no resultado projetado, esse plano pode ser validado pelo Financeiro ou não. Se as metas financeiras não forem atendidas, debates acerca da operação e/ou das negociações com clientes precisam acontecer de forma a alinhar as expectativas entre o orçamento e o realizado. Assim que a projeção do plano satisfizer o orçamento (ou chegue o mais próximo possível dele, para o caso de pico de demanda), o Plano Consensual/Proposta é atestado como viável pelo Financeiro e passa a ser chamado de Previsão de Vendas Restrita Consensual (FR2). Dependendo do nível de autonomia dos participantes, pode acontecer de algumas decisões só poderem ser tomadas na próxima etapa, onde diretores e o presidente da companhia estão presentes e podem dar a última palavra. Nesse caso, após o aval do Financeiro, é 
elaborada a pauta da última etapa e, por último, as decisões são compartilhadas com os participantes da Executive Review, para que todos possam analisar com antecedência e propor melhorias (FR3). A Figura 15 ilustra com mais detalhes as possibilidades do processo, incorporando o nível 3.

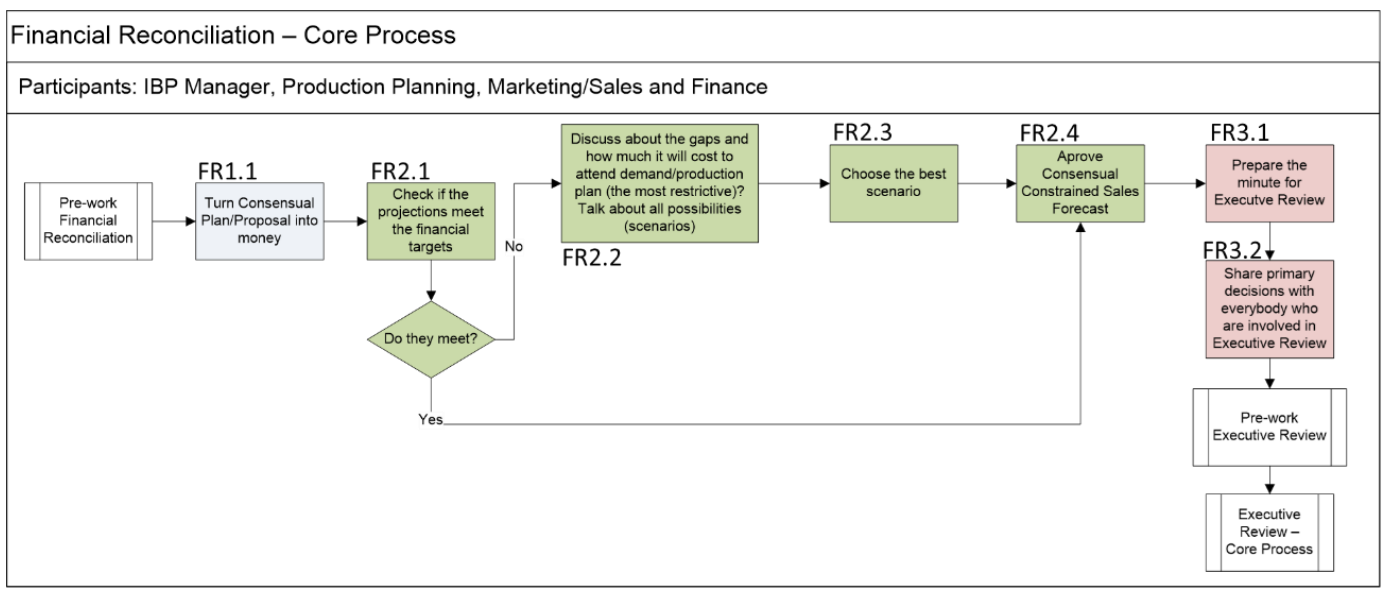

Figura 15 - Processo Principal - Financial Reconciliation (nível 3). Fonte: Autor

\subsection{4.}

\section{Executive Review (ER)}

O objetivo da Executive Review é apresentar e validar os cenários levantados e as recomendações do time, construídos nas etapas anteriores. Caso existam conflitos nas recomendações, o General Manager decidirá o plano. Esse plano se tornará o consenso para todos os departamentos. É nesse momento em que decisões como contratação de mão de obra, aumento ou terceirização de capacidade, gastos extraordinários, novas campanhas, mudanças nos volumes de produção e política de estoque são aprovados definitivamente.

O Pre-work Executive Review é feito apenas pelo IBP Manager, que prepara os assuntos a serem tratados durante a reunião. Isso pode incluir os resultados de vendas comparado ao orçamento, nível de serviço de atendimento aos clientes, produtos novos, decisões em aberto acerca de produtos específicos ou famílias, projeções de resultados com base nas ações a serem tomadas, pontos de melhoria acerca do ciclo de reuniões, entre outros. Assim que pauta é preparada, o gerente deixa pré-estabelecido qual membro do time é responsável por esclarecer cada ponto do plano, de forma a reforçar a importância do plano em questão. A Figura 16 apresenta a Executive Review no nível 2. 


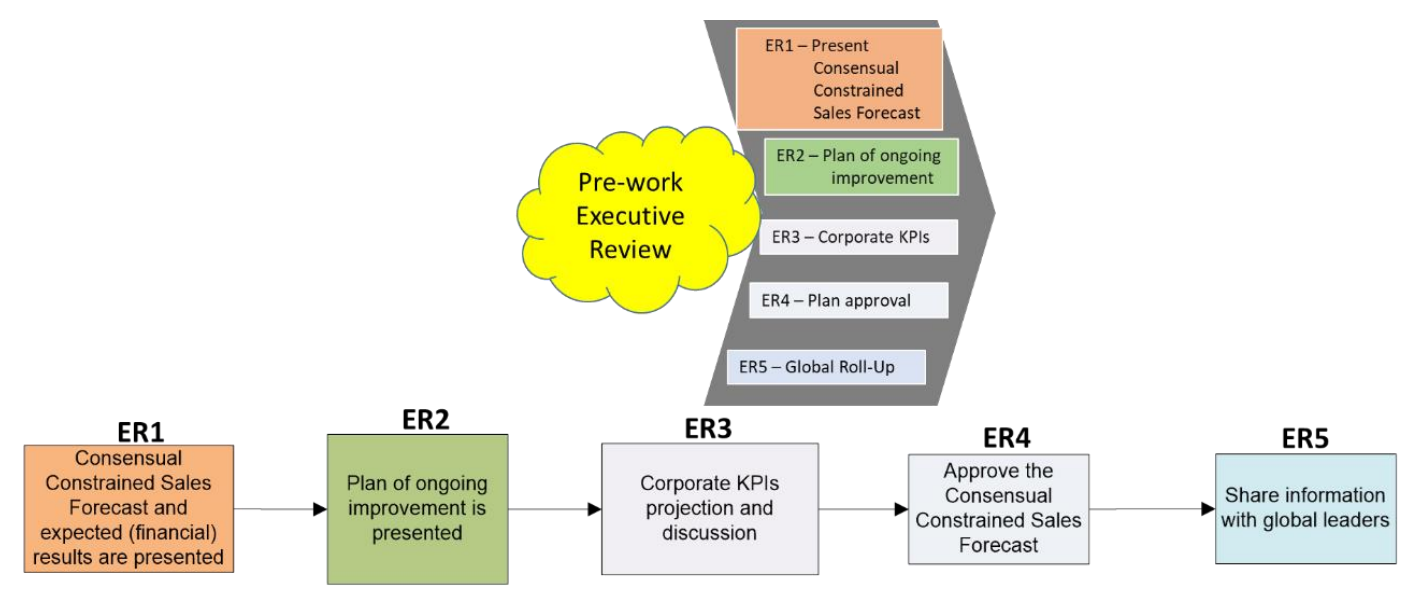

Figura 16 - Processo Principal - Executive Review (nível 2). Fonte: Autor

Expostos os resultados nos últimos períodos, a Previsão de Vendas Restrita Consensual e os resultados esperados para o horizonte de planejamento da empresa, inclusive em termos financeiros, são apresentados (ER1). A seguir, são apresentadas e debatidas iniciativas que visam aumentar a performance do time e da companhia (ER2). Tais iniciativas podem variar significativamente, de acordo com as dificuldades enfrentadas e oportunidades identificadas, ou seja, o conteúdo apresentado nesse momento não precisa ser repetido todos os meses. Pode ser feita a revisão de alguma métrica (alterar a meta de acuracidade de previsão de $80 \%$ para $85 \%$, por exemplo), sugestões para melhorar a tomada de decisão no processo, como adotar algum sistema mais dinâmico, entre outras. Trazidas as oportunidades de melhoria, são apresentados os impactos que as iniciativas e as tendências de mercado causam nos indicadores de performance (ER3). Após esses três passos, o General Manager tem informações suficientes para avaliar se a empresa está dentro das expectativas e aprovar a Previsão de Vendas Restrita Consensual (ER4). Se o plano apresentar resultados satisfatórios à primeira vista, é necessário negociar as alterações. Essa negociação e projeções de outros cenários são avaliados durante a reunião, por isso é fundamental que todos os participantes das etapas anteriores estejam presentas nessa última etapa. Ao final das negociações e da aprovação da Previsão de Vendas Restrita Consensual como plano aprovado, pode ser que a empresa precise reportar esse plano para equipes em outros países, o chamado Global Roll-Up (ER5). O tratamento dado pelos outros países também varia de acordo com o contexto. A Figura 17 ilustra com mais detalhes as possibilidades do processo, incorporando o nível 3. 


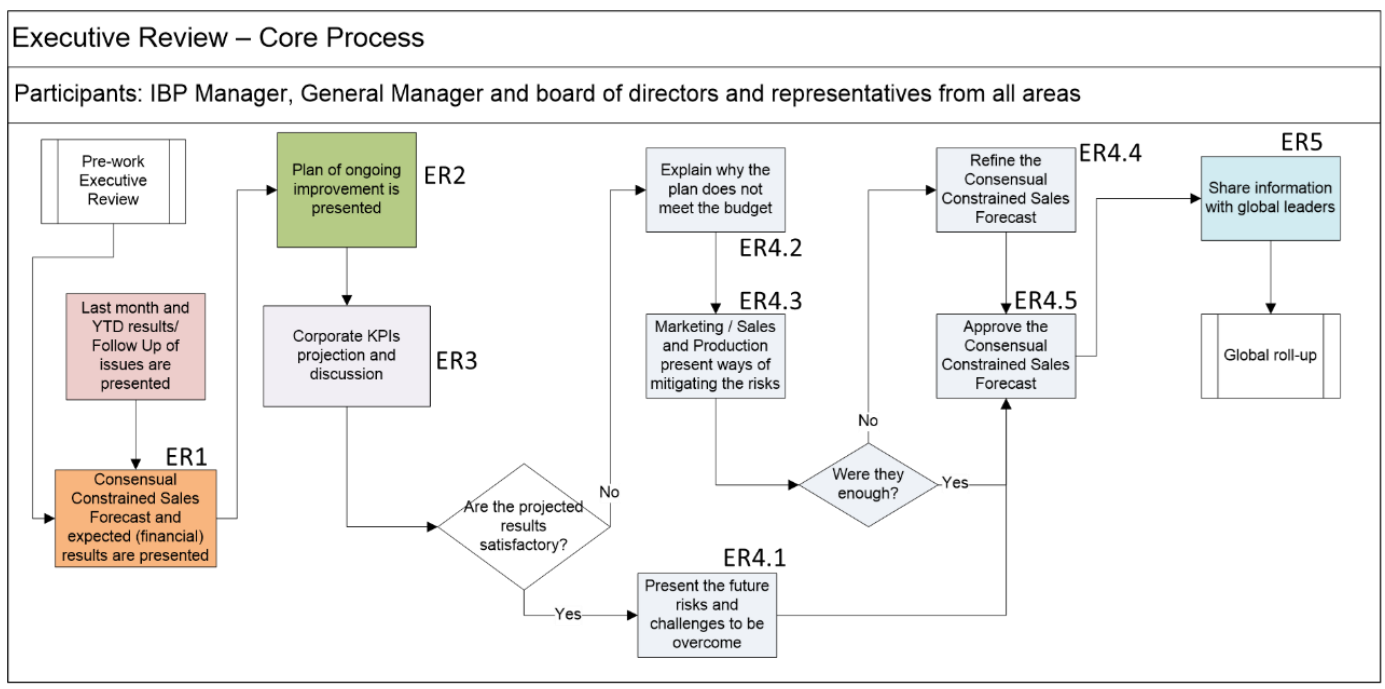

Figura 17 - Processo Principal - Executive Review (nível 3). Fonte: Autor

\subsection{5.}

\section{Pre-works}

Um dos pontos mais sensíveis do processo de S\&OP/IBP é a preparação dos participantes para cada uma das reuniões, os chamados pre-works. Dar um tratamento especial a esse processo foi considerado de fundamental importância, uma vez que as informações levantadas, principalmente no que diz respeito à desempenho e projeções, e as conversas realizadas nesse momento impactam significativamente na eficácia e eficiência da reunião. Esta subseção apresentada algumas formas de executar os pre-works, com base em evidências empíricas obtidas na pesquisa. Vale ressaltar que todos os pre-works são incorporados ao nível 3, uma vez que as informações a serem coletadas previamente podem variar consideravelmente de empresa para empresa.

\subsubsection{1.}

\section{Pre-work Demand Review}

O Pre-work Demand Review praticado por todos os entrevistados envolve o setor de Marketing e Vendas. Uma vez que as atribuições de Marketing e Vendas variavam de acordo com cada empresa, foi adotada a nomenclatura "Marketing/Vendas", indicando que as tarefas podem ser feitas em conjunto ou de forma separada. Recomenda-se que esse processo ocorra de maneira conjunta.

O processo não precisa seguir exatamente a mesma ordem mostrada na $\mathrm{Fi}$ gura 18, porém é importante que todas as tarefas sejam executadas. Assim que o 
resultado de vendas do mês anterior esteja fechado, Marketing e/ou Vendas alimentam algum modelo estatístico, que calcula, de forma puramente matemática, as vendas para os próximos períodos. Após esse cálculo, atualiza-se os indicadores de desempenho estabelecidos pela companhia como os mais adequados. Esses indicadores podem ser a comparação entre as vendas em quantidades e em valor contra o plano estabelecido no ano anterior, o nível de serviço, entre outros. A seguir, são identificados os riscos, oportunidades, ameaças e tendências de mercado. Essas análises dos fatores externos são fundamentais para avaliar se a operação, do jeito que ela se encontra, tem capacidade para competir no mercado no presente e no futuro. A capacidade operacional precisa ser analisada tanto sob a perspectiva interna, quanto em relação à capacidade dos fornecedores. Essa dinâmica permite que a empresa seja proativa e avise os parceiros atuais a respeito de mudanças nas demandas, além de permitir buscar novos parceiros, caso seja necessário. Outra tarefa envolve lançamentos, onde Marketing e/ou Vendas verificam com o time responsável por lançar produtos novos, na Figura 18 ilustrado como Pesquisa de Desenvolvimento, as datas que os novos produtos devem estar disponíveis. A última tarefa é gerenciar o portfólio, ou seja, identificar os produtos que continuam no mercado e por quanto tempo, até que uma nova versão esteja disponível.

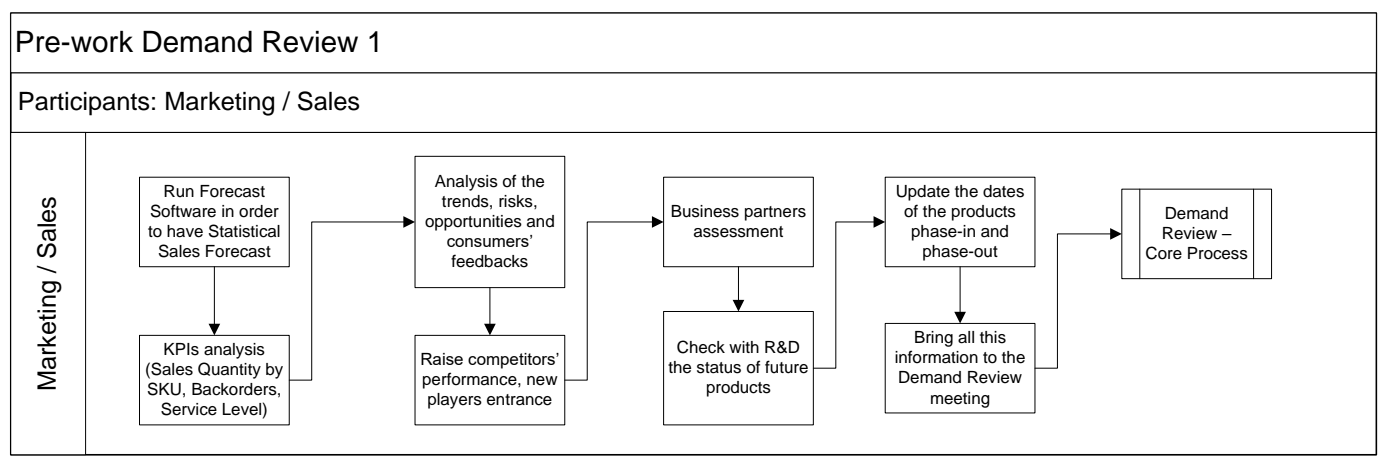

Figura 18 - Pre-work Demand Review 1 (nível 3). Fonte: Autor

O segundo pre-work recomendado envolve rotinas do setor financeiro. Esse processo foi visto em apenas dois casos. Uma vez que todas as empresas enxergaram valor na participação de Finanças desde o início do processo, recomenda-se que o preparatório para a Demand Review seja executado por alguém de Finanças. Usar a perspectiva financeira de maneira detalhada, conforme ilustrado na Figura 19, pode tornar as decisões mais precisas em termos monetários, porém essa forma de analisar não precisa ser implementada de uma vez. Antes de incluir alguém do 
Financeiro, é possível que os gestores dos produtos comecem a incluir as análises de receita, custos e margens de contribuição. O refinamento pode acontecer de maneira gradual. A Figura 19 apresenta esse caso.

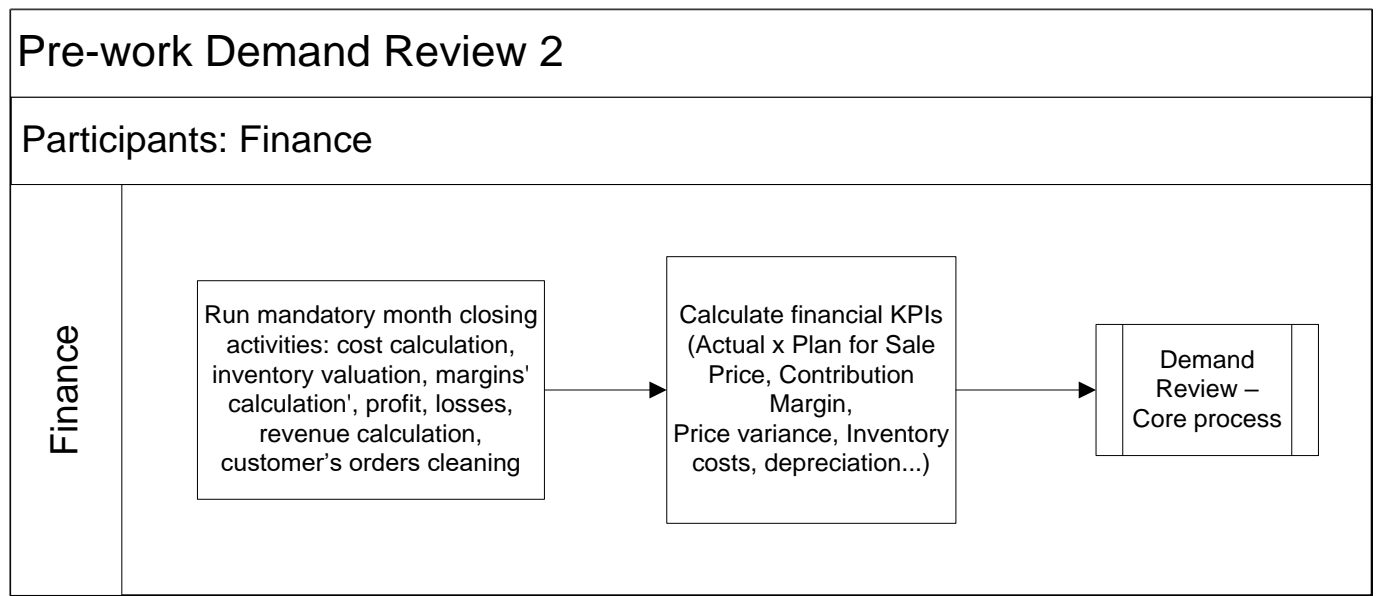

Figura 19 - Pre-work Demand Review 2 (nível 3). Fonte: Autor

O último pre-work recomendado só é aplicado na XYZ. Trata-se da inclusão da área de Planejamento de Produção na etapa de Demand Review. Todos os entrevistados não o praticam, porém acharam a ideia muito interessante, com potencial de tornar as discussões da Demand Review mais realistas. Caso o Planejamento de Produção participe da Demand Review, as principais informações que essa área precisa trazer estão relacionadas aos níveis de estoque e disponibilidade de produtos. O proveito de incluir Planejamento de Produção aumenta quando as informações trazidas são analisadas também em valores monetários. A Figura 20 sintetiza esse caso.

\begin{tabular}{|c|c|c|c|c|c|}
\hline \multicolumn{6}{|c|}{ Pre-work Demand Review 3} \\
\hline \multicolumn{6}{|c|}{ Participants: Production Planning } \\
\hline 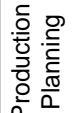 & \begin{tabular}{|c|} 
Calculate its KPIs (Inventory \\
Level, Products Return, \\
Destruction (finished products \\
and raw materials)) \\
\end{tabular} & $\begin{array}{l}\text { Check for } \\
\text { Backorder } \\
\text { (quantity and } \\
\text { value) }\end{array}$ & $\begin{array}{c}\text { Estimate when } \\
\text { products will be } \\
\text { available }\end{array}$ & $\begin{array}{c}\text { Bring these } \\
\text { information to the } \\
\text { meeting }\end{array}$ & $\begin{array}{c}\text { Demand } \\
\text { Review- } \\
\text { Core Process }\end{array}$ \\
\hline
\end{tabular}

Figura 20 - Pre-work Demand Review 3 (nível 3). Fonte: Autor

\subsubsection{2.}

\section{Pre-work Supply Review}

Assim que a Demand Review termina, todos os participantes da Supply Review recebem a Previsão de Vendas Irrestrita Consensual. O objetivo de todas as 
áreas do Pre-work Supply Review é fazer uma análise de capacidade e dizer, na reunião, o que é possível ser entregue, o que não é possível e o porquê.

O primeiro pre-work envolve as áreas operacionais: Planejamento de Produção, Produção e Logística. É o momento em que se analisa as capacidades de produção, movimentação, armazenagem e expedição. Vale ressaltar que na Figura 21 foi incluída a área de Pesquisa e Desenvolvimento. Essa área pode não ser mandatória em todos os contextos. No caso da XYZ, é fundamental que Pesquisa e Desenvolvimento, uma área altamente técnica, participe das discussões junto às áreas operacionais, pois ela, além de dizer o momento que determinado produto deve ser disponibilizado, também é quem explica os impactos que os novos produtos causam nas máquinas. Em outras palavras, Pesquisa e Desenvolvimento, no contexto químico, por exemplo, é fundamental para auxiliar na manutenção da capacidade produtiva.

O processo inicia com a comparação entre o plano acordado no mês anterior e a Previsão de Vendas Irrestrita Consensual vinda da Demand Review. Em mercados estáveis, é comum que não haja mudanças drásticas entre um mês e outro, entretanto, se tais mudanças ocorrerem, é preciso verificar o impacto delas na capacidade de resposta. Se não for possível entregar todos os produtos sinalizados na $D e$ mand Review, é preciso identificar os produtos prioritários e não permitir que esses sejam desabastecidos. Assim que os produtos prioritários são identificados, cria-se um novo mix a ser proposto e analisado na Supply Review. A Figura 21 sintetiza este pre-work.

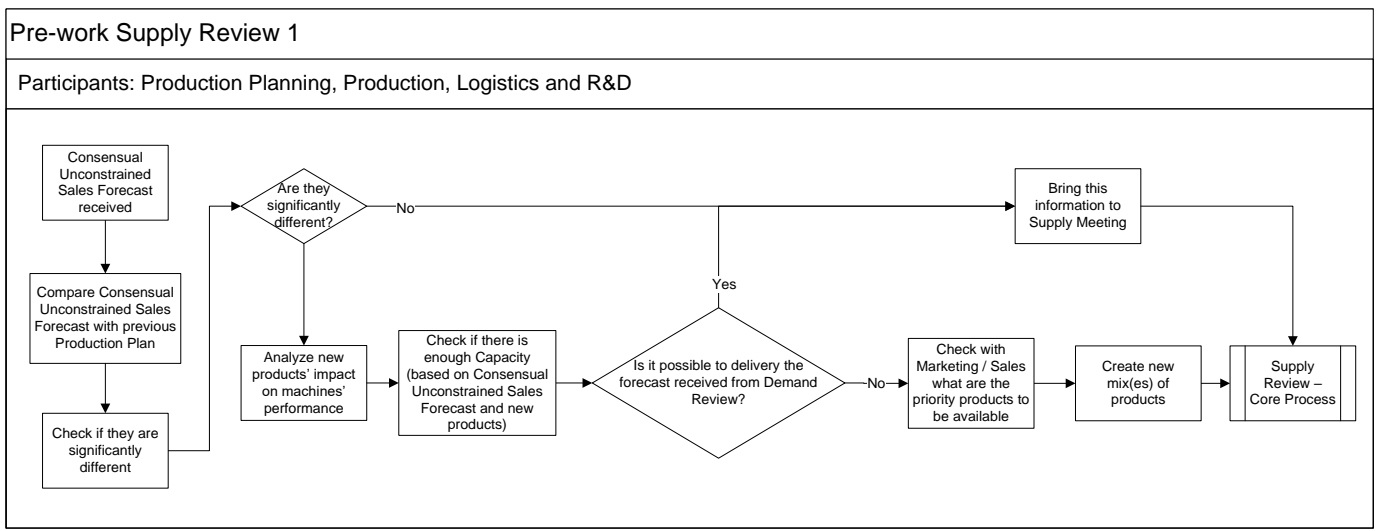

Figura 21 - Pre-work Supply Review 1 (nível 3). Fonte: Autor 
A segunda atividade prévia também é muito importante para a indústria química. Envolve duas áreas muito técnicas: Qualidade e Assuntos Regulatórios. Assuntos Regulatórios é essencial em setores que precisam lidar com agências reguladoras.

Assim que a Previsão de Vendas Irrestrita Consensual é recebida, o time de Assuntos Regulatórios leva informações que dizem respeito aos produtos em linha e aos produtos novos em termos de licenças, certificação de processos, entre outros. Qualidade analisa se os produtos, matérias-primas e processos estão sob controle. A participação de Qualidade pode trazer benefícios inclusive para mercados que não tenham o mesmo nível de regulação que o de produtos químicos. A Figura 22 ilustra esse segundo pre-work.

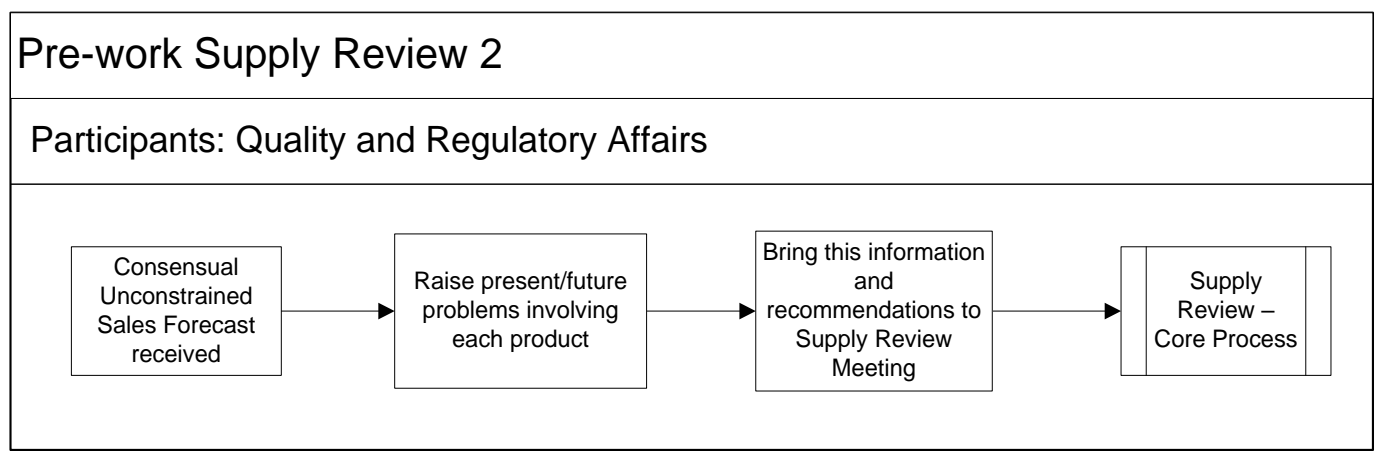

Figura 22 - Pre-work Supply Review 2 (nível 3). Fonte: Autor

O terceiro pre-work envolve apenas o setor de Projetos. Ele pode ser alocado para o Pre-work Supply Review 1 e exercer um papel parecido com Pesquisa e Desenvolvimento, porém recomenda-se um tratamento diferente para esse setor. Projetos é responsável por trazer informações acerca das iniciativas que visam aumentar a capacidade produtiva ou melhorar o atendimento aos clientes. Independentemente de a empresa ter restrição ou excesso de capacidade, sempre é possível melhorar o nível de atendimento aos clientes. Por isso, Projetos exerce a função de comunicar as melhorias que estão sendo preparadas pela empresa e quando é a previsão de disponibilidade. Tal informação é útil no momento de debate acerca da capacidade de atendimento de demandas no médio/longo prazo. A Figura 23 expõe o terceiro pre-work. 


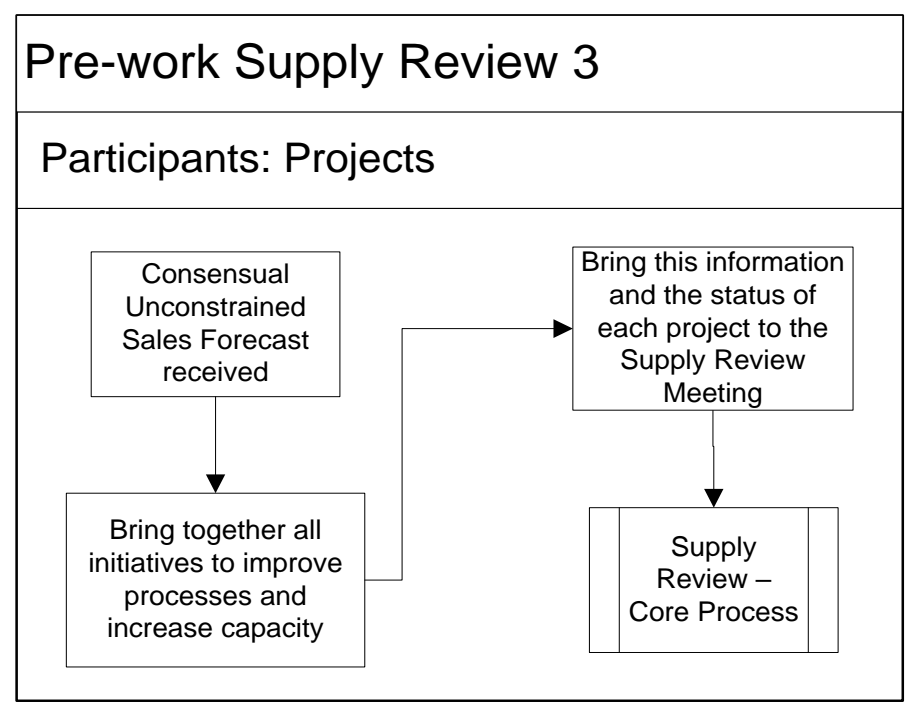

Figura 23 - Pre-work Supply Review 3 (nível 3). Fonte: Autor

O quarto pre-work envolve as áreas responsáveis pelo abastecimento de insumos. Uma vez que a empresa pode ter fornecedores de qualquer lugar do mundo, é importante levar em consideração a área de Comércio Exterior, além de Compras. O time de Compras analisa não só formas de viabilizar os insumos para a produção, mas também a performance dos fornecedores, de forma a decidir pela manutenção, troca ou adição de novos fornecedores proativamente. Comércio Exterior trabalha com questões burocráticas envolvendo a alfândega do país, logo essa área contribui com o acompanhamento do que está em processo de desembaraço e como a burocracia do setor alfandegário pode influenciar o planejamento da produção. A Figura 24 resume o pre-work. 


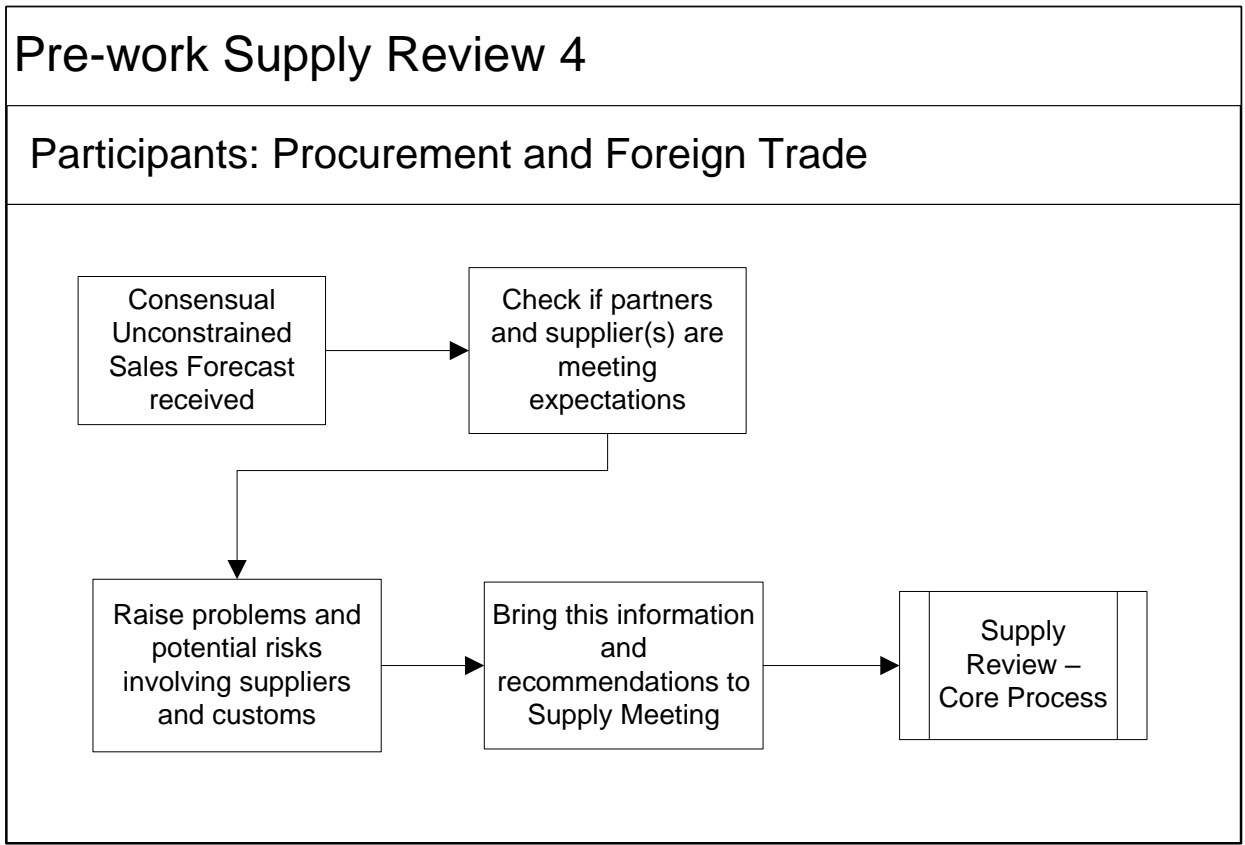

Figura 24 - Pre-work Supply Review 4 (nível 3). Fonte: Autor

\subsubsection{3.}

\section{Pre-work Financial Reconciliation}

Assim que a Supply Review termina, existe a possibilidade de se ter chegado a um Plano Consensual ou não. Primeiramente, é preciso entender se a empresa enfrenta excesso ou restrição de capacidade. A segunda análise é se o orçamento financeiro está sendo entregue ou não. Dependendo do cenário em que a empresa se encontre, o foco e a dinâmica do Pre-work Financial Reconciliation podem variar consideravelmente.

Em cenário de excesso de capacidade, o foco está em aumentar a demanda, logo Marketing e/ou Vendas são os protagonistas. Eles que dizem a estratégia adotada para aumentar a demanda, por exemplo, aumentar as promoções, mudar a política de preços, entre outros. Além disso, projetam os custos de cada medida traga uma receita maior do que as despesas, aumentando o lucro da empresa. Essa lógica é adotada independentemente de o orçamento financeiro estar sendo cumprido ou não.

Já em cenário de restrição de capacidade, o foco está em aumentar a quantidade a ser abastecida, logo Planejamento de Produção trabalha para elaborar cenários que atendam aos volumes ou, pelo menos, amenize os efeitos de um pico de demanda, com propostas a serem avaliadas e aprovadas pelo Financeiro. Outro 
ponto de atenção é o atingimento das metas financeiras. Caso a capacidade produtiva não seja suficiente para entregar todo o volume pedido, a empresa precisa priorizar os produtos a serem disponibilizados. A escolha pode seguir critérios como maior margem, o quão estratégico determinado produto é para garantir penetração no mercado, entre outros. Independentemente de o resultado financeiro estar em linha com o orçamento, não é saudável para a empresa, no médio e longo prazo, ficar escolhendo produtos e não atender às demandas do mercado, por isso as áreas operacionais precisam pensar em formas melhorar o atendimento aos pedidos. A Figura 25 ilustra tal pre-work.

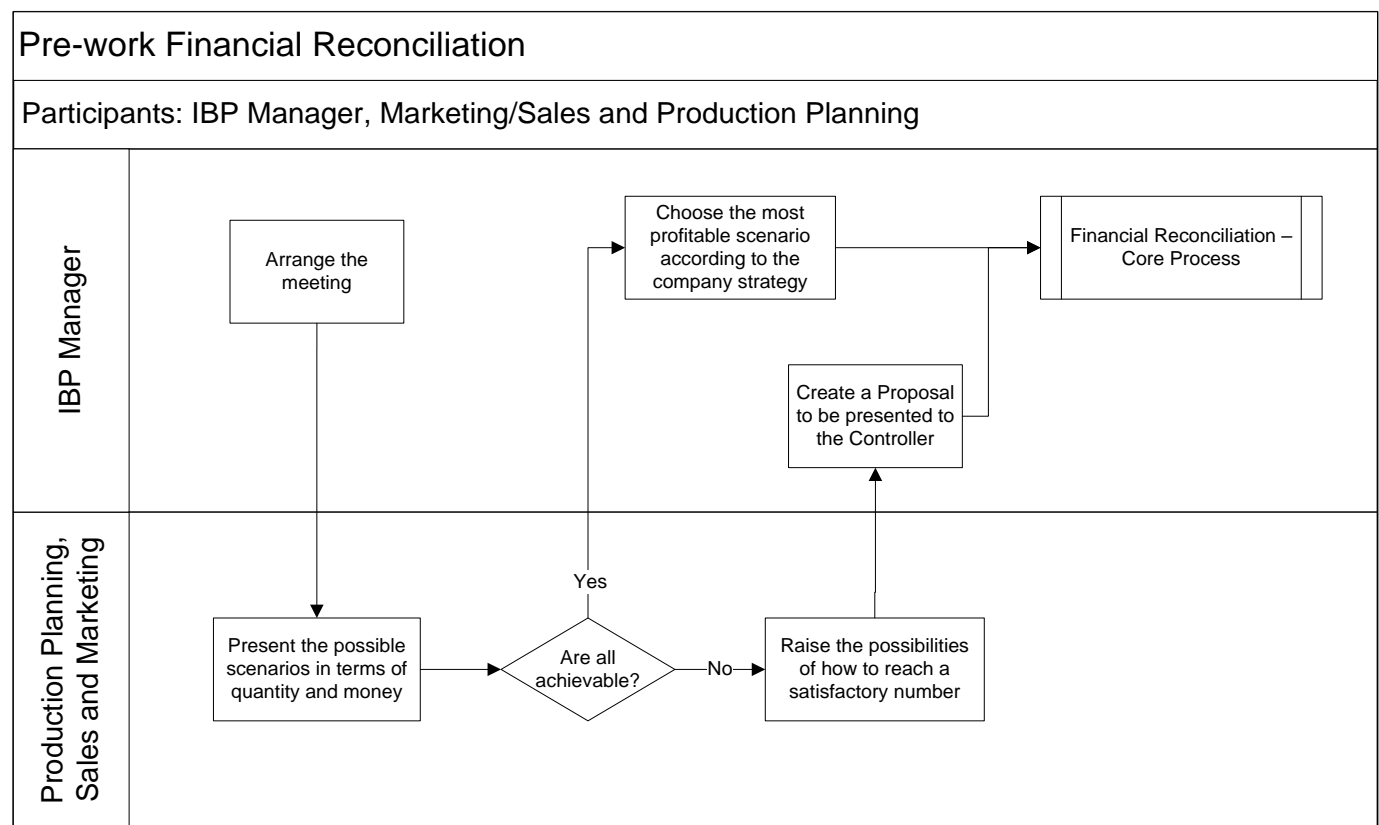

Figura 25 - Pre-work Financial Reconciliation (nível 3). Fonte: Autor

\subsubsection{4.}

\section{Pre-work Executive Review}

Após o Financeiro auxiliar na análise da revisão do plano e dizer se está de acordo com o resultado projetado, os participantes da Executive Review recebem e as decisões e aguardam a última reunião para esclarecer dúvidas e/ou fazer observações. Enquanto isso, o responsável por coordenar o processo prepara a apresentação geral e delega os responsáveis por esclarecer e/ou defender os pontos levantados durante o ciclo. Os esclarecimentos podem estar relacionados ao comportamento da demanda futura (tendências de mercado apresentadas na Demand Review), à forma como a produção espera operar para abastecer o mercado, à causa de picos e/ou vales de demanda, ao que fez os custos ficarem mais altos/baixo, entre 
outros. Isso pode ser feito para cada SKU, por família, ou olhando os dados como um todo. A empresa decide a forma mais adequada ao seu contexto. A Figura 26 apresenta esse pre-work.

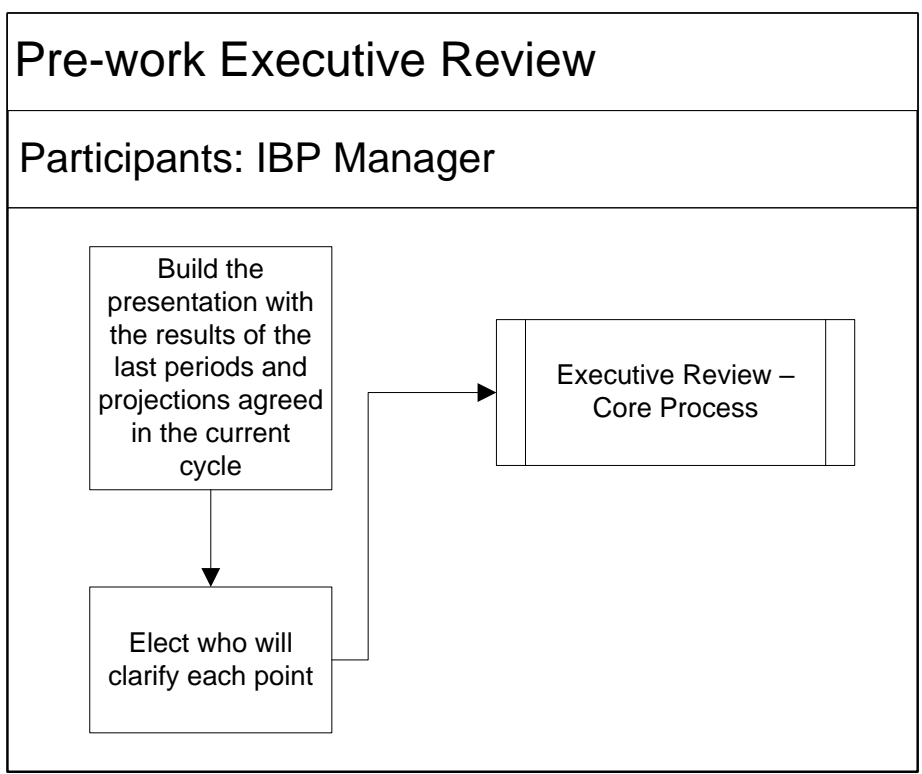

Figura 26 - Pre-work Executive Review (nível 3). Fonte: Autor

\section{3.}

Processos de Suporte - Perspectiva Pessoas

O fluxo do processo de S\&OP/IBP não pode ser estruturado sem levar em conta o capital humano. Por isso, cada etapa precisa ser pensada de forma que as pessoas alocadas consigam, dentro das responsabilidades de suas funções, planejar cenários viáveis. Contudo, durante as entrevistas, ficou claro que não há um padrão em relação às atribuições de cada área, ou seja, é possível que Marketing, por exemplo, exerça papeis diferentes em cada empresa, em algumas vezes se sobrepondo com Vendas. Por essa razão, as sugestões de como cada área pode trabalhar no processo podem ser adaptadas para o contexto dos usuários.

Nessa seção, são apresentados possíveis atores, suas atribuições e como pode ser a interação entre eles no processo de $S \& O P / I B P$. Vale ressaltar que a proposta tem como base o setor químico, da XYZ, porém pode servir como inspiração para os praticantes de outros setores. Uma vez que os contextos são diferentes, não necessariamente a configuração que funciona bem em uma empresa, funciona em todas. A dinâmica de funcionamento do processo é a mesma descrita na seção 4.2.

Vale ressaltar o papel do IBP Manager, que é o que vai manter sempre a coerência entre os planos de Demanda e Supply. Como ele participa de todas as 
etapas, e sabe os produtos rentáveis e os estratégicos, ele vai sempre buscar a conciliação durante as reuniões, de forma a apresentar um plano sustentável, tanto em termos financeiros, quanto de abastecimento de mercado, para os diretores no final.

\subsection{1.}

Processos de Suporte - Perspectiva Pessoas - Demand Review

O Processo de Suporte na perspectiva de pessoas em Demand Review contempla o Gerente de IBP, Vendas, Marketing, Finanças e Planejamento da Produção, conforme descrito na Figura 27.

O Gerente do IBP trabalha para coordenar as informações das áreas, a fim de promover a discussão e análise colaborativa do mercado. Inicia todas as reuniões do ciclo com apresentação de resultados e análise de indicadores de performance, tanto dos específicos da reunião em questão, quanto dos indicadores corporativos, que medem a empresa como um todo. No caso da Demand Review, após a apresentação, realiza a função de consolidar dados para transmitir todas as necessidades, riscos, oportunidades e tendências retiradas do mercado para gerentes e áreas operacionais. É também responsável por fazer questionamentos e desafios, com base nas análises feitas, e decidir o melhor mix de entrega. Esse melhor mix não é necessariamente aquele que maximiza o lucro, mas que maximize o nível de serviço. Os desafios podem envolver aumentar a meta de vendas, caso o Comercial esteja vendendo acima da expectativa ou fazer com que as promoções dos produtos sejam mais efetivas, caso tenha havido um resultado ruim, mesmo com um investimento grande em promover os produtos. A discussão acerca desses ajustes é respaldada pelo Planejamento de Produção, cuja participação é recomendada, pois essa área possui informações acerca da operação que podem auxiliar no embasamento de determinada promoção ou desistência de algum plano desalinhado com a realidade. Ao mesmo tempo, Planejamento de Produção também pode se beneficiar de participar já na primeira etapa, pois é possível saber com antecedência as quantidades que são necessárias no estoque e os tempos de resposta necessários para atender bem aos clientes.

A área de Vendas é a dona da previsão. Ela está em contato com os consumidores, visando atingir metas quantitativas, como nível de serviço, e financeiras, como lucratividade. No exemplo da Figura 27, essa área cria a Previsão de Vendas 
Irrestrita com base na Previsão Estatística de Vendas, quantidade histórica de vendas por SKU, acuracidade das previsões de vendas, análise financeira, dados do Planejamento de Produção e no feedback de Marketing. Caso a empresa não disponha de um software para isso, pode adotar algum modelo estatístico e calcular via planilha eletrônica. $\mathrm{O}$ contato com o cliente traz a sensibilidade do mercado em relação aos preços praticados. Vendas é o responsável, também, por rever a política de preços e indicar a ordem de grandeza que a demanda tende a aumentar ou diminuir com as variações nos preços. Esse é um trabalho que pode ser feito em paralelo ao S\&OP/IBP, e em conjunto com Marketing, Finanças e Planejamento de Produção de forma a entregar um resultado financeiro melhor. A comunicação da decisão, bem como seus benefícios, é feita na Executive Review.

Marketing tem como objetivo de melhor atender os clientes, identificando seus desejos, e aumentar a base de clientes, é responsável por monitorar as ações dos concorrentes, planejar novos lançamentos, indicar as tendências e se os parceiros conseguem corresponder às expectativas ou se são necessários novos acordos. Outra atribuição importante é a revisão do portfólio. Empresas que lançam e descontinuam muitos produtos em curto intervalo de tempo precisam atualizar constantemente os departamentos acerca das prioridades. Dependendo do tipo de produto, se os produtos em questão forem importados finalizados e revendidos no mercado nacional, é recomendado que Marketing esteja respaldado por áreas mais técnicas como Pesquisa e Desenvolvimento e/ou Assuntos Regulatórios.

A área de Finanças controla as variações financeiras da operação como margem de contribuição, variação de preço de venda e custos de estoque e faz simulações dos resultados projetados para garantir que o orçamento seja respeitado. Além disso, exerce uma função consultiva para auxiliar a tomada de decisões, como o preço e o momento de lançar produtos novos junto ao setor de Marketing. Na parte final da reunião, avalia se a Previsão de Vendas Irrestrita atende aos objetivos financeiros estabelecidos, de forma a validá-la como Previsão de Vendas Irrestrita Consensual. É importante frisar que o Financeiro não tem a última palavra na aprovação da Previsão Irrestrita de Vendas Consensual. Esse atributo é do gerente do processo, que pode ser alguém do Financeiro ou não. O foco não é simplesmente entregar o mix que gere o maior lucro, mas elaborar um plano que, além de rentável, atenda aos objetivos estratégicos. O Financeiro traz mais uma perspectiva para o atingimento das metas e respaldo nas negociações dos mixes. 
O Planejamento de produção traz indicadores de desempenho como nível de estoque, devoluções, destruição de produtos finalizados e matéria-prima e a capacidade, de maneira grosseira, de produção para colaborar com a elaboração das previsões de venda. Além disso, tem um papel consultivo para que as áreas em contato com o mercado, como Vendas e Marketing, possam verificar se há capacidade de resposta a uma determinada exigência de clientes, quando produtos em atraso (backorders) devem estar disponíveis, entre outros. Conforme mencionado, o Planejamento de Produção também pode tirar proveito de participar da primeira reunião de S\&OP/IBP, pois é possível saber com antecedência as expectativas, de forma a tornar a Supply Review mais direcionada ao atendimento do mercado. Dois pontos merecem destaque. O primeiro é que a estrutura incentiva que as áreas de Marketing, Vendas e Planejamento de Produção saiam com um plano de ação para o caso de existir algum gap entre o orçamento e a realidade. O segundo ponto é que as tarefas apresentadas podem ser divididas de acordo com a vontade da empresa, por exemplo, em certas ocasiões, Vendas pode absorver algumas das funções que foram definidas para o Marketing.

A Figura 27 sintetiza a participação das áreas funcionais responsáveis pelas pessoas na Demand Review.

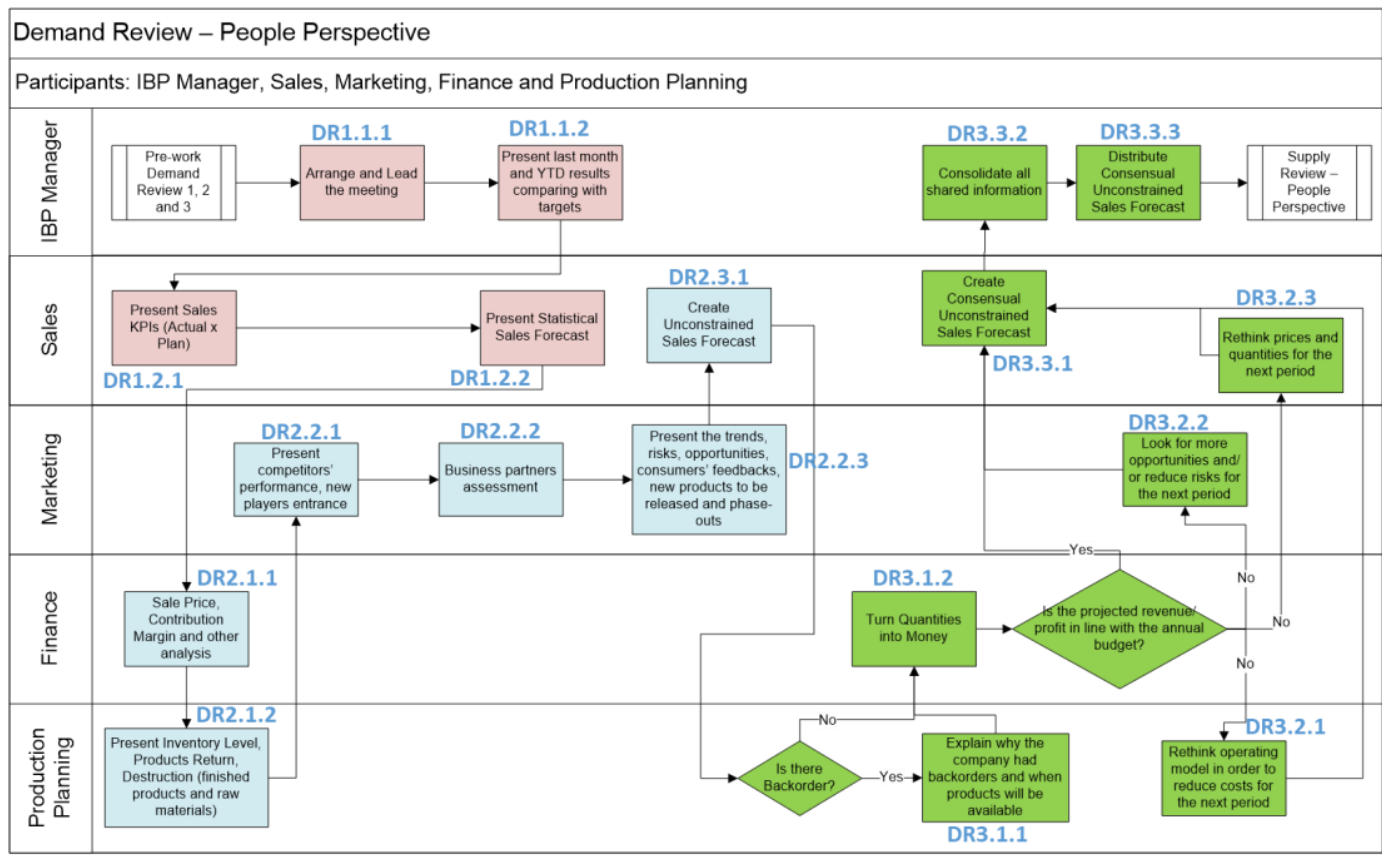

Figura 27 - Processos de Suporte - Demand Review - Perspectiva Pessoas (nível 4). Fonte: Autor 


\subsection{2.}

\section{Processo de Suporte - Perspectiva Pessoas - Supply Review}

O Processo de Suporte na perspectiva de pessoas em Supply Review contempla o Gerente de IBP, Planejamento de Produção, Produção e Logística, Qualidade, Assuntos Regulatórios, Projetos, Pesquisa e Desenvolvimento, Comércio Exterior e Compras, conforme ilustrado na Figura 28.

O Gerente do IBP ouve todas as partes interessadas do processo, seus problemas e capacidades, a fim de verificar se é possível entregar a Previsão de vendas Irrestrita Consensual. Independentemente de ser possível ou não, é o responsável pela definição do(s) cenário(s) a ser(em) analisado(s) pelo Financeiro no próximo passo. Em empresas onde as áreas operacionais possuem informações financeiras, o gerente tem autonomia, dados e capacidade para sugerir mudanças de cenários, por exemplo, fornecer mais de um produto e menos de outro para compensar quantidade ou resultado financeiro.

O Planejamento de produção é responsável por informar se é possível entregar a Previsão de Vendas Irrestrita Consensual. Se for possível, a participação de áreas como Produção e Logística pode não ser necessária. Caso contrário, Produção e Logística devem ter representantes na reunião para explicar as restrições com mais detalhes. De acordo com as restrições, define-se as alternativas para fornecer o número irrestrito, como horas extras, trabalho durante o fim de semana, subcontratação, entre outras, bem como as projeções de quantos produtos extras podem ser entregues com tais ações. Dependendo do mercado e do quão abaixo a empresa está do número, outras ações mais complexas, como terceirização da produção, podem ser tomadas, o que exige a participação de áreas como Compras, Comércio Exterior e Assuntos Regulatórios. No final do processo, caso haja necessidade de alterar o mix de entrega, roda novamente o sistema para agendar um novo mix.

A Produção e a Logística fornecem informações sobre as capacidades operacionais de produção e movimento. Eles explicam porque não é possível entregar a Previsão de Vendas Irrestrita Consensual com os recursos disponíveis.

A Qualidade é responsável por trazer informações sobre a qualidade das matérias-primas e produtos. Em setores como saúde e tecnologia, a participação pode ser obrigatória, pois, além do estoque de produtos acabados, pode haver um estoque de produtos em análise que precisa ser gerenciado. 
Os Assuntos Regulatórios, como Qualidade, podem ser obrigatórios em mercados como o farmacêutico, já que é uma atividade altamente regulada e que toda ação deve estar de acordo com as licenças. É responsável por analisar as discussões e definir se a empresa tem permissão para fazê-lo ou se precisa comunicar à agência reguladora.

A gerência de Projetos é responsável por trazer, com alguns meses de antecedência, informações sobre iniciativas que visam melhorar o desempenho da operação. Isso vale tanto para o cenário de restrição de capacidade, onde uma parte da demanda não é atendida por conta da necessidade de se entregar um mix de produtos que gere um resultado financeiro satisfatório, quanto de excesso de capacidade, onde a empresa toma as iniciativas com base nas tendências de mercado apontadas pelo Marketing, na Demand Review. Além disso, prioriza as iniciativas à luz das tendências identificadas nessa reunião. A empresa pode alocar um funcionário do Planejamento de Produção para essa função.

A área de Pesquisa e Desenvolvimento tem sua participação muito customizável. Se os produtos novos, em fase final de estudos, forem produzidos na planta em questão, é preciso saber se a empresa tem excesso ou restrição de capacidade. Em caso de excesso, Pesquisa e Desenvolvimento só entraria na Demand Review. Para um cenário de restrição de capacidade, ele pode participar da Supply Review também, mostrando como os produtos novos impactam na linha de produção, para que todos possam se preparar adequadamente.

As áreas de Comércio Exterior e Compras são responsáveis por trazer matérias-primas, produtos acabados ou equipamentos para a empresa. Compras é responsável por negociar com os fornecedores preços, prazos e qualidade e avaliar o desempenho de suas operações. Comércio Exterior é responsável pelas importações e exportações. Ambos trazem seus prazos e estimam as datas nas quais as matériasprimas devem estar disponíveis nas condições desejadas. Se a empresa enfrenta muitos problemas com fornecedores e/ou alfândega, podem propor alternativas como certificar outro fornecedor, alterar o modal de transporte, renegociar preços, entre outras.

Se os números propostos não atenderem ao orçamento, novas simulações são feitas após a reunião para apresentar um Plano Consensual e uma forma alternativa de fornecer os produtos para o Financeiro na Financial Reconciliation. 
A Figura 28 sintetiza a participação das áreas funcionais responsáveis pelas pessoas na Supply Review.

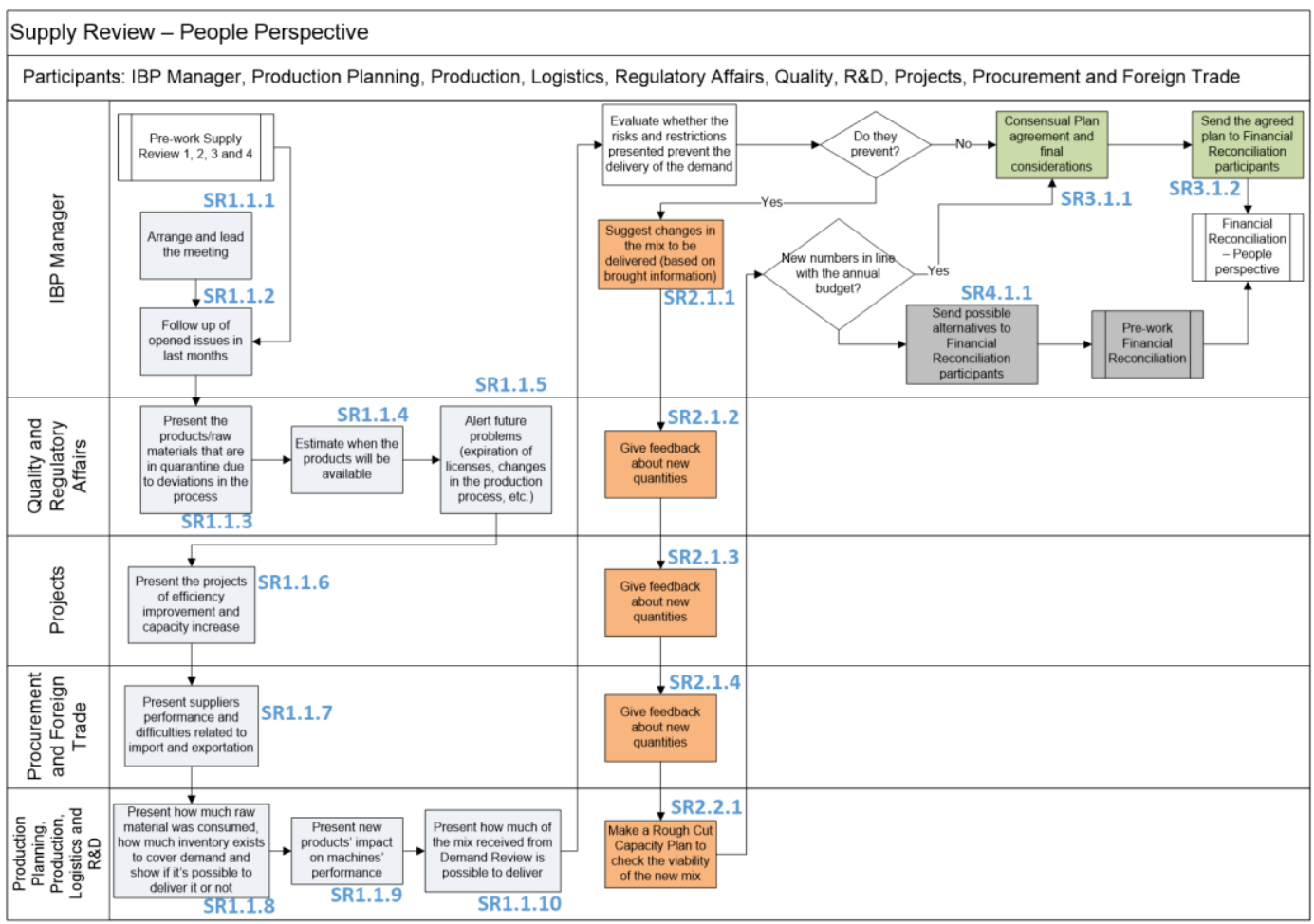

Figura 28 - Processos de Suporte - Supply Review - Perspectiva Pessoas (nível 4). Fonte: Autor

\subsection{3.}

Processo de Suporte - Perspectiva Pessoas - Financial Reconciliation

O Processo de Suporte na perspectiva de pessoas em Financial Reconciliation contempla o Gerente de IBP, Planejamento de Produção, Marketing, Vendas e Finanças, conforme ilustrado na Figura 29.

O Gerente do IBP apresenta o plano acordado ou cenários a serem definidos para Finanças. Se não houver consenso sobre o melhor cenário a ser perseguido, é responsável por mediar possíveis conflitos de interesse e definir o melhor número para a empresa. O objetivo é alinhar os discursos para que todos defendam o mesmo plano na Executive Review, chamado de Previsão de Vendas Restrita Consensual, porém é importante ter algumas alternativas caso não haja consenso entre os diretores.

Se a Previsão de Vendas Irrestrita Consensual não puder ser entregue, Planejamento de Produção é responsável por explicar e apoiar as ações que podem ser executadas para entregar a Previsão de Vendas Irrestrita Consensual ou outro mix 
satisfatório. As ações focam em reduzir os riscos de abastecimento e/ou aumentar a capacidade produtiva, como hora extra, turno extra e terceirização.

Se a projeção financeira da Previsão de Vendas Irrestrita Consensual não cumprir o orçamento ou se não houver capacidade suficiente para entregar o mix com as restrições, Marketing e Vendas são responsáveis por explorar as oportunidades de mercado para compensar a falta de alguns produtos com mais produtos de outro tipo. Além disso, podem analisar cenários com alteração de preços e campanhas mais agressivas com o suporte financeiro.

Finanças é responsável por apoiar a validade das projeções financeiras feitas pela equipe e propor ajustes para evitar estouros no orçamento e atender aos objetivos estratégicos.

A Figura 29 sintetiza a participação das áreas funcionais responsáveis pelas pessoas na Financial Reconciliation.

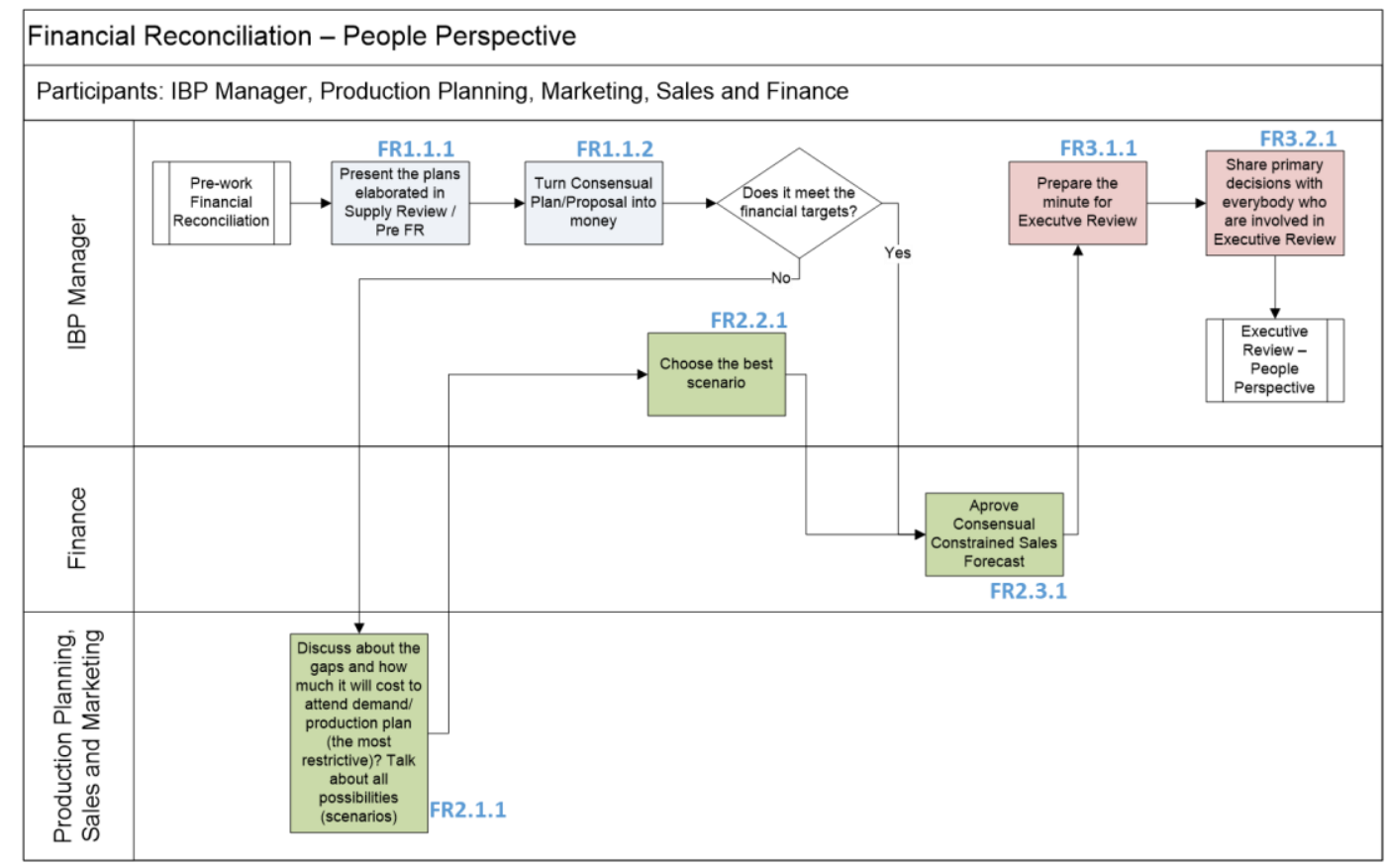

Figura 29 - Processos de Suporte - Financial Reconciliation - Perspectiva Pessoas (nível 4). Fonte: Autor

\subsection{4.}

\section{Processo de Suporte - Perspectiva Pessoas - Executive Review}

O Processo de Suporte na perspectiva de pessoas em Supply Review contempla o Gerente de IBP, o Presidente, o corpo de diretores da empresa e representantes de todas as áreas que participaram das outras três etapas, conforme ilustrado na Figura 30. 
O Gerente de IBP é responsável por apresentar o plano acordado e o cenário projetado em relação ao mercado, indicadores de desempenho e melhorias de processos. Em caso de necessidade de mudança, media as negociações, buscando um novo consenso.

O Presidente analisa os planos apresentados, as projeções e os impactos dos planos nos indicadores de performance para aprovar ou apontar mudanças necessárias para satisfazer alguma outra demanda de partes interessadas externas. Está em todas as reuniões, logo não existe Executive Review que termine sem um plano de ação e a aprovação de uma Previsão de Vendas Restrita Consensual. Mesmo que existam opiniões divergentes, o Presidente tem a última palavra para determinar qual das opções deve ser buscada. Em outras palavras, o Presidente pode mudar tudo a qualquer momento. A tendência é que com um nível de maturidade maior, ele intervenha menos. Portanto, é possível que existam diversos cenários para avaliar e o Presidente aprove um cenário diferente do recomendado por outras áreas.

O corpo de diretores é responsável por levantar pontos em relação ao plano apresentado, a fim de melhorá-lo. Caso algum diretor não possa comparecer à reunião e exista alguma divergência de opiniões acerca do plano enviado após a $F i$ nancial Reconciliation, recomenda-se que os diretores discordantes conversem previamente, de forma a negociar e buscar um alinhamento consensual acerca das prioridades.

Quando necessário, os representantes de todas as áreas que participam do processo são responsáveis por apresentar explicações mais detalhadas para justificar o plano, bem como oportunidades de melhoria no processo identificadas. Além de explicações, pode acontecer algum evento ao longo do mês que exija ajustes no plano. Esses eventos podem envolver alguma oportunidade, imprevistos na operação, entre outros. É responsabilidade dos representantes trazer a discussão para que os diretores possam refletir e tomar a decisão sobre o assunto.

A Figura 30 sintetiza a participação das áreas funcionais responsáveis pelas pessoas na Executive Review. 


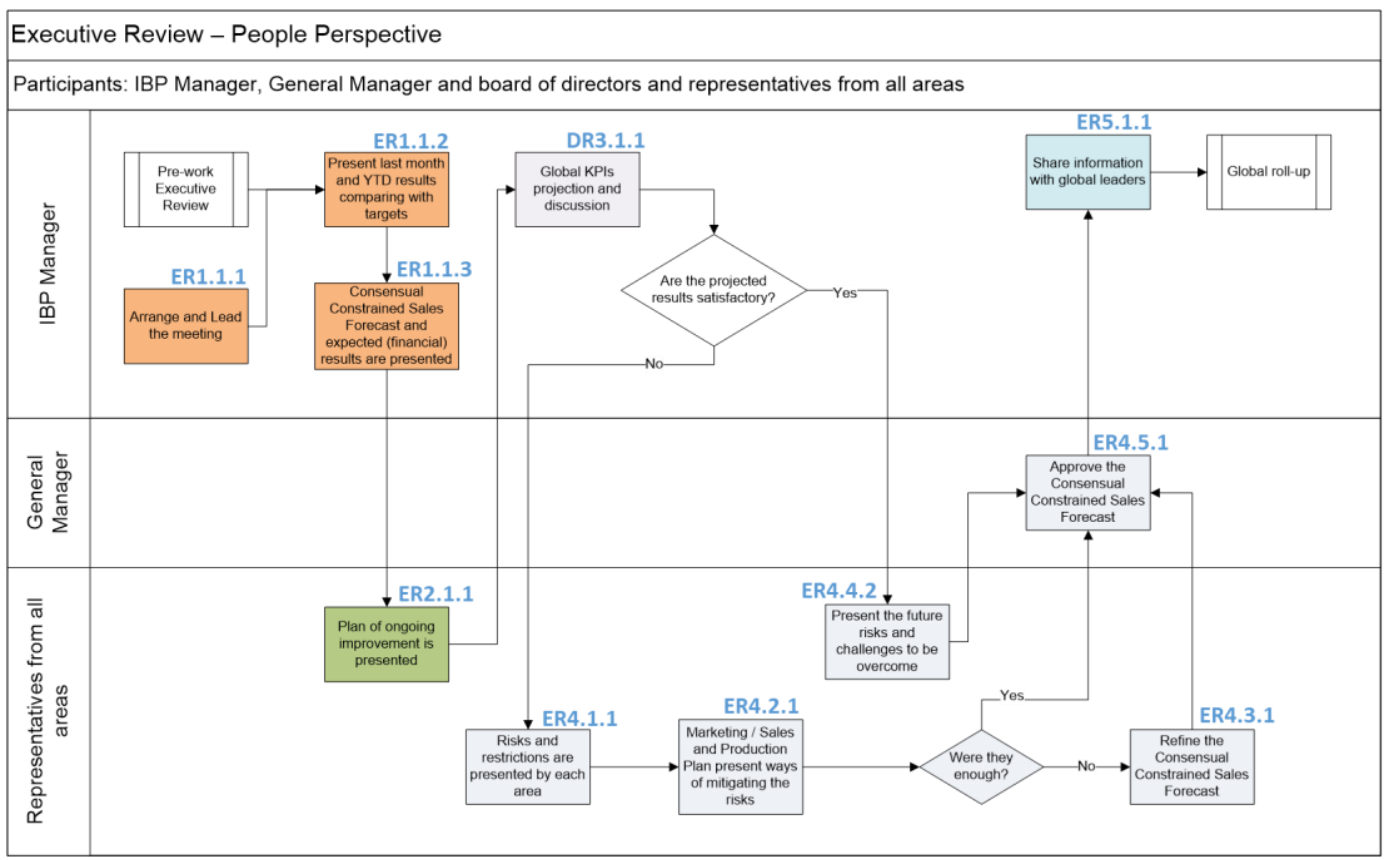

Figura 30 - Processos de Suporte - Executive Review - Perspectiva Pessoas (nível 4). Fonte: Autor

\section{4.}

\section{Suporte Tecnológico}

Apesar de o subprocesso de Suporte Tecnológico não fazer parte do escopo deste trabalho, o uso de softwares sem um alinhamento entre as pessoas e a estrutura organizacional pode dificultar a execução do processo de S\&OP/IBP (Kristensen e Jonsson, 2018). Goh e Eldridge (2015) afirmam que o processo de S\&OP/IBP é viabilizado com o uso de Enterprise Resource Planning (ERP) e outros sistemas de planejamento. Ivert e Jonsson (2014) abordam a importância de um sistema Advanced Planning and Scheduling (APS), que permite simular cenários futuros e otimizar o abastecimento, com base nas restrições levantadas.

Embora existam estudos sobre os benefícios de tecnologias mais avançadas para melhorar os resultados obtidos com o S\&OP/IBP, o MS Excel foi unânime tanto na empresa XYZ, quanto nos entrevistados. Essa ferramenta não é utilizada de forma isolada, mas em conjunto com outros recursos, como ERP, em todas as etapas do ciclo de reuniões como ferramenta de suporte.

Conforme Goh e Eldridge (2019), o contexto é fundamental para a definição do processo. Logo, empresas em mercados mais dinâmicos podem se beneficiar de algoritmos e modelos estatísticos mais sofisticados para melhorar as previsões. A empresa XYZ, por exemplo, adota um algoritmo de machine learning e outra ferramenta de Business Analytics para auxiliar na etapa de Demand Review com previsões e tendências de mercado mais acuradas. Nenhuma ferramenta é utilizada 
para realizar o sequenciamento, mas foi sinalizada a existência de um projeto para implementar um sistema APS para agilizar tanto os Pre-works Supply Review e Financial Reconciliation, quanto as reuniões em si, uma vez que essa ferramenta pode simular e projetar resultados em alta velocidade.

Outras ferramentas como softwares colaborativos foram identificadas como promissoras por alguns dos entrevistados, mas ressaltaram que esse tipo de abordagem exige mais familiaridade dos praticantes com o processo. Algumas ferramentas operacionais também podem ser utilizadas, eventualmente, para simular a capacidade de resposta, como os softwares de Warehouse Management System (WMS), Material Requirement Planning (MRP), Manufacturing Resources Planning (MRP II), entre outros, principalmente na etapa de Supply Review.

\section{5. \\ Processos de Coordenação}

Os Processos de Coordenação têm o objetivo utilizar indicadores de desempenho para monitorar e corrigir possíveis desvios nas metas estabelecidas. Visando a flexibilização da estrutura, não é estabelecido quais indicadores os usuários devem adotar. Uma vez que cada empresa está inserida em um contexto diferente e possui metas diferentes, é essencial que os praticantes possam escolher as métricas que melhor incentivem e conduzam o atingimento do plano estratégico.

Com base no estudo de caso conduzido, o levantamento e análise dos indicadores agrega mais valor às reuniões quando feitos durante os pre-works. Iniciar as reuniões com os indicadores calculados tende a melhorar a qualidade das decisões. A ideia é promover debates proativos acerca dos desafios futuros e desestimular que os participantes fiquem culpando uns aos outros.

A estrutura fornece um leque de métricas combinando o conjunto apresentado em Hulthén et al. (2016) com as recomendações dos praticantes da XYZ e dos entrevistados para que cada empresa, com base no seu contexto, escolha os indicadores locais mais interessantes para cada etapa, de forma a melhorar os indicadores corporativos, que medem a empresa como um todo. Em outras palavras, cada etapa do processo de S\&OP/IBP pode apresentar um conjunto de métricas abrangente, porém é recomendado adotar um conjunto pequeno de indicadores que indiquem o atingimento dos objetivos estratégicos. Os indicadores corporativos apresentados são praticados pela empresa XYZ e seguem a recomendação de Hulthén et al. 
(2016), de retratar tanto o lado da demanda, quanto do abastecimento, quanto o financeiro. Entretanto, tais indicadores podem ser bastante adaptados para outros cenários.

A Figura 31 apresenta uma lista de indicadores para a Demand Review, segregados para casos em que Finanças participa (ou quando os outros participantes analisam pela perspectiva financeira) e para os casos em que Planejamento de Produção participa.

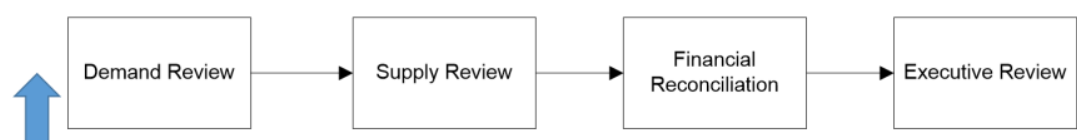

Pre-work Demand Review (Actual x Plan)

Sales Quantity by Family and SKU, Service Level, Trends, Risks, Opportunities, Consumers' feedbacks, Competitors' performance, New players entrance, Information of products phase-in and phase-out, Priority items to be made available, Sale price, Contribution Margin, Inventory Valuation and Costs, Profit, Losses, Revenue, Price Variance, Depreciation, Inventory Level, Products Return, Destruction (finished products and raw materials), Quantity and Value in Backorder and when the products will be available

Finance attending the meeting

Production Planning attending the meeting

Figura 31 - Processos de Coordenação - Indicadores de desempenho sugeridos para Pre-work Demand Review. Fonte: Autor

A Figura 32 apresenta uma lista de indicadores para a Supply Review. Caso Planejamento de Produção não participe da Demand Review, os indicadores trabalhados por essa área são apresentados nessa segunda etapa.

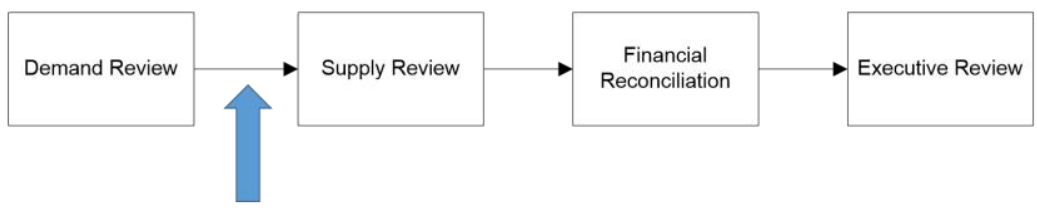

Pre-work Supply Review (Actual x Needed)

Products/raw materials in quarantine due to deviations in the process, Projects of efficiency improvement and capacity increase, Suppliers performance and difficulties related to import and exportation (lead time, timeliness, quality variation etc), How much raw material was consumed, How much inventory exists to cover demand, Capacity Availability, Backorder (quantity and value), Inventory Level, Products Return, Destruction (finished products and raw materials), Quantity and Value in Backorder and when the products will be available, Priority items to be made available

Figura 32 - Processos de Coordenação - Indicadores de desempenho sugeridos para Pre-work Supply Review. Fonte: Autor

A Figura 33 apresenta uma lista de indicadores para o Financial Reconcilition. Caso a análise financeira não seja feita em nenhuma das duas primeiras etapas, 
os indicadores financeiros são expostos nessa terceira. As métricas que tratam de demanda e abastecimento são tratadas de acordo com o contexto da empresa: restrição ou excesso de capacidade. Nessa etapa, é preciso avaliar se o resultado projetado atende aos objetivos estratégicos da empresa, que são o foco dos diretores.

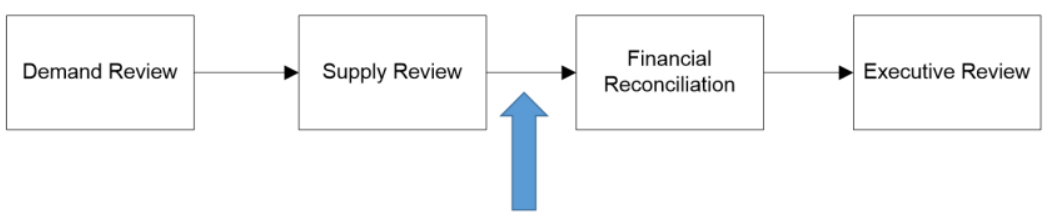

\section{Pre-work Financial Reconciliation}

Demand and supply metrics will depend on the context. The plan should be analyzed based on the financial metrics like the Return on Investment/Assets, Profitability, Revenue, Operational Costs. Contribution margin (product and company), Sale price, Contribution Margin, Inventory Valuation and Costs, Profit, Losses, Revenue, Price Variance, Depreciation

Figura 33 - Processos de Coordenação - Indicadores de desempenho sugeridos para Pre-work Financial Reconciliation. Fonte: Autor

A Figura 34 apresenta uma lista de indicadores para a Executive Review. Esses indicadores são a ponte entre os objetivos estratégicos e a operação. O corpo de diretores enfatiza o atendimento deles de forma a entregar os números com os quais se comprometeram. Caso tais indicadores estejam abaixo do esperado, é recomendado que sejam analisados os indicadores apresentados nas etapas anteriores, para que se encontre relações entre indicadores locais e o resultado do sistema.

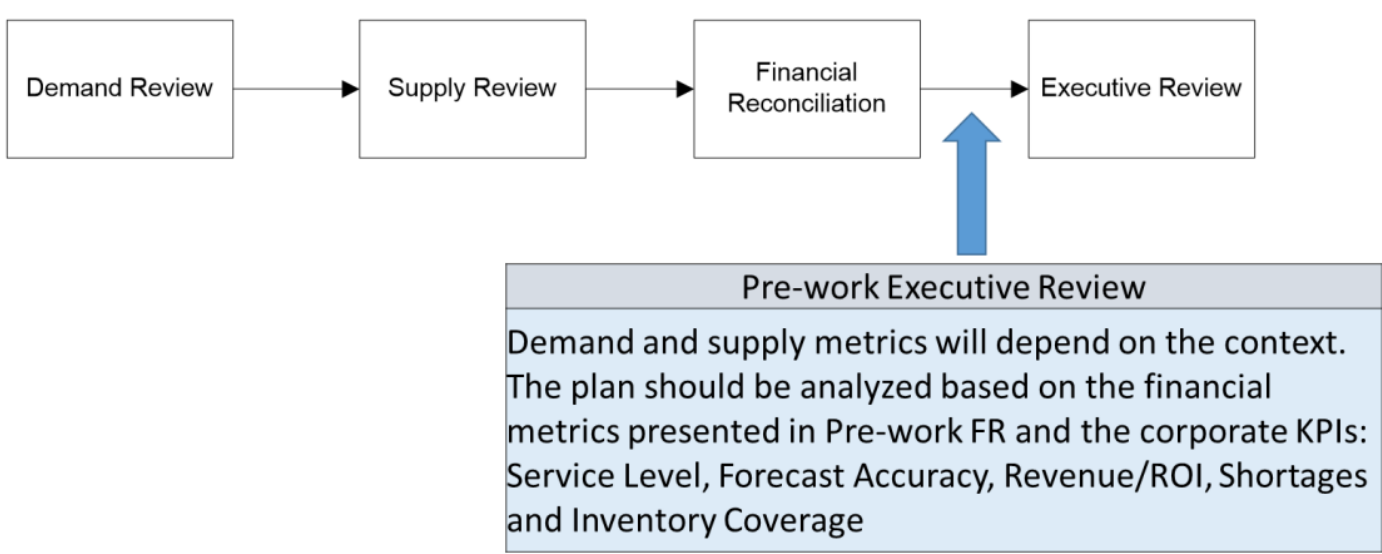

Figura 34 - Processos de Coordenação - Indicadores de desempenho sugeridos para Pre-work Executive Review. Fonte: Autor 
A Figura 35 sintetiza métricas que podem ser adotadas para evitar melhorias isoladas, conforme alerta Thomé et al. (2012a). Tais métricas estimulam o aprimoramento das áreas relacionadas à demanda (e.g. Marketing e Vendas) e à operação (e.g. Planejamento de Produção, Produção e Logística), sem perder o foco em entregar um resultado financeiro satisfatório para os stakeholders.

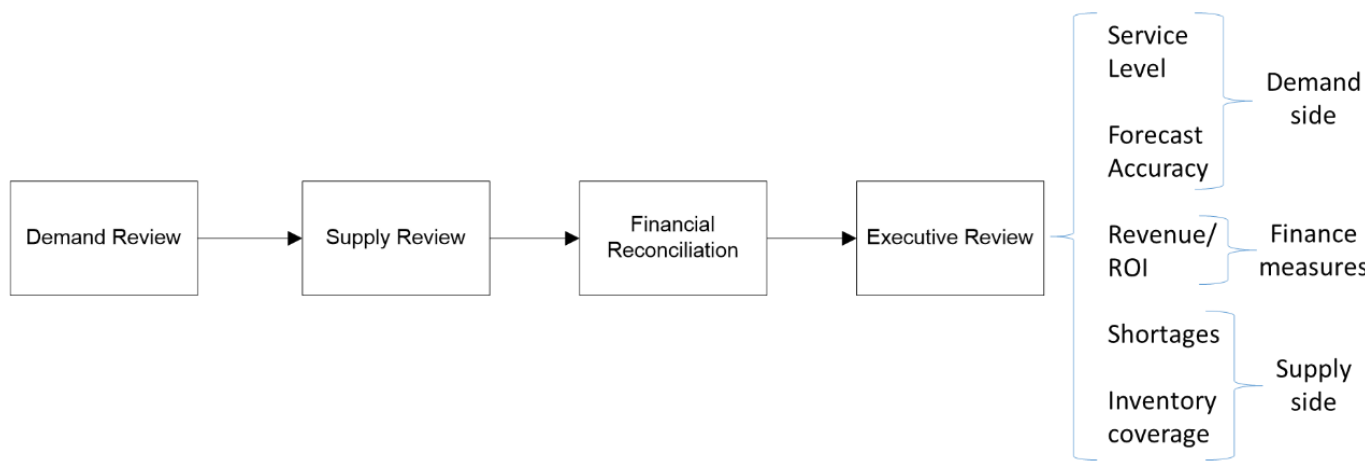

Figura 35 - Processos de Coordenação - Indicadores de desempenho sugeridos para a Corporação. Fonte: Autor 


\section{5 \\ Discussões}

Neste capítulo, são apresentados 13 pontos de atenção a serem avaliados pelos praticantes do processo de $\mathrm{S} \& \mathrm{OP} / \mathrm{IBP}$, a fim de amenizar os impactos das diferenças entre contextos. Esses pontos são resultados de entrevistas com os praticantes, e as comparações entre as opiniões dos especialistas, da empresa XYZ e os achados disponíveis na literatura. Recomenda-se que os 13 pontos sejam debatidos durante a definição da dinâmica do processo. Para os casos em que a empresa já possui um processo estabelecido, os pontos devem ser levados em consideração durante o redesenho do processo, para que o processo novo acompanhe as particularidades do contexto da empresa.

\section{1.}

\section{Finanças em S\&OP/IBP}

O início da pesquisa teve como um dos principais pontos de discussão a diferença entre os termos S\&OP e IBP. De acordo com as definições dadas por acadêmicos, IBP e S\&OP são termos similares, pois ao passo que Kristensen e Jonsson (2018) definem IBP como sendo o S\&OP que envolve finanças, Wagner et al. (2014) disseram que Finanças deve fazer parte das reuniões de S\&OP, ou seja, a diferença é que Wagner et al. (2014) não adotaram outra nomenclatura, bem como Grimson e Pyke (2007) e Thomé et al. (2012a). No caso das consultorias, elas afirmam que o IBP é uma versão mais sofisticada do S\&OP (Palmatier e Crum, 2013). A principal diferença é que o IBP incentiva que todas as áreas de negócios da empresa façam parte do ciclo de reuniões (Aberdeen, 2011; Thor e Dhir, 2011). Em termos práticos, nenhum dos entrevistados foram capazes de definir com segurança a diferença entre S\&OP e IBP. Além da XYZ, poucos praticantes afirmaram executar um IBP. Uma vez que a maioria não viu diferença na forma de operação, os nomes S\&OP e IBP foram tratados em conjunto (S\&OP/IBP), bem como em Aberdeen (2016). 
A análise financeira no processo, principalmente na Demand Review, onde poucos praticantes afirmaram fazer, foi vista com bons olhos pelos que não trabalham dessa forma. O ponto mais exaltado está relacionado à ideia apresentada por Palmatier e Crum (2013), de que notícia ruim é melhor ser identificada antes do que depois, ou seja, para tirar o máximo de proveito da estrutura, é recomendado que se fale de dinheiro logo no início do ciclo para promover debates acerca de planos que, independentemente do mix de entrega, gere resultados financeiros satisfatórios. Apesar de a estrutura proposta não determinar que o Financeiro deva participar, ela sugere que seja falado de dinheiro. A participação de Finanças é defendida por Wagner (2014) e por SAP (2018).

Contudo, algumas preocupações foram explicitadas. Dois entrevistados relataram receio de colocar o Financeiro e as outras áreas se sentirem tolhidas na negociação. A estrutura busca mitigar essa preocupação frisando que o Financeiro não deve ter a palavra final, mas o gerente do processo de S\&OP/IBP. Nas empresas onde o responsável pelo Financeiro não compreendeu que o foco do S\&OP/IBP não é apenas maximizar o lucro, mas garantir a sustentabilidade do negócio, pode-se ter pessoas fora do Financeiro falando de dinheiro durante as reuniões, enquanto o Financeiro está sendo treinado para agregar no processo.

O olhar financeiro é crítico em empresas com restrição de capacidade. Uma vez que não se pode entregar tudo, é preciso escolher o que entregar, e muitas vezes a decisão está mais baseado em estratégia (entregar produtos menos lucrativos que abrem portas para produtos mais lucrativos) do que simplesmente escolher o mix mais rentável. A ótica financeira ajuda a escolher, com base em produtos estratégicos, um mix que traga lucro. Essa abordagem deixa todos cientes dos números rapidamente, o que torna o fluxo menos estressante, pois evita de acontecer retrabalho em poucos dias de forma intensa para entregar um plano que satisfaça o orçamento financeiro só porque não se levou esse aspecto em consideração logo de início.

Numa empresa com excesso de capacidade, onde tudo que é pedido, consegue ser entregue, a análise financeira deve focar nos investimentos necessários para explorar mercados novos e reduzir os níveis de ociosidade. Não colocar análise financeira logo no início pelo fato de estar em um cenário de excesso de capacidade dificulta a expansão dos negócios (Cecere et al., 2009). 


\section{2. \\ Período congelado (Frozen period)}

De maneira unânime, os entrevistados dizem ser necessário o estabelecimento de um período congelado de demanda, isto é, não pode haver alteração na quantidade pedida dentro desse tempo. Por outro lado, não existe um consenso acerca da duração desse período. A empresa XYZ trabalha com 3 meses, outros afirmaram trabalhar com 2 meses e um terceiro grupo, 1 mês. Não foram encontrados trabalhos que abordem esse aspecto na literatura acadêmica.

Em cenários de restrição de capacidade, recomenda-se que o período congelado seja compatível com o tempo de reação da empresa e da cadeia. Por exemplo, se demora um mês para a empresa aumentar sua capacidade produtiva colocando outro turno, o período congelado deveria ser um mês, isto é, qualquer alteração na previsão de vendas só poderia ocorrer do segundo mês em diante, pois a contratação do turno extra já está providenciada para o mês seguinte. O mesmo raciocínio vale para o caso em que a restrição está em fornecedores com lead time longo. Se houver excesso de capacidade, o período congelado pode ser menos de um mês.

Vale ressaltar que a existência de um período congelado não impede a empresa de avaliar pedidos grandes vindos na metade do mês e que não havia sido mapeado. Tudo depende da proposta e dos indicadores de desempenho. Caso a proposta seja muito lucrativa e os indicadores estejam abaixo da meta, é possível que ocorra uma negociação dentro do S\&OP/IBP para analisar a viabilidade de atender esse tipo de pedido.

\section{3.}

\section{Horizonte de planejamento}

O modelo clássico de Wallace e Stahl (2008) recomenda planejar a demanda e operação num horizonte de, pelo menos, 18 meses. Na visão dos especialistas que trabalhavam na operação, as informações mais importantes são aquelas relacionadas aos assuntos que exigem mudanças em um tempo mais curto que o tempo de reação da cadeia, que variava entre 2 e 12 meses, ou seja, eles não dão a mesma importância para períodos mais distantes, como recomenda o modelo clássico.

Além disso, dois aspectos foram destacados na questão do horizonte de planejamento. O primeiro é a sazonalidade dos produtos, ou seja, quando é sabido que 
em determinados períodos do ano ocorre um pico ou vale de demanda. $\mathrm{O}$ segundo está ligado aos eventos de grande porte, isto é, quando a empresa participa de algum festival de música, competição esportiva, entre outros. As empresas que, de alguma forma, estão envolvidas com tais espetáculos, que podem ocorrer em um intervalo maior do que 24 meses, adaptam o processo de S\&OP/IBP para esse tipo de ocorrência. Por isso, o horizonte de planejamento não deveria ser fixo, mas determinado pelos tempos e pelo tipo de mercado das empresas.

\section{4.}

\section{Pre-works}

Os pre-works são de fundamental importância no processo, pois é durante esse período que as informações relevantes para a tomada de decisão são levantadas e debatidas em reunião. Na XYZ, onde o nível de maturidade é alto, os pre-works de Demand Review e Supply Review são considerados os mais importantes, por isso costumam levar mais tempo do que as reuniões em si. A ideia é que se gaste menos tempo buscando dados com qualidade e mais tempo fazendo análises mais precisas. Isso melhora a precisão da tomada de decisões. Como consequência, os pre-works e as reuniões de Financial Reconciliation e Executive Review ocorrem de maneira mais fluida.

Entretanto, nem sempre essa é a realidade. Quando aparecem outras demandas na rotina das pessoas, elas podem atrasar o pre-work, fazendo com que a reunião não tenha todas as informações necessárias disponíveis no nível de detalhe desejado. Outro fator que pode gerar atrasos é a troca de funcionários. Quando alguém que faz parte do processo de S\&OP/IBP deixa o cargo, nem sempre a pessoa contratada consegue entrar no ritmo das outras áreas de maneira rápida. Essa demora pode estar associada tanto ao uso das ferramentas, quanto ao entendimento pleno do processo (Pedroso et al., 2016; Scavarda et al., 2017).

Em outras empresas, a realidade se mostra mais difícil do que na XYZ. O alinhamento acerca dos dados necessários para cada reunião não é padronizado, ou seja, a cada ciclo, as pessoas trazem informações diferentes. Muitas vezes, os preworks acabam demorando mais do que as reuniões em si, podendo chegar a ser considerado um gargalo para a realização das reuniões nas datas combinadas. No 
fim, o mais importante é que os pre-works consigam apresentar informações relevantes para a tomada de decisões que viabilizem o atingimento dos objetivos estratégicos.

\section{5.}

\section{Ganhos operacionais com o S\&OP/IBP}

Ao remodelar o processo, deixando de chamar de S\&OP para adotar o termo IBP, a XYZ afirmou que não houve melhorias operacionais diretas, como redução de lead times de produção ou aumento de capacidade. As melhorias estão mais relacionadas à visibilidade das informações do que com melhorias de performance propriamente ditas. Essa visibilidade permite saber a intenção de produção, o que pode indicar oportunidades de investimento e melhoria na fábrica. Em outras palavras, o IBP não beneficia diretamente o lead time. Ele funciona como um expositor de sintomas. Se está faltando produto, é porque não está sendo entregue, o que gera necessidades de melhoria no processo produtivo. Isso está alinhado à Kristensen e Jonsson (2018), que afirmam não ser possível o S\&OP/IBP ter bom desempenho se há falhas no modelo operacional.

Goh e Eldridge (2015) avaliaram os impactos que o S\&OP/IBP gerou em empresas asiáticas que não tinham nada implementado. Elas conseguiram reduzir o tempo de lançamento de produtos, o nível de inventário e melhorar a qualidade das previsões de maneira significativa. Esses resultados foram possíveis, pois seguiram um dos precedentes de um S\&OP/IBP de sucesso identificados por Swaim et al. (2016), que é a integração organizacional.

Apesar de a XYZ não ter obtido melhorias operacionais significativas, o relato é que a mudança de S\&OP para IBP tornou a visão financeira mais forte, o que estimulou as pessoas a buscarem um alinhamento maior de números. Em outras palavras, uma vez que o processo de S\&OP já estava funcionando, a empresa conseguiu amenizar a visão por silos, pois tanto as áreas focadas na operação, quanto as áreas focadas no atendimento ao cliente passaram a trocar mais informações. $\mathrm{O}$ IBP foi um projeto para incluir Finanças e refinar os processos, de forma a permitir que todos falarem a mesma língua, busquem os mesmos números e não executem mais uma reunião que só visa falar de dificuldades, mas que seja proativa na identificação e resolução de problemas. 
Ainda falando sobre os ganhos operacionais, a comparação com os contextos dos entrevistados ficou comprometida, porque apenas 3 participaram do processo de implementação, ou seja, apenas eles puderam identificar as mudanças relacionadas ao uso do processo. Todos os outros já chegaram nas empresas com o processo funcionando. Entretanto, os poucos que acompanharam a implementação não conseguiram ver melhorias tangíveis. Nenhum dos casos possui dados numéricos históricos capazes de comprovar a melhoria da operação. Os resultados nítidos estão relacionados à melhor comunicação, que resulta em melhor alinhamento entre os interessados e melhor preparo para o curto e, principalmente, médio e longo prazos. A justificativa para esse não acompanhamento dos benefícios do processo foi que a rotina de trabalho não permite, pois sempre existem várias atividades, como lançamento e descontinuação de produtos, o que afeta não só as áreas de Marketing e Vendas, mas a operação como um todo.

Todos os outros entrevistados viram os resultados de Goh e Eldridge (2015) com surpresa. A maioria especulou que uma vez que a empresa relatada pelos asiáticos não tinha um processo formal, pode ser que o $\mathrm{S} \& \mathrm{OP} / \mathrm{IBP}$ realmente traga resultados acima da média em um ambiente de silos. Porém, quando já se tem um processo e uma cultura, ainda que pouco entranhada, os ganhos operacionais já não são tão significativos. Esse aspecto cultural foi sugerido como um ponto de aprofundamento em pesquisas por Pedroso et al. (2016).

Outro aspecto identificado em relação às melhorias operacionais após a implementação do processo de S\&OP/IBP é o comportamental. Ao se adotar o processo de $\mathrm{S} \& \mathrm{OP} / \mathrm{IBP}$ em empresas muito verticalizadas, com baixa interação para se alinhar os planos, os trabalhos de cada área passam a ser analisados pelas outras. Uma vez que cada setor está sendo observado, foi notado um comportamento que visava melhorar os indicadores de desempenho para que que ninguém seja criticado. Portanto, áreas operacionais, como a Logística, que antes do S\&OP/IBP demorava muito tempo para fazer as movimentações, tendem a tomar iniciativas para diminuir esse número e acompanhar o nível de outras áreas. Em outras palavras, o $\mathrm{S} \& \mathrm{OP} / \mathrm{IBP}$ tem potencial para trazer ganhos operacionais, pois esse processo influencia no comportamento das pessoas, principalmente, por meio do estabelecimento de metas para determinados indicadores de desempenho. Esse ponto também foi abordado por Oliva e Watson (2011) e Ambrose e Rutherford (2016), que abordaram a questão comportamental na integração entre áreas. Eles sugerem que mais 
estudos acadêmicos abordem esse tópico para incrementar o funcionamento do $\mathrm{S} \& \mathrm{OP} / \mathrm{IBP}$.

A influência do S\&OP/IBP no comportamento das pessoas, resultando em melhor comunicação e alinhamento entre os planos, pode ser uma das explicações para as diversas evidências levantadas por Thomé et al. (2012b), que apontam para a influência positiva que o S\&OP/IBP tem sobre a performance da empresa. Parece que o fato de o S\&OP/IBP, na visão dos praticantes entrevistados, não trazer tais melhorias é resultado da falta de maturidade das empresas em relação à aplicação do processo de S\&OP/IBP, conforme descrito por Rexhausen et al. (2012).

\section{6. \\ Realização de diversas reuniões em paralelo referentes à mesma etapa}

Por conta do número pequeno de SKUs e de famílias de produtos, a XYZ consegue agendar cada reunião com todos os respectivos participantes, isto é, realizam uma Demand Review com todos os devidos participantes, uma Supply Review com todos os devidos participantes e assim por diante. Algumas empresas com uma quantidade maior de produtos e famílias, para evitar que as reuniões demorem muito, realizam uma Demand Review abordando apenas as famílias ou fazem mais de uma Demand Review simultaneamente, dividas por famílias que não possuem relação com outras, para que mais produtos possam ser avaliados individualmente. Essa é uma forma de tratar o $\mathrm{S} \& \mathrm{OP} / \mathrm{IBP}$ em contextos com muitos produtos. Em vez de juntar todo mundo em uma reunião, os funcionários são divididos de acordo com a relação entre as famílias e eles criam vários planos paralelos durante a $D e$ mand Review e a Supply Review. Esses planos em paralelo são consolidados no Prework Financial Reconciliation ou no Pre-work Executive Review, dependendo da forma que a empresa julgar mais adequada.

\section{7. \\ Participação de clientes e fornecedores}

Grimson e Pyke (2007) mostraram em seus estudos de caso exemplos de participação de clientes e fornecedores no ciclo de S\&OP/IBP. Thomé et al. (2014a) concluíram que a participação de fornecedores impacta positivamente no processo. 
Goh e Eldridge (2015) fizeram um estudo de caso que mostrou melhorias significativas em uma empresa asiática que incluiu fornecedores no processo de S\&OP/IBP.

Porém, a empresa XYZ e a maioria dos entrevistados não incentiva a participação de clientes e fornecedores. A justificativa é que não querem discutir assuntos estratégicos, principalmente no que diz respeito a custos, com terceiros observando. Quase todos concordaram que se a participação de clientes ou fornecedores apresentar algum risco à capacidade de negociação da empresa, é melhor não trazer ninguém e trabalhar por meio de contratos especificando o nível de serviço desejado, com multas em caso de descumprimento, ou com softwares mais sofisticados como o Demand Sensing, apresentado por SAP (2018), capaz de fazer análises de dados robustas que ajudam a enxergar possibilidades para melhorar o atendimento.

A única condição que esses praticantes afirmaram que trazer clientes e fornecedores era essencial era em indústrias muito técnicas como a automotiva e de aviação, onde é comum existirem pouco fornecedores de determinadas peças. Nesse caso, qualquer atraso no abastecimento de alguma matéria prima faz a linha de produção parar, gerando perdas muito altas em termos monetários. Com isso, a resistência diminui, já que é preciso aumentar a eficiência dos processos.

Aqueles que concordaram em chamar clientes e fornecedores argumentam que, cada vez mais, é preciso aumentar a capacidade de resposta das cadeias. Isso só é possível com todos envolvidos no alinhamento das datas e quantidades. Outro aspecto levantado é que perder um cliente, hoje, é muito caro, o que pode compensar dar uma chance para um fornecedor participar, a fim de reduzir o tempo de resposta, mesmo sabendo do risco de ele quebrar algum tipo de acordo de confidencialidade. Além disso, ser confiável em um ambiente competitivo é um grande diferencial. De acordo com os praticantes, todo mundo quer fazer negócio com pessoas de confiança. No longo prazo, o resultado desse tipo de relacionamento tende a ser melhor.

Eventualmente, um fornecedor pode descobrir que o cliente paga valores muito baixos comparados ao preço de venda ou ao quanto outro fornecedor recebe, porém é importante analisar sob a perspectiva de marketing. Ser um fornecedor de uma multinacional pode ser um atrativo para que os próximos clientes sintam confiança e fechem novas parcerias. Ou seja, apesar de o fornecedor estar em desvantagem perante um cliente, isso pode facilitar o acordo com novos parceiros. 
Trazer mais de um fornecedor é também interessante, pois reduz o risco de ficar desabastecido, caso um fornecedor único feche. Além disso, mostra para todos que existe uma competição entre fornecedores, o que incentiva o aumento cada vez maior do nível do serviço para que não sejam trocados por outro, afinal, copiar certos produtos, hoje, é mais fácil.

\section{8. \\ System Setup}

Wallace e Stahl (2008) dividiu o processo de S\&OP/IBP em 5 etapas, sendo a primeira Data Gathering. Apesar de os praticantes não estarem mais considerando Data Gathering como etapa formal, essa parte de tratamento de dados ainda precisa ser feita, seja por uma pessoa, seja pelo computador. Como a necessidade por coletar informações antes da reunião vai continuar existindo, essa etapa é feita nos preworks.

Por isso, o Data Gathering foi dividido em atividades de coleta de dados durante os pre-works e preparação do sistema para o mês vigente, o chamado System Setup. O System Setup é feito no começo do mês para preparar o cálculo de informações financeiras e limpar o sistema das ordens não realizadas. Se essas informações, de um mês para o outro, não fizerem diferença significativa, talvez não seja necessário aguardar muito. Basta esperar pelo fechamento dos números de venda do mês anterior para poder calcular os indicadores de desempenho e avaliar o ciclo.

Os 10 praticantes entrevistados, bem como os usuários da XYZ, representam empresas grandes e com experiência no assunto. Porém, não é possível afirmar que a etapa de Data Gathering é dispensável para todas as empresas. Por exemplo, em uma empresa pouco madura ou com recursos financeiros mais escassos, como seria o caso de uma empresa de pequeno porte, a etapa de Data Gathering continuaria existindo nos moldes originais, até que as pessoas fiquem mais a par dos conceitos do processo ou até que um sistema automatize as rotinas de fechamento de mês e coleta e tratamento de dados. As companhias que possuem acesso a sistemas que possibilitam o acesso em tempo real a informações dinâmicas, como demanda e capacidade produtiva, podem fazer os pre-works com muita antecedência ou um pouco antes das reuniões do ciclo. O System Setup é feito com informações que ficam estáticas, como as financeiras e as ordens não realizadas. 


\section{9 . \\ Etapa de Global Roll-Up}

Apesar de essa etapa ser muito específica para empresas de atuação global, não há um consenso em relação à forma que ele deveria acontecer. Por exemplo, a XYZ executa o S\&OP/IBP em nível nacional mensalmente, porém os números acordados na Executive Review alimentam a plataforma regional, onde a cada 3 meses são analisadas as previsões de demanda para que um país possa auxiliar o fornecimento de outro em produtos específicos. A seguir, a plataforma regional alimenta a plataforma global, onde a mesma dinâmica é feita, mas para que um continente possa vir a abastecer outro.

Entretanto, essa dinâmica depende muito do contexto. Um dos praticantes trabalha em uma empresa na qual a planta do Brasil é responsável por $25 \%$ da capacidade mundial. Nesse caso, não existia o Global Roll-Up, os líderes globais participavam diretamente da última reunião, presencialmente ou por vídeo conferência. Isso mostra que o processo de compartilhamento de informações com matrizes e/ou filiais não tem como ser padronizado.

\subsection{0 .}

\section{Quem deve ser o responsável pelas previsões?}

A maioria dos praticantes está acostumada com a área de Vendas ser responsável por elaborar as previsões. Porém, na XYZ o responsável é o time de Marketing. Wallace e Stahl (2008) defendem que o dono do número é aquele que vai ser cobrado caso os indicadores de vendas estejam ruins. No setor de consumo, Vendas costuma ser o responsável, pois é quem tem acesso aos dados de vendas nos varejistas e do histórico. No caso da XYZ, no braço farmacêutico, o Marketing faz o papel de elaborar as previsões, pois são os responsáveis por visitar os médicos e promover os produtos, ou seja, a influência nas vendas nas farmácias está mais ligada à prescrição do medicamento do que uma propaganda de televisão.

\subsection{1.}

\section{Gestão de atendimento}

Em alguns setores, a incerteza da demanda é muito grande, o que dificulta o trabalho de previsão de demanda. Contudo, executar o processo de S\&OP/IBP 
mais de uma vez durante o mês é totalmente inviável, de acordo com todos os entrevistados. As empresas que se encontram nesse tipo de mercado, utilizam como recurso o chamado mini loop, que é a análise rápida da possibilidade de atender determinado pedido ou não. É praticamente como se um novo ciclo de S\&OP/IBP fosse iniciado em casos de imprevistos, para que a resposta ao imprevisto possa ser a mais efetiva possível.

Como o objetivo das empresas estudadas é aprovar o plano mensal até a terceira semana do mês, é possível que um pedido grande seja feito após a realização da Demand Review. Independentemente do momento do mês, algumas empresas seguem um protocolo para debater e decidir se é possível absorver aquele pedido, quanto custaria e se o aumento na receita justifica o aumento dos gastos, mesmo que o pedido esteja dentro do período congelado. Portanto, já que a capacidade de resposta de cada empresa é diferente, é preciso que a própria empresa, em conjunto com seus funcionários, defina a forma de lidar com pedidos grandes e inesperados.

O modelo de maturidade de Grimson e Pyke (2007) diz que as empresas mais maduras tendem a tornar o processo "event driven", isto é, assim que algum imprevisto ocorre, os times não esperam a próxima reunião para conversar, eles se reúnem imediatamente para desenhar a forma de contornar o problema. A XYZ, com seu processo maduro, utiliza da mesma estratégia. Ela e os entrevistados dizem que essa capacidade de reação para se iniciar um mini loop e buscar maneiras de resolver imprevistos é cada vez mais necessária, por conta do alto grau de incerteza, principalmente, no que diz respeito à demanda. Essa mentalidade está alinhada com a de Lim et al. (2014), que ilustram a dificuldade de coordenar as áreas em uma economia tão dinâmica como a atual.

\subsection{2.}

\section{Existência de um time para gerenciar o S\&OP/IBP}

A determinação de um gerente responsável pela execução correta do S\&OP/IBP se mostrou muito eficiente, independentemente do nível de maturidade, principalmente das pessoas. A XYZ, onde o processo de S\&OP/IBP está totalmente enraizado na cultura da empresa, utiliza uma pessoa para garantir que as decisões sejam feitas com base em informações confiáveis e após análise completa. Essa 
estratégia está alinhada com Grimson e Pyle (2007), que relatam empresas contratando ou dando treinamentos para que funcionários selecionados ajudem a tirar o melhor de cada área, tornando o processo cada vez mais efetivo.

Os entrevistados disseram que suas empresas também adotam um time de S\&OP/IBP. O tamanho do time responsável por gerenciar o S\&OP/IBP varia de acordo com a maturidade do processo, ou seja, quanto menos maduro, mais pessoas são necessárias para a formação de um time, principalmente, para que cada membro esteja próximo das áreas mais importantes (Vendas, Marketing, Planejamento de Produção e Finanças) para impulsionar a participação efetiva dessas áreas. À medida que a maturidade fosse aumentando, as áreas conseguiriam trabalhar sozinhas e não precisaria de um time grande, bastaria algumas poucas pessoas para que fizessem avaliação constantemente do processo e dos resultados obtidos. Em níveis de maturidade maior, é possível colocar pessoas acumulando funções, e não alguém focado apenas no $\mathrm{S} \& \mathrm{OP} / \mathrm{IBP}$.

Apesar de esse trabalho não abordar em profundidade a área tecnológica, a existência de um time um pouco maior no início da jornada de implementação do S\&OP/IBP seria para ajudar, também, na utilização adequada dos possíveis softwares, como alimentar corretamente o modelo estatístico para a previsão de vendas, sequenciamento da produção, entre outras.

\subsection{3. \\ Desafios para melhorar os resultados}

Dentre os desafios identificados pelos entrevistados, melhorar a comunicação durante o processo foi mencionado por todos. Os outros desafios mencionados estão muito relacionados ao nível de maturidade do processo e das pessoas. Por exemplo, XYZ apontou como principais desafios obter informações de vendas dos clientes de maneira rápida e precisa e melhor entendimento dos custos, de forma a possibilitar a visualização dos impactos das ações na Demonstração de Resultados do Exercício.

Enquanto isso, outras empresas, com um processo menos maduro, ainda estão com dificuldades de convencer o financeiro a se envolver com processo, restringindo as discussões a volumes de produção e venda. Além disso, quem tem as informações relevantes para tomada de decisão em cada etapa ainda não atingiu o nível de precisão e pontualidade para proporcionar debates ricos e efetivos. 
Em relação ao foco, muitos entrevistados relataram que as empresas em que atuam sofrem com a cultura de "apagar incêndios", ou seja, muito tempo das reuniões é dedicado a negociar formas de resolver problemas, em vez de debater proativamente os desafios identificados ao longo do processo, seja pelas áreas ligadas à demanda, seja pelas áreas ligadas à operação. Por exemplo, alguns entrevistados disseram que ao longo do ano a atenção varia entre reduzir estoques, aumentar a capacidade, reduzir custos, entre outros.

A falta de indicadores que estimulem a melhoria do resultado da empresa como um todo, e que evitem conflitos de interesse também é uma barreira que precisa ser superada (Grimson e Pyke, 2007; Thomé et al., 2012b). A XYZ e os entrevistados tinham indicadores que, muitas vezes, era preciso que os diretores negociassem entre eles para definir quem teria o indicador prejudicado em prol do plano da empresa. Rexhausen et al. (2012) descreveram situações parecidas nas empresas que praticam o S\&OP/IBP e não haviam extraído todos os benefícios esperados. Conforme mostrado em Ambrose e Rutherford (2016), sistemas de medição de desempenho, atrelado a recompensas e incentivos conjuntos, é o maior impulsionador geral da eficácia do S\&OP/IBP.

Entretanto, nenhum desses desafios pode ser superado sem o apoio total da alta administração da empresa e um entendimento claro dos participantes sobre o processo e seu objetivo. Quando não acontece o patrocínio dos diretores, o processo não é estruturado de forma clara e o engajamento e o resultado das discussões são abaixo das expectativas. Além disso, a capacidade de negociação e trabalho em equipe também precisam ser desenvolvidos, já que o objetivo não é acordar o melhor plano para uma área, mas o melhor plano para a empresa (Swaim et al, 2016). Por último, o desenho do processo precisa se enquadrar em ambientes onde existem cada vez mais SKUs e ciclos de vida de produtos cada vez mais curtos (Swaim et al., 2016; Danese et al., 2017). 


\section{Conclusões e considerações finais}

Essa dissertação teve como objetivo elaborar uma estrutura de modelo de referência para o processo de S\&OP/IBP, apontada como uma carência na literatura. A partir da utilização do método de Schütte (1998), incluindo pesquisas na literatura acerca do tema, de um estudo de caso em uma indústria química e da mediação de um grupo focal com 6 especialistas, foi construída a primeira versão da estrutura de referência para o processo de S\&OP/IBP. A estrutura foi refinada através de entrevistas com 10 praticantes do processo de S\&OP/IBP em diferentes contextos, evoluindo para a primeira versão da estrutura do modelo de referência. A versão final da estrutura refinada foi validada após a mediação de um grupo focal com 6 participantes ( 3 da empresa, 1 dos praticantes e 2 dos especialistas), finalizando a construção da estrutura do modelo de referência.

A estrutura é descrita com base no raciocínio de Meise (2001) e Püster (2016), onde é preciso definir os Processos Principal, de Suporte e de Coordenação. Foram descritos e exemplificados 4 níveis de funcionamento da estrutura. Quanto maior o nível, mais detalhado é o processo, logo mais dependente do contexto da empresa é a estrutura. A estrutura sugere que todo Processo Principal siga a sequência de etapas Demand Review-Supply Review-Financial Reconciliation-Executive Review (nível 1), que tem como base o modelo clássico de Wallace e Stahl (2008). O processo dentro de cada etapa (níveis 2 e 3), bem como seus participantes (nível 4) e a forma de medir o desempenho são dependentes do contexto no qual a empresa está inserida. Exemplos e recomendações foram apresentados no Capítulo 4, com base no estudo de caso realizado em uma empresa do setor químico no Brasil, a XYZ. Vale destacar que os níveis 1 e 2 são gerais e tendem a atender as diferentes características das indústrias, enquanto que os níveis 3 e 4 tendem a ser mais customizados e dependentes dos contextos das indústrias. Os níveis 3 e 4 foram apresentados nesta dissertação de forma a exemplificar suas visões e não como uma sugestão de padrão a ser utilizado nas empresas. 
Foram debatidos com especialistas e praticantes 13 tópicos acerca do processo e comparados com resultados encontrados na literatura. Tais tópicos têm como objetivo amenizar o impacto que as diferenças contextuais possam exercer em cada empresa. Em outras palavras, cada tópico representa um ponto de atenção a ser avaliado pelos praticantes do processo de S\&OP/IBP dentro dos contextos de suas empresas. Isso significa que a estrutura proposta entrega melhores resultados se a empresa levar em consideração todos os pontos de atenção apresentados no Capítulo 5 antes de definir a dinâmica do processo. Alguns deles não são abordados de forma profunda em artigos científicos (Período congelado, Pre-works, Realização de diversas reuniões, System Setup, Etapa de Global Roll-Up), o que indica um campo de oportunidades para aprofundar os benefícios de cada tópico para diferentes contextos. O objetivo de elaborar uma primeira estrutura de modelo de referência para o processo de S\&OP/IBP foi alcançado, porém é fundamental que a estrutura seja analisada sob a perspectiva de mais pontos de vista, de forma a transformála em um modelo de referência consolidado, visando uma maior generalização e completando as quarta e quinta etapas de Schütte (1998) para modelos de referência. Esta é uma continuação natural desta pesquisa.

Para pesquisas futuras, além da maior aplicação da estrutura proposta em mais contextos, é necessário aprofundar a caracterização do Processo de Suporte em relação às tecnologias utilizadas ao longo do processo, visto que tal aplicação não fez parte do escopo dessa dissertação. Os 13 pontos de atenção apresentados também precisam ser debatidos após o detalhamento da perspectiva tecnológica. Uma vez que existe uma grande variedade de recursos tecnológicos disponíveis, é recomendado que se mantenha a flexibilidade da estrutura e que as sugestões de uso de tecnologia estejam relacionadas ao contexto dos usuários.

Outra oportunidade está relacionada aos debates acerca dos impactos ambientais causados pelas empresas. Como eles têm recebido muita atenção, a sustentabilidade tende cada vez mais a ser incluída nos objetivos estratégicos dos negócios, de forma a gerar vantagem competitiva. Nesse caso, o processo de S\&OP/IBP precisa ser adaptado para explorar melhor os aspectos relacionados a marketing de produtos sustentáveis, logística reversa e operações de reaproveitamento de recursos.

Além disso, a estrutura elaborada visa atender, majoritariamente, organizações mais complexas. Isso não significa que pequenas empresas não possam tirar 
proveito das ideias apresentadas. Porém, para esses contextos, a adoção da estrutura é mais difícil, já que a mesma pessoa faz o papel de vários setores ao mesmo tempo, por conta do número enxuto de funcionários. Por exemplo, um dos sócios pode exercer o papel de Vendas, Financeiro, Compras e aprovar a Previsão de Vendas Irrestrita, enquanto o outro sócio organiza a produção, armazenagem e distribuição e vai dizer a Previsão Restrita de Vendas. É recomendado que sejam realizadas pesquisas avaliando especificamente esse cenário.

A estrutura de modelo de referência proposta possui contribuições práticas e acadêmicas. Em termos práticos, a estrutura apresenta pontos a serem debatidos pelos praticantes, de forma a amenizar os efeitos que a diferença entre contextos pode gerar. Além disso, a estrutura apresenta exemplos de fluxos detalhados do processo, o que contribui para uma maior compreensão do processo por parte das pessoas. Academicamente, os fluxos detalhados do processo facilitam a aplicação da estrutura em diferentes contextos, de forma a refiná-la e consolidá-la como um modelo de referência. $\mathrm{O}$ mesmo raciocínio vale para os 13 pontos levantados no capítulo 5, já que alguns deles não são tratados profundamente na literatura. 


\section{Referências bibliográficas}

ABERDEEN GROUP. Executive Sales and Operations Planning Maturity Level and Key Solution Criterion. Research brief, 2011. Disponível em: <encurtador.com.br/enL01>. Acesso em: 12 de setembro. 2018.

ABEDEEN GROUP. The top 3 metrics driving strategic actions for IBP/S\&OP users. Aberdeen Group, 2016. Disponível em: <www.aberdeen.com>. Acesso em: 12 de setembro. 2018.

ABPMP. BPM CBOK: Guide to the business process management common body of knowledge. Association of Business Process Management Professionals, 1. ed. Brasil, 2013.

AMBROSE, S. C.; RUTHERFORD, B. N. Sales and operations planning (S\&OP): A group effectiveness approach. Academy of Marketing Studies Journal, 20(2), pp. 36-60, 2016.

BAUMANN, $F$. The shelf-connected supply chain: strategically linking CPFR with S\&OP at the executive level. Journal of Business Forecasting, 29(4), pp. 21-27, 2010.

BECKER, J.; DELFMANN, P.; KNACKSTEDT, R. Konfigurative Referenzmodellierung. Wissensmanagement Mit Referenzmodellen, pp. 25-144, (https://doi.org/10.1007/978-3-642-52449-3 2), 2002.

BECKER, J.; DELFMANN, P.; KNACKSTEDT, R. Adaptive reference modeling: Integrating configurative and generic adaptation techniques for information models, in Becker, J. and Delfmann, P. (Ed.) Reference modeling, Physica, Heidelberg, Germany, pp. 27-58, 2007.

BIEMANS, F. P.; VISSERS, C. A. Reference model for manufacturing planning and control systems, Journal of Manufacturing Systems, Vol. 8, No. 11, pp. 35-46, 1989.

BRYMAN, A. Social research methods. Oxford: Oxford University Press, 2004.

BRYMAN, A.; BELL, E. Business research methods. 2nd ed. Oxford: Oxford University Press, 2007.

CECERE, L.; BARRET, J.; MOORAJ, H. Sales and Operations Planning: Transformation from Tradition. Industry Value Chain Strategies. AMR Research, Boston, MA, USA, 2009. 
CHALMETA, R.; WILLIAMS, T. J.; LARIO, F.; ROS, L. Developing an object-oriented reference model for manufacturing. IFAC Proceedings, 30(1), pp. 351-356, 1997.

COX, J. F.; BLACKSTONE, J. H. APICS Dictionary, Tenth ed. APICS, Alexandria, VA, USA, 2002.

DANESE, P.; MOLINARO, M.; ROMANO, P. Managing evolutionary paths in sales and operations planning: key dimensions and sequences of implementation. International Journal of Production Research, 56(5), pp. 2036-2053, 2017.

FETTKE, P. Eine Methode Zur Induktiven Entwicklung von Referenzmodellen. Tagungsband Multikonferenz Wirtschaftsinformatik 2014 (MKWI 2014). pp. 1035-1047, 2014.

FETTKE, P.; LOOS, P.; ZWICKER, J. Business process reference models: Survey and classification. International Conference on Business Process Management, Springer, pp. 469-483, 2005.

GIL, A. C. Como elaborar projetos de pesquisa. 5. ed. São Paulo: Atlas, 2010.

GOH, S. H.; ELDRIDGE, S. New product introduction and supplier integration in sales and operations planning: evidence from the Asia Pacific region. International Journal of Physical Distribution \& Logistics Management, 45(9/10), pp. 861-886, 2015.

GOH, S. H.; ELDRIDGE, S. Sales and Operations Planning: The effect of coordination mechanisms on supply chain performance. International Journal of Production Economics, 214, pp. 80-94, 2019.

GRIMSON, J. A.; PYKE, D. F. Sales and operations planning: an exploratory study and framework. International Journal of Logistics Management, 18(3), pp. 322-346, 2007.

HULTHÉN, H.; NÄSLUND, D.; NORRMAN, A. Framework for measuring performance of the sales and operations planning process. International Journal of Physical Distribution \& Logistics Management, 46(9), pp. 809835, 2016.

HULTHÉN, H.; NÄSLUND, D.; NORRMAN, A. Challenges of Measuring Performance of the Sales and Operations Planning Process. OPERATIONS AND SUPPLY CHAIN MANAGEMENT, 10(1), pp. 4 - 16, 2017.

IVERT, L. K.; JONSSON, P. The potential benefits of APS systems in sales and operations planning. Industrial Management \& Data Systems, 110(5), pp. 659-681, 2010. 
IVERT, L. K.; JONSSON, P. When should advanced planning and scheduling systems be used in sales and operations planning?. International Journal of Operations \& Production Management, 34(10), pp. 13381362, 2014.

IVERT, L. K.; DUKOVSKA-POPOVSKA, I.; FREDRIKSSON, A.; DREYER, $H$. C.; KAIPIA, R. Contingency between S\&OP design and planning environment. International Journal of Physical Distribution \& Logistics Management, 45(8), pp. 747-773, 2015a.

IVERT, L. K.; DUKOVSKA-POPOVSKA, I.; KAIPIA, R.; FREDRIKSSON, A.; DREYER, H. C.; JOHANSSON, M. I.; CHABADA, L.; DAMGAARD, C. M.; TUOMIKANGAS, N. Sales and operations planning: responding to the needs of industrial food producers. Production Planning \& Control, 26(4), pp. 280-295, 2015b.

KAIPIA, R.; HOLMSTRÖM, J.; SMÅROS, J.; RAJALA, R. Information sharing for sales and operations planning: contextualized solutions and mechanisms. Journal of Operations Management, 52(1), pp. 15-29, 2017.

KATHURIA, R.; MAHESHKUMAR, P. J.; PORTH S. J. Organizational alignment and performance: past, present and future. Management Decision, 45(3), pp. 503-517, 2007.

KREUTER, T.; KALLA, C. P.; HELLINGRATH, B.; SCAVARDA, L. F.; THOMÉ, A. M. T. Reference Modelling: A Solution for Current Sales and Operations Planning Challenges?. In: 26th EurOMA Conference Operations Adding Value to Society, 2019, Helsinki. Proceedings of the 26th EurOMA Conference, 2019.

KRISTENSEN, J.; JONSSON, P. Context-based sales and operations planning (S\&OP) research: A literature review and future agenda. International Journal of Physical Distribution and Logistics Management, 48(1), pp. 19-46, 2018.

KRUEGER, R. A. Focus groups: A practical guide for applied research. 2nd ed. London: Sage, 1998.

LAPIDE, L. Sales and operations planning part III: a diagnostic model. Journal of Business Forecasting, 24(1),13-16, 2005.

LIM, L. L.; ALPAN, G.; PENZ, B. Reconciling sales and operations management with distant suppliers in the automotive industry: a simulation approach. International Journal of Production Economics, 151(1), pp. 20-36, 2014.

MASON, J. Qualitative researching. London: Sage, 2002. 
MCCUTCHEON, D. M.; MEREDITH, J. R. Conducting case study research in operations management. Journal of Operations Management, 11(3), pp. 239-256, 1993.

MEISE, V. Ordnungsrahmen zur prozessorientierten Organisationsgestaltung: Modelle für das Management komplexer Reorganisationsprojekte. Hamburg: Verlag Dr. med. Kovac; 1 ${ }^{\mathrm{a}}$ edition, 2001.

NOROOZI, S.; WIKNER, J. Sales and operations planning in the process industry: a literature review. International Journal of Production Economics, 188(1), pp. 139-155, 2017.

OLHAGER, J. Evolution of operations planning and control: From production to supply chains. International Journal of Production Research, 51(23/24), pp. 6836-6843, 2013.

OLIVA, R.; WATSON, N. Cross-functional alignment in supply chain planning: a case study of sales and operations planning. Journal of Operations Management, 29(5), pp. 434-448, 2011.

OZTEMEL, E.; TEKEZ, E. K. A general framework of a reference model for intelligent integrated manufacturing systems (REMIMS). Engineering Applications of Artificial Intelligence, 22(6), pp. 855-864, 2009.

PALMATIER, G. E.; CRUM, C. The Transition from Sales and Operations Planning to Integrated Business Planning. Dog Ear Publishing, New London, 2013.

PATTON, M. Q. Qualitative research \& evaluation methods. 3rd ed. London: Sage, 2002.

PEDROSO, C. B.; DA SILVA, A. L.; TATE, W. L. Sales and Operations Planning (S\&OP): Insights from a multi-case study of Brazilian Organizations. International Journal of Production Economics, 182, pp. 213-229, 2016.

PÜSTER, J. Prozessmodelle Für Einzelhandel, Großhandel Und ECommerce. Advances in Information Systems and Management Science (Bd. 55), Logos, Berlin, 2016.

REHSE, J. R.; FETTKE, P.; LOOS, P. A Graph-Theoretic Method for the Inductive Development of Reference Process Models. Software and Systems Modeling, 16(3), pp. 833-873, 2017.

REXHAUSEN, D.; PIBERNIK, R.; KAISERD, G. Customer Facing Supply Chain Practices: The Impact of Demand and Distribution Management on Supply Chain Success. Journal of Operations Management, 30, 269-281, 2012. 
RODRIGUES, V. S.; PIECYK, M.; POTTER, A.; MCKINNON, A.; NAIM, M.; EDWARDS, J. Assessing the application of focus groups as a method for collecting data in logistics. International Journal of Logistics Research and Applications, 13(1), pp. 75-94, 2010.

SAP. SAP Best Practices for SAP Integrated Business Planning. Alemanha, 2018.

SCAVARDA, L. F.; HELLINGRATH, B.; KREUTER, T.; THOMÉ, A. M. T.; SEELING, M. X.; FISCHER, J. H.; MELLO, R. A case method for Sales and Operations Planning: a learning experience from Germany. Production, 27, pp. 1-17, 2017.

SCHÜTTE, R. Grundsätze Ordnungsmäßiger Referenzmodellierung: Konstruktion Konfigurations- Und Anpassungsorientierter Modelle, Gabler, Wiesbaden, Germany, 1998.

SEELING, M. X.; SCAVARDA, L. F.; THOMÉ, A. M. T.; HELLINGRATH, B. In: Springer Proceed. Business, Economics, Adriana Leiras et al. (Eds): Operations Management for Social Good - 2018 POMS International Conference in Rio, 978-3-030-23815-5, 473728_1_En, (45), 2019a.

SEELING, M. X.; SCAVARDA, L. F.; THOMÉ, A. M. T. A sales and Operations planning application in the Brazilian subsidiary of a multinational chemical company. Brazilian Journal of Operations and Production Management (accepted), 2019b.

SKIPWORTH, H.; GODSELL, J.; WONG, C. Y.; SAGHIRI, S.; JULIEN, D. Supply chain alignment for improved business performance: An empirical study. Supply Chain Management, 20(5), pp. 511-533, 2015.

STADTLER, H.Supply chain management and advanced planning: basics, overview and challenges. European Journal of Operational Research, 163(3), 575-588, 2005.

SWAIM, J. A.; MALONI, M.; BOWER, P.; MELLO, J. Antecedents to effective sales and operations planning. Industrial Management \& Data Systems, 116(6), pp. 1279-1294, 2016.

THOMÉ, A. M. T.; SCARVADA, L. F.; FERNANDEZ, N. S.; SCARVADA, A. $S$. Sales and Operations planning: $A$ research synthesis. International Journal of Production Economics, 138(1), 1-13, 2012a.

THOMÉ, A. M. T.; SCARVADA, L. F.; FERNANDEZ, N. S.; SCARVADA, A. $S$. Sales and Operations planning and the firm performance. International Journal of Productivity and Performance Management, 61(4), 359$381,2012 b$. 
THOMÉ, A. M. T.; SOUSA, R. S.; SCAVARDA, L. F. The impact of sales and operations planning practices on manufacturing operational performance. International Journal of Production Research, 52(7), 21082121, 2014a.

THOMÉ, A. M. T.; SOUSA, R. S.; SCAVARDA, L. F. Complexity as contingency in sales and operations planning. Industrial Management and Data Systems, 114(5), 678-695, 2014b.

TOHAMY, N.; KOHLER, J.; PUKKILA, M.; TARAFDAR, D. Toolkit: S\&OP Maturity Self-Assessment for Supply Chain Leaders. Gartner, Inc, Stamford, CT, 2013.

TOOR, T.P.S.; DHIR, T. Benefits of integrated business planning, forecasting, and process management. Business Strategy Series, 12(6), pp. 275-288, 2011.

TUOMIKANGAS, N.; KAIPIA, R. A coordination framework for sales and operations planning (S\&OP): synthesis from the literature. International Journal of Production Economics, 154, pp. 243-262, 2014.

VISWANATHAN, N. Sales and operations Planning: Integrate with Finance and Improve Revenue. Aberdeen Group, Boston, MA, USA, 2009.

VOSS, C.; TSIKRIKTSIS, N.; FROHLICH, M. Case research in operations management. International Journal of Operations \& Production Management, 22(2), pp. 195-219, 2002.

WAGNER, S. M.; ULLRICH, K. K.; TRANSCHEL, S. The game plan for aligning the organization. Business Horizons, 57(2), pp. 189-201, 2014.

WALLACE, T. F.; STAHL, R. A. Sales and Operations Planning: The How-To Handbook. 3rd ed., T.F. Wallace \& Company, Columbia Township, $\mathrm{OH}, 2008$.

YIN, R. K. Estudo de caso: planejamento e métodos. 2. ed. Porto Alegre: Bookman, 2001. 


\section{Apêndice I: Questionário de S\&OP/IBP para a empresa XYZ}

1. Você possui alguma experiência prévia com o processo de S\&OP/IBP?

2. Qual o papel do S\&OP/IBP na empresa? Quando foi implementado? Quais as razões para sua adoção? Quais os principais benefícios esperados/problemas a serem resolvidos?

3. O processo de S\&OP/IBP possui um dono / responsável (e.g., produção, finanças, supply chain). Se sim, quem é esse responsável? Se não, como é dividida a responsabilidade do processo?

4. Quem faz parte do S\&OP/IBP (e.g., área/participante) e quais suas responsabilidades? Clientes, fornecedores ou demais parceiros fazem parte formalmente do processo (e.g., com presença nas reuniões) ou apenas fornecendo dados (e.g., informações sobre vendas com nível de inventário)? Se sim, qual o seu papel? Se não, por que não? Como fazê-los ter voz ativa se participassem?

5. Qual o papel do financeiro no processo de S\&OP/IBP?

6. Como é dividido o processo, em termos de etapas? É um ciclo mensal com reuniões semanais?

7. Qual o horizonte de planejamento para o S\&OP/IBP, tanto em termos de execução, quanto em termos de projeção?

8. Quem participa de cada reunião do processo?

9. O que os participantes levam em termos de inputs (e.g., informações e conhecimentos) para cada etapa do ciclo? O que eles levam de outputs?

10. Que métricas são utilizadas para medir cada etapa do processo, em termos de tempo de reunião, informações geradas, facilidade, agilidade e qualidade na tomada de decisão? Cada função/área tem um indicador, ou são indicadores unificados? Esses indicadores estão melhorando?

11. A alta direção comparece em todas as reuniões executivas?

12. O time entende bem o processo? Eles se sentem confortáveis durante o ciclo da S\&OP/IBP?

13. As pessoas confiam umas nas outras em termos de dados e informações apresentadas?

14. Existe algum tipo de divergência durante o processo? Caso sim, por que ele existe?

15. Todas as pessoas possuem autonomia para expor suas ideias? Ou alguma área centraliza muito na figura do diretor/gerente?

16. Quais são os maiores benefícios que o processo trouxe para a empresa? Por exemplo:

a. O lucro da empresa aumentou depois da implantação da S\&OP/IBP? E o ROI? E o Fluxo de Caixa?

b. A empresa ficou mais ágil e flexível depois do S\&OP/IBP? Por quê?

17. Quais os maiores desafios que o processo precisa superar para colher resultados ainda melhores? 
18. Que tipo de métricas os gestores dão mais peso? Financeiras (e.g., custo unitário, eficiência de máquina, gasto com frete, hora extra, custeio $A B C$, custeio por absorção, mão de obra, despesas com viagens, energia etc.) ou de fluxo (e.g., OTIF, nível de serviço, lead times, giro de estoque etc.)?

a. É normal tentarem harmonizar essas métricas? Por exemplo, entregar rápido e certo com menor custo?

b. A alta administração cobra mais eficiência para entregar mais rápido ou para reduzir mais custos? Os gargalos de produção são tratados especialmente ou a produção é vista como um todo?

19. Quando há mudança no forecast, alguém fica incomodado? Quem e por quê?

20. A restrição da empresa, hoje, está na capacidade produtiva ou no mercado?

21. As pessoas são treinadas para pensar holisticamente, visando o bem da empresa como um todo? Ou as pessoas andam muito preocupadas com seus ótimos locais?

22. Existe uma linguagem universal na empresa para que todos pensem e trabalhem alinhados com os mesmos conceitos? Ou é normal as pessoas usarem vários termos para as mesmas coisas, prejudicando a comunicação em determinados momentos?

23. Após o processo de S\&OP/IBP, existe uma consolidação global das informações geradas nos países? 


\section{Apêndice II: Condução do grupo focal 1 (não estruturado e exploratório)}

Agenda:

1. Apresentação do mapeamento feito com base em estudos e na empresa XYZ

2. Perguntas aos especialistas:

a. O fluxo está de acordo com a experiência de vocês?

b. O que acham de alguns pontos específicos, como formas de interação entre áreas, os inputs, os pre-works, entre outros?

3. Respostas/Compartilhamento de experiências/Feedback dos especialistas

4. Especialistas levantam discussões acerca de pontos do processo e/ou do contexto apresentado.

5. Anotações feitas e usadas como base para o questionário de refinamento com os praticantes. 


\section{Apêndice III: Questionário aos praticantes}

1. Qual a sua experiência com o processo de S\&OP/IBP? Você vê diferença entre os termos?

2. Onde estão os principais erros/dificuldades encontrados nas empresas?

3. O Financeiro costuma participar? Tem voz ativa? Como deve ser a atuação dele?

4. Mesmo com a existência de um processo formal funcionando, você acha que $\mathrm{S} \& O P / I B P$ traz melhoria operacional, como queda nos níveis de inventário e lead time e aumento no nível de serviço? Como?

5. Acha viável a realização de mais de um ciclo durante o mês na sua empresa? E mini-loops (para tentar atender demandas grandes surgidas após a reunião para acordar a previsão)?

6. Na sua empresa, quem é o dono do número da previsão de vendas? Marketing ou Vendas? Como você acha que as empresas deveriam escolher o dono?

7. O fluxo clássico, sugerido por Wallace e Stahl, divide o ciclo em 5 etapas, sendo a primeira Data Gathering. Alguns autores/praticantes acham que essa etapa não pode mais ser chamada de etapa, uma vez que os sistemas de informação já entregam os dados organizados. Você concorda com isso?

8. Você sugere o uso de métricas para medir cada etapa do processo, em termos de tempo de reunião, informações geradas, facilidade, agilidade e qualidade na tomada de decisão? Ou esse tipo de medição não tem importância, uma vez que os planos orçados estão sendo atendidos?

9. Qual a sua opinião sobre o uso do Frozen Period? Como ele deve ser tratado?

10. Qual a sua opinião sobre a participação de fornecedores e clientes no processo de S\&OP/IBP?

11. Você acha que a discussão sobre novos produtos, preços e promoções deve ser formalmente debatida no ciclo de S\&OP/IBP? Ou deve ser feita em paralelo ("dever de casa") e apenas comunicada na reunião?

12. Além do que foi perguntado, o que mais você sugere que poderia ser acrescentado no modelo? 


\section{Apêndice IV: Condução do grupo focal 2 (estruturado e ex- plicativo)}

Agenda:

1. Apresentação do mapeamento refinado após as entrevistas com os praticantes

2. Perguntas aos participantes
a. O que acharam das etapas propostas?
b. O que acharam da participação de determinadas áreas em cada etapa?
c. Mudariam alguma coisa no processo?
d. Consideram os 13 pontos de atenção levantados válidos?
e. Indicariam outros aspectos?

3. Respostas/Compartilhamento de experiências/Feedback dos participantes

4. Acham que esse processo apresentado serve como guia para qualquer um que esteja implementando, ou queira implementar, um processo de $\mathrm{S} \& \mathrm{OP} / \mathrm{IBP}$ ? 